\title{
A STUDY OF OSTEOCYTE APOPTOSIS IN MECHANICALLY LOADED AND UNLOADED MURINE TIBIAE
}

\author{
A Thesis \\ presented to \\ the Faculty of California Polytechnic State University, \\ San Luis Obispo
}

\author{
In Partial Fulfillment \\ of the Requirements for the Degree \\ Master of Science in Biomedical Engineering
}

by

Josiah Elihu Kessler

May 2016 
(C) 2016

Josiah Elihu Kessler

ALL RIGHTS RESERVED 
TITLE:

AUTHOR:

DATE SUBMITTED:

COMMITTEE CHAIR: $\quad$ Scott Hazelwood, Ph.D.

Professor of Biomedical Engineering

COMMITTEE MEMBER: $\quad$ David Clague, Ph.D.

Professor of Biomedical Engineering

COMMITTEE MEMBER: Dan Walsh, Ph.D.

Professor of Biomedical Engineering 


\begin{abstract}
A Study of Osteocyte Apoptosis in Mechanically Loaded and Unloaded Murine Tibiae Josiah Elihu Kessler
\end{abstract}

Previous research has provided evidence in support of apoptotic osteocytes playing a role in the bone remodeling process. In this study, we examined the regional and quadrantal variations of apoptotic and viable osteocytes in cyclically loaded and unloaded samples. Left tibias of C57 Black 6 Taconic mice (C57B1/6) were cyclically loaded for either 2 weeks or 5 weeks, with the right tibias being used as controls. After loading, tibias were resected, processed, and then stained using either a TUNEL stain, to show apoptotic osteocytes, or a $2.0 \%$ methyl green solution, to reveal viable cells. Crosssectional images from each tibia were then captured and analyzed in each region (distal, midshaft and proximal) and quadrant (cranial, lateral, caudal, and medial) by counting the number of osteocytes, both apoptotic and viable, and subsequently calculating the percentages and densities of those osteocytes. Individual analysis of each sample group showed that the 5 week loaded bones, with the most statistically significant p-values, had the most regional variations within the samples, specifically showing decreased apoptotic and viable osteocytes in the lateral quadrants. Comparative analysis revealed a statistically significant higher percentage and density of apoptotic osteocytes in 5 week loaded samples compared to all other samples. This provides further quantitative evidence in support of apoptotic osteocytes playing a role in bone remodeling.

Keywords: osteocyte apoptosis, bone remodeling, cyclic loading 


\section{ACKNOWLEDGMENTS}

I would like to thank Dr. Scott Hazelwood for the opportunity to work on this

project. Thank you for your patience, understanding and guidance throughout the entire process. I want to thank my committee members for their time and input. I would also like to thank Jessica Chan for spending hours in the lab with me. Thank you Dr. Lily Laiho for the training and use of your microscope as well as Dr. Trevor Cardinal for help with taking care of and processing the subjects. I would also like to thank Tom Rose for his generous help in reconstructing the images and organizing the files. Finally, I would like to thank my family and my wonderful wife Kasey for their unfailing support.

This project was supported by NIH Grant \# AR51555. 


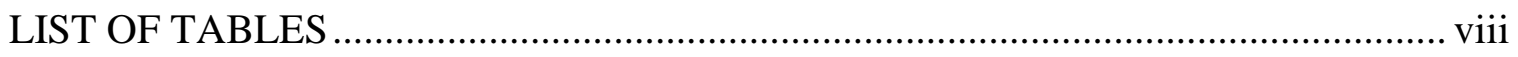

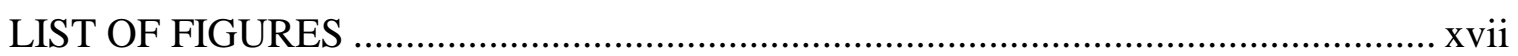

\section{CHAPTER}

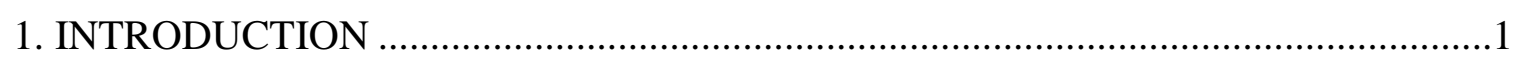

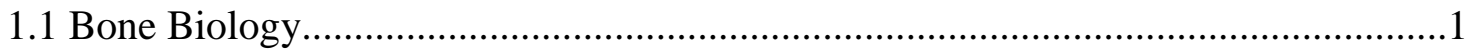

1.1.1 Bone Function and Properties ................................................................

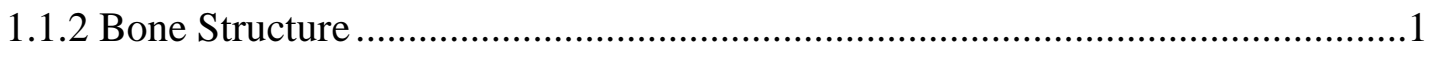

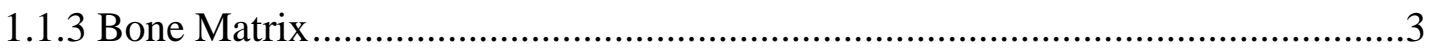

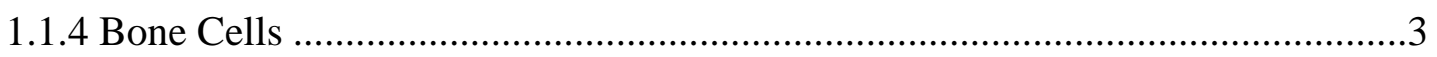

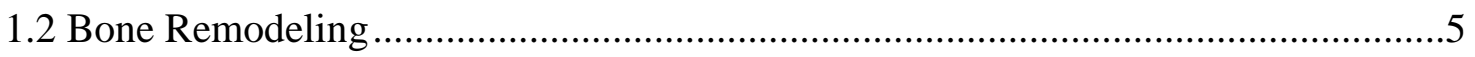

1.2.1 Modeling vs. Remodeling ..............................................................................5

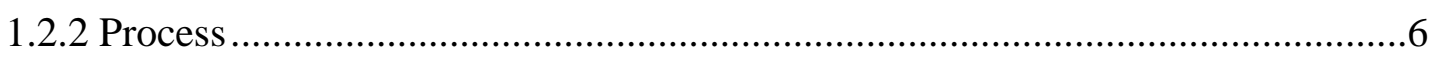

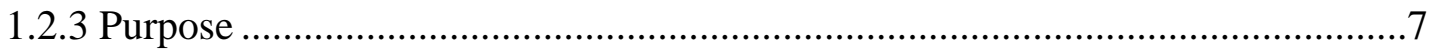

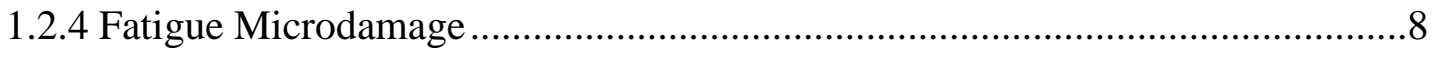

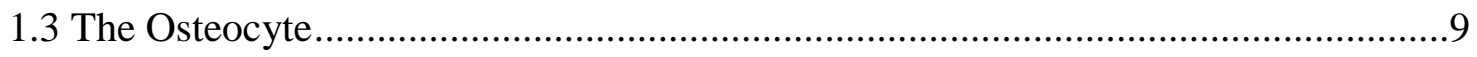

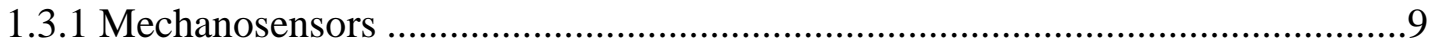

1.4 Osteocyte Apoptosis........................................................................................12

1.4.1 Apoptosis and Bone Remodeling ……………….....................................13

1.5 Study Goals (And Previous Studies) ………………............................................16

2. MATERIALS AND METHODS...................................................................17

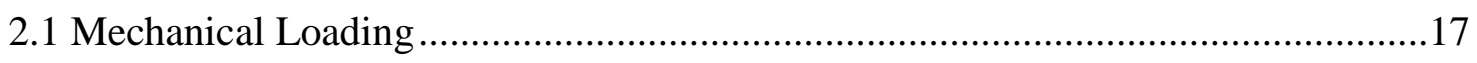

2.2 Specimen Sacrifice, Fixation and Decalcification ...............................................21

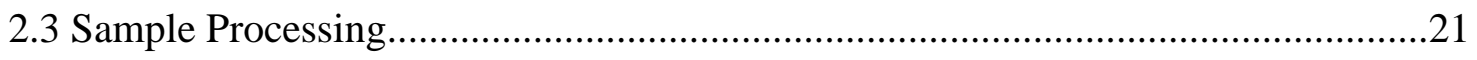

2.4 TUNEL staining and Osteocyte Apoptosis ............................................................22

2.5 Image Capture, Processing, and Analysis .............................................................24

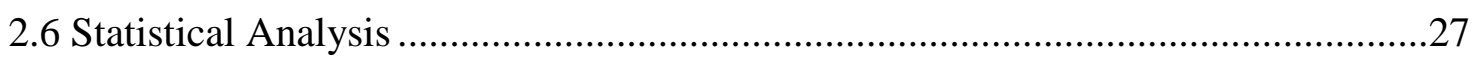

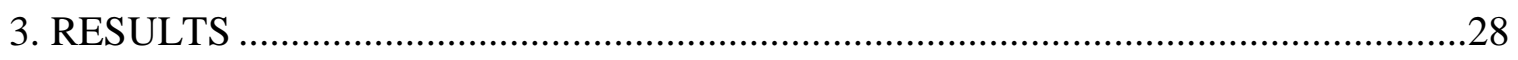

3.1 Individual statistics for left tibias loaded for 2 weeks ............................................28 
3.2 Individual statistics for right tibias used as 2 week controls

3.3 Individual statistics for left tibias loaded for 5 weeks.........................................40

3.4 Individual statistics for right tibias used as 5 week controls ...............................46

3.5 Comparison Between 2 Week Loaded Left Tibias and Unloaded Right Tibia

Controls

3.6 Comparison Between 5 Week Loaded Left Tibias and Unloaded Right Tibia

Controls

3.7 Comparison Between 2 Week Loaded Left Tibias and 5 Week Loaded Left

Tibias .66

3.8 Comparison Between 2 Week and 5 Week Unloaded Right Tibia Controls ...........74

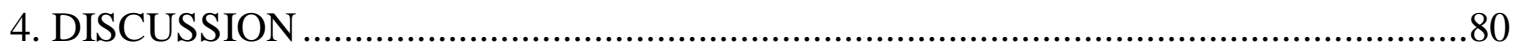

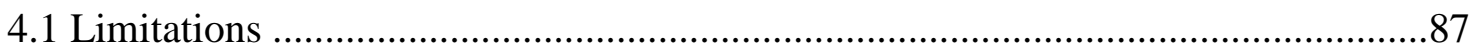

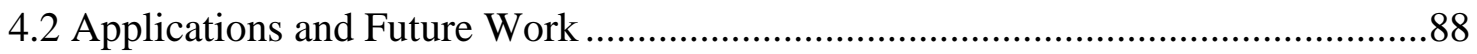

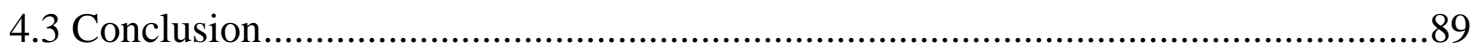

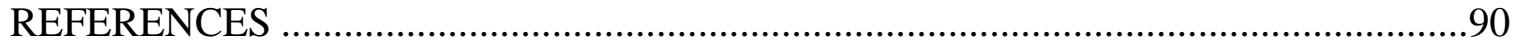

APPENDICES
A. Mice Loading Protocol
B. Microtome Protocol
C. TUNEL and Methyl Green Staining Procedures
102 


\section{LIST OF TABLES}

Table

Page

1. Apoptotic osteocyte density, viable osteocyte density, percentage of apoptotic osteocytes, and percentage of viable osteocytes for left tibias in all subjects that were loaded for 2 weeks. Standard deviations in parentheses......

2. Quadrantal differences of apoptotic osteocyte density, viable osteocyte density, percentage of apoptotic osteocytes, and percentage of viable osteocytes for left tibias in all subjects that were loaded for 2 weeks. Standard deviations in parentheses.

3. Mean quadrantal data gathered from the proximal region for apoptotic osteocyte density, viable osteocyte density, percentage of apoptotic osteocytes, and percentage of viable osteocytes for left tibias in all subjects that were loaded for 2 weeks.

Standard deviations in parentheses.

4. Mean quadrantal data gathered from the midshaft region for apoptotic osteocyte density, viable osteocyte density, percentage of apoptotic osteocytes, and percentage of viable osteocytes for left tibias in all subjects that were loaded for 2 weeks.

Standard deviations in parentheses.

5. Mean quadrantal data gathered from the distal region for apoptotic osteocyte density, viable osteocyte density, percentage of apoptotic osteocytes, and percentage of viable osteocytes for left tibias in all subjects that were loaded for 2 weeks. Standard deviations in parentheses.

6. Regional differences of apoptotic osteocyte density, viable osteocyte density, percentage of apoptotic osteocytes, and percentage of viable osteocytes for left tibias in all subjects that were loaded for 2 weeks. Standard deviations in parentheses.

7. Mean regional data gathered from the cranial quadrant for apoptotic osteocyte density, viable osteocyte density, percentage of apoptotic osteocytes, and percentage of viable osteocytes for left tibias in all subjects that were loaded for 2 weeks.

Standard deviations in parentheses.

8. Mean regional data gathered from the lateral quadrant for apoptotic osteocyte density, viable osteocyte density, percentage of apoptotic osteocytes, and percentage of viable osteocytes for left tibias in all subjects that were loaded for 2 weeks.

Standard deviations in parentheses.

9. Mean regional data gathered from the caudal quadrant for apoptotic osteocyte density, viable osteocyte density, percentage of apoptotic osteocytes, and percentage of viable osteocytes for left tibias in all subjects that were loaded for 2 weeks. Standard deviations in parentheses. 
10. Mean regional data gathered from the medial quadrant for apoptotic osteocyte density, viable osteocyte density, percentage of apoptotic osteocytes, and percentage of viable osteocytes for left tibias in all subjects that were loaded for 2 weeks.

Standard deviations in parentheses.

11. Apoptotic osteocyte density, viable osteocyte density, percentage of apoptotic osteocytes, and percentage of viable osteocytes for right tibias used as controls in all subjects that were loaded for 2 weeks. Standard deviations in parentheses.

12. Quadrantal differences of apoptotic osteocyte density, viable osteocyte density, percentage of apoptotic osteocytes, and percentage of viable osteocytes for right tibias used as controls in all subjects that were loaded for 2 weeks. Standard deviations in parentheses.

13. Mean quadrantal data gathered from the proximal region for apoptotic osteocyte density, viable osteocyte density, percentage of apoptotic osteocytes, and percentage of viable osteocytes for right tibias used as controls in all subjects that were loaded for 2 weeks. Standard deviations in parentheses.

14. Mean quadrantal data gathered from the midshaft region for apoptotic osteocyte density, viable osteocyte density, percentage of apoptotic osteocytes, and percentage of viable osteocytes for right tibias used as controls in all subjects that were loaded for 2 weeks. Standard deviations in parentheses.

15. Mean quadrantal data gathered from the distal region for apoptotic osteocyte density, viable osteocyte density, percentage of apoptotic osteocytes, and percentage of viable osteocytes for right tibias used as controls in all subjects that were loaded for 2 weeks. Standard deviations in parentheses.

16. Regional differences of apoptotic osteocyte density, viable osteocyte density, percentage of apoptotic osteocytes, and percentage of viable osteocytes for right tibias used as controls in all subjects that were loaded for 2 weeks. Standard deviations in parentheses

17. Mean regional data gathered from the cranial quadrant for apoptotic osteocyte density, viable osteocyte density, percentage of apoptotic osteocytes, and percentage of viable osteocytes for right tibias used as controls in all subjects that were loaded for 2 weeks. Standard deviations in parentheses.

18. Mean regional data gathered from the lateral quadrant for apoptotic osteocyte density, viable osteocyte density, percentage of apoptotic osteocytes, and percentage of viable osteocytes for right tibias used as controls in all subjects that were loaded for 2 weeks. Standard deviations in parentheses. 
19. Mean regional data gathered from the caudal quadrant for apoptotic osteocyte density, viable osteocyte density, percentage of apoptotic osteocytes, and percentage of viable osteocytes for right tibias used as controls in all subjects that were loaded for 2 weeks. Standard deviations in parentheses.

20. Mean regional data gathered from the medial quadrant for apoptotic osteocyte density, viable osteocyte density, percentage of apoptotic osteocytes, and percentage of viable osteocytes for right tibias used as controls in all subjects that were loaded for 2 weeks. Standard deviations in parentheses.

21. Apoptotic osteocyte density, viable osteocyte density, percentage of apoptotic osteocytes, and percentage of viable osteocytes for left tibias in all subjects that were loaded for 5 weeks. Standard deviations in parentheses.

22. Quadrantal differences of apoptotic osteocyte density, viable osteocyte density, percentage of apoptotic osteocytes, and percentage of viable osteocytes for left tibias in all subjects that were loaded for 5 weeks. Standard deviations in parentheses.

23. Mean quadrantal data gathered from the proximal region for apoptotic osteocyte density, viable osteocyte density, percentage of apoptotic osteocytes, and percentage of viable osteocytes for left tibias in all subjects that were loaded for 5 weeks.

Standard deviations in parentheses.

24. Mean quadrantal data gathered from the midshaft region for apoptotic osteocyte density, viable osteocyte density, percentage of apoptotic osteocytes, and percentage of viable osteocytes for left tibias in all subjects that were loaded for 5 weeks.

Standard deviations in parentheses.

25. Mean quadrantal data gathered from the distal region for apoptotic osteocyte density, viable osteocyte density, percentage of apoptotic osteocytes, and percentage of viable osteocytes for left tibias in all subjects that were loaded for 5 weeks. Standard deviations in parentheses.

26. Regional differences of apoptotic osteocyte density, viable osteocyte density, percentage of apoptotic osteocytes, and percentage of viable osteocytes for left tibias in all subjects that were loaded for 5 weeks. Standard deviations in parentheses.

27. Mean regional data gathered from the cranial quadrant for apoptotic osteocyte density, viable osteocyte density, percentage of apoptotic osteocytes, and percentage of viable osteocytes for left tibias in all subjects that were loaded for 5 weeks. Standard deviations in parentheses.

28. Mean regional data gathered from the lateral quadrant for apoptotic osteocyte density, viable osteocyte density, percentage of apoptotic osteocytes, and percentage of viable osteocytes for left tibias in all subjects that were loaded for 5 weeks. Standard deviations in parentheses. 
29. Mean regional data gathered from the caudal quadrant for apoptotic osteocyte density, viable osteocyte density, percentage of apoptotic osteocytes, and percentage of viable osteocytes for left tibias in all subjects that were loaded for 5 weeks.

Standard deviations in parentheses.

30. Mean regional data gathered from the medial quadrant for apoptotic osteocyte density, viable osteocyte density, percentage of apoptotic osteocytes, and percentage of viable osteocytes for left tibias in all subjects that were loaded for 5 weeks.

Standard deviations in parentheses.

31. Apoptotic osteocyte density, viable osteocyte density, percentage of apoptotic osteocytes, and percentage of viable osteocytes for right tibias used as controls in all subjects that were loaded for 5 weeks. Standard deviations in parentheses.

32. Quadrantal differences of apoptotic osteocyte density, viable osteocyte density, percentage of apoptotic osteocytes, and percentage of viable osteocytes for right tibias used as controls in all subjects that were loaded for 5 weeks. Standard deviations in parentheses.

33. Mean quadrantal data gathered from the proximal region for apoptotic osteocyte density, viable osteocyte density, percentage of apoptotic osteocytes, and percentage of viable osteocytes for right tibias used as controls in all subjects that were loaded for 5 weeks. Standard deviations in parentheses.

34. Mean quadrantal data gathered from the midshaft region for apoptotic osteocyte density, viable osteocyte density, percentage of apoptotic osteocytes, and percentage of viable osteocytes for right tibias used as controls in all subjects that were loaded for 5 weeks. Standard deviations in parentheses.

35. Mean quadrantal data gathered from the distal region for apoptotic osteocyte density, viable osteocyte density, percentage of apoptotic osteocytes, and percentage of viable osteocytes for right tibias used as controls in all subjects that were loaded for 5 weeks. Standard deviations in parentheses.

36. Regional differences of apoptotic osteocyte density, viable osteocyte density, percentage of apoptotic osteocytes, and percentage of viable osteocytes for right tibias used as controls in all subjects that were loaded for 5 weeks. Standard deviations in parentheses.

37. Mean regional data gathered from the cranial quadrant for apoptotic osteocyte density, viable osteocyte density, percentage of apoptotic osteocytes, and percentage of viable osteocytes for right tibias used as controls in all subjects that were loaded for 5 weeks. Standard deviations in parentheses. 
38. Mean regional data gathered from the lateral quadrant for apoptotic osteocyte density, viable osteocyte density, percentage of apoptotic osteocytes, and percentage of viable osteocytes for right tibias used as controls in all subjects that were loaded for 5 weeks. Standard deviations in parentheses.

39. Mean regional data gathered from the caudal quadrant for apoptotic osteocyte density, viable osteocyte density, percentage of apoptotic osteocytes, and percentage of viable osteocytes for right tibias used as controls in all subjects that were loaded for 5 weeks. Standard deviations in parentheses.

40. Mean regional data gathered from the medial quadrant for apoptotic osteocyte density, viable osteocyte density, percentage of apoptotic osteocytes, and percentage of viable osteocytes for right tibias used as controls in all subjects that were loaded for 5 weeks. Standard deviations in parentheses.

41. Quadrantal differences of apoptotic osteocyte density, viable osteocyte density, percentage of apoptotic osteocytes, and percentage of viable osteocytes between loaded left tibias and control right tibias in all subjects that were loaded for 2 weeks. Standard deviations in parentheses.

42. Mean quadrantal data gathered from the proximal region for apoptotic osteocyte density, viable osteocyte density, percentage of apoptotic osteocytes, and percentage of viable osteocytes compared between loaded left tibias and control right tibias in all subjects that were loaded for 2 weeks. Standard deviations in parentheses.

43. Mean quadrantal data gathered from the midshaft region for apoptotic osteocyte density, viable osteocyte density, percentage of apoptotic osteocytes, and percentage of viable osteocytes compared between loaded left tibias and control right tibias in all subjects that were loaded for 2 weeks. Standard deviations in parentheses.

44. Mean quadrantal data gathered from the distal region for apoptotic osteocyte density, viable osteocyte density, percentage of apoptotic osteocytes, and percentage of viable osteocytes compared between loaded left tibias and control right tibias in all subjects that were loaded for 2 weeks. Standard deviations in parentheses.

45. Regional differences of apoptotic osteocyte density, viable osteocyte density, percentage of apoptotic osteocytes, and percentage of viable osteocytes between loaded left tibias and control right tibias in all subjects that were loaded for 2 weeks. Standard deviations in parentheses.

46. Mean regional data gathered from the cranial quadrant for apoptotic osteocyte density, viable osteocyte density, percentage of apoptotic osteocytes, and percentage of viable osteocytes compared between loaded left tibias and control right tibias in all subjects that were loaded for 2 weeks. Standard deviations in parentheses. 
47. Mean regional data gathered from the lateral quadrant for apoptotic osteocyte density, viable osteocyte density, percentage of apoptotic osteocytes, and percentage of viable osteocytes compared between loaded left tibias and control right tibias in all subjects that were loaded for 2 weeks. Standard deviations in parentheses.

48. Mean regional data gathered from the caudal quadrant for apoptotic osteocyte density, viable osteocyte density, percentage of apoptotic osteocytes, and percentage of viable osteocytes compared between loaded left tibias and control right tibias in all subjects that were loaded for 2 weeks. Standard deviations in parentheses.

49. Mean regional data gathered from the medial quadrant for apoptotic osteocyte density, viable osteocyte density, percentage of apoptotic osteocytes, and percentage of viable osteocytes compared between loaded left tibias and control right tibias in all subjects that were loaded for 2 weeks. Standard deviations in parentheses.

50. Quadrantal differences of apoptotic osteocyte density, viable osteocyte density, percentage of apoptotic osteocytes, and percentage of viable osteocytes between loaded left tibias and control right tibias in all subjects that were loaded for 5 weeks. Standard deviations in parentheses.

51. Mean quadrantal data gathered from the proximal region for apoptotic osteocyte density, viable osteocyte density, percentage of apoptotic osteocytes, and percentage of viable osteocytes compared between loaded left tibias and control right tibias in all subjects that were loaded for 5 weeks. Standard deviations in parentheses.

52. Mean quadrantal data gathered from the midshaft region for apoptotic osteocyte density, viable osteocyte density, percentage of apoptotic osteocytes, and percentage of viable osteocytes compared between loaded left tibias and control right tibias in all subjects that were loaded for 5 weeks. Standard deviations in parentheses.

53. Mean quadrantal data gathered from the distal region for apoptotic osteocyte density, viable osteocyte density, percentage of apoptotic osteocytes, and percentage of viable osteocytes compared between loaded left tibias and control right tibias in all subjects that were loaded for 5 weeks. Standard deviations in parentheses.

54. Regional differences of apoptotic osteocyte density, viable osteocyte density, percentage of apoptotic osteocytes, and percentage of viable osteocytes between loaded left tibias and control right tibias in all subjects that were loaded for 5 weeks. Standard deviations in parentheses.

55. Mean regional data gathered from the cranial quadrant for apoptotic osteocyte density, viable osteocyte density, percentage of apoptotic osteocytes, and percentage of viable osteocytes compared between loaded left tibias and control right tibias in all subjects that were loaded for 5 weeks. Standard deviations in parentheses. 
56. Mean regional data gathered from the lateral quadrant for apoptotic osteocyte density, viable osteocyte density, percentage of apoptotic osteocytes, and percentage of viable osteocytes compared between loaded left tibias and control right tibias in all subjects that were loaded for 5 weeks. Standard deviations in parentheses.

57. Mean regional data gathered from the caudal quadrant for apoptotic osteocyte density, viable osteocyte density, percentage of apoptotic osteocytes, and percentage of viable osteocytes compared between loaded left tibias and control right tibias in all subjects that were loaded for 5 weeks. Standard deviations in parentheses.

58. Mean regional data gathered from the medial quadrant for apoptotic osteocyte density, viable osteocyte density, percentage of apoptotic osteocytes, and percentage of viable osteocytes compared between loaded left tibias and control right tibias in all subjects that were loaded for 5 weeks. Standard deviations in parentheses.

59. Quadrantal differences of apoptotic osteocyte density, viable osteocyte density, percentage of apoptotic osteocytes, and percentage of viable osteocytes between left tibias loaded for 2 weeks and left tibias loaded for 5 weeks. Standard deviations in parentheses.

60. Mean quadrantal data gathered from the proximal region for apoptotic osteocyte density, viable osteocyte density, percentage of apoptotic osteocytes, and percentage of viable osteocytes compared between left tibias loaded for 2 weeks and left tibias loaded for 5 weeks. Standard deviations in parentheses

61. Mean quadrantal data gathered from the midshaft region for apoptotic osteocyte density, viable osteocyte density, percentage of apoptotic osteocytes, and percentage of viable osteocytes compared between left tibias loaded for 2 weeks and left tibias loaded for 5 weeks. Standard deviations in parentheses.

62. Mean quadrantal data gathered from the distal region for apoptotic osteocyte density, viable osteocyte density, percentage of apoptotic osteocytes, and percentage of viable osteocytes compared between left tibias loaded for 2 weeks and left tibias loaded for 5 weeks. Standard deviations in parentheses.

63. Regional differences of apoptotic osteocyte density, viable osteocyte density, percentage of apoptotic osteocytes, and percentage of viable osteocytes between left tibias loaded for 2 weeks and left tibias loaded for 5 weeks. Standard deviations in parentheses

64. Mean regional data gathered from the cranial quadrant for apoptotic osteocyte density, viable osteocyte density, percentage of apoptotic osteocytes, and percentage of viable osteocytes compared between left tibias loaded for 2 weeks and left tibias loaded for 5 weeks. Standard deviations in parentheses. 
65. Mean regional data gathered from the lateral quadrant for apoptotic osteocyte density, viable osteocyte density, percentage of apoptotic osteocytes, and percentage of viable osteocytes compared between left tibias loaded for 2 weeks and left tibias loaded for 5 weeks. Standard deviations in parentheses.

66. Mean regional data gathered from the caudal quadrant for apoptotic osteocyte density, viable osteocyte density, percentage of apoptotic osteocytes, and percentage of viable osteocytes compared between left tibias loaded for 2 weeks and left tibias loaded for 5 weeks. Standard deviations in parentheses.

67. Mean regional data gathered from the medial quadrant for apoptotic osteocyte density, viable osteocyte density, percentage of apoptotic osteocytes, and percentage of viable osteocytes compared between left tibias loaded for 2 weeks and left tibias loaded for 5 weeks. Standard deviations in parentheses.

68. Quadrantal differences of apoptotic osteocyte density, viable osteocyte density, percentage of apoptotic osteocytes, and percentage of viable osteocytes between right tibias unloaded for 2 weeks and right tibias unloaded for 5 weeks both used as controls. Standard deviations in parentheses.

69. Mean quadrantal data gathered from the proximal region for apoptotic osteocyte density, viable osteocyte density, percentage of apoptotic osteocytes, and percentage of viable osteocytes compared between right tibias unloaded for 2 weeks and right tibias unloaded for 5 weeks both used as controls. Standard deviations in parentheses

70. Mean quadrantal data gathered from the midshaft region for apoptotic osteocyte density, viable osteocyte density, percentage of apoptotic osteocytes, and percentage of viable osteocytes compared between right tibias unloaded for 2 weeks and right tibias unloaded for 5 weeks both used as controls. Standard deviations in parentheses.

71. Mean quadrantal data gathered from the distal region for apoptotic osteocyte density, viable osteocyte density, percentage of apoptotic osteocytes, and percentage of viable osteocytes compared between right tibias unloaded for 2 weeks and right tibias unloaded for 5 weeks both used as controls. Standard deviations in parentheses

72. Regional differences of apoptotic osteocyte density, viable osteocyte density, percentage of apoptotic osteocytes, and percentage of viable osteocytes between right tibias unloaded for 2 weeks and right tibias unloaded for 5 weeks both used as controls. Standard deviations in parentheses. 
73. Mean regional data gathered from the cranial quadrant for apoptotic osteocyte density, viable osteocyte density, percentage of apoptotic osteocytes, and percentage of viable osteocytes compared between right tibias unloaded for 2 weeks and right tibias unloaded for 5 weeks both used as controls. Standard deviations in parentheses

74. Mean regional data gathered from the lateral quadrant for apoptotic osteocyte density, viable osteocyte density, percentage of apoptotic osteocytes, and percentage of viable osteocytes compared between right tibias unloaded for 2 weeks and right tibias unloaded for 5 weeks both used as controls. Standard deviations in parentheses

75. Mean regional data gathered from the caudal quadrant for apoptotic osteocyte density, viable osteocyte density, percentage of apoptotic osteocytes, and percentage of viable osteocytes compared between right tibias unloaded for 2 weeks and right tibias unloaded for 5 weeks both used as controls. Standard deviations in parentheses.

76. Mean regional data gathered from the medial quadrant for apoptotic osteocyte density, viable osteocyte density, percentage of apoptotic osteocytes, and percentage of viable osteocytes compared between right tibias unloaded for 2 weeks and right tibias unloaded for 5 weeks both used as controls. Standard deviations in parentheses 


\section{LIST OF FIGURES}

Figure

Page

1. Cortical and trabecular bone structure (International Osteoporosis Foundation, 2011)

2. The structure of a Basic Multicellular Unit (BMU): The upper portion shows a longitudinal section through an active BMU while the lower portion displays a cartoon showing how the osteoclasts and osteoblasts work. The blue osteoclasts can be seen resorbing bone, while the green osteoblasts follow laying down unmineralized osteoid, stained blue, that slowly becomes mineralized, which can be seen stained

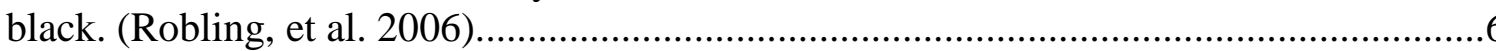

3. The cycle of bone remodeling (Hill 1998)...............................................................

4. Osteocyte network comprised of osteocyte lacunae (A) that are connected via canaliculi (B) to allow for communication within the network. In the middle, resides a Haversian space (C) (Martin, et al. 1998)..............................................................

5. Mechanotransduction in bone (Klein-Nulend, et al. 1995).....................................11

6. The difference between necrotic and apoptotic cells (Gewies 2003)........................13

7. Equipment used to provide isoflurane anesthesia to subjects...................................18

8. Loading fixture used to support and secure the mouse during the loading process. ....19

9. Interface in WinTest program that shows the cyclical loading procedure.

10. Sinusoidal waveform observed while running the cyclical loading procedure. .20

11. TUNEL stained image showing stained osteocytes and empty lacunae. .25

12. Methyl green stained image showing stained osteocytes and empty lacunae. .25

13. An example of what cross-sectional views across 3 regions of murine tibia look like stacked on top of each other, with samples on the left side(A) being TUNEL stained cross-sections, and samples directly to the right (B) being methyl green stained cross-sections ( $\mathrm{Cr}=$ cranial, $\mathrm{Ca}=$ caudal, $\mathrm{M}=$ medial, $\mathrm{L}=$ lateral). To the right of the cross-sections is an image of a tibia and fibula divided regionally to show the corresponding regions in which each cross-section sample was taken from. 


\section{INTRODUCTION}

\subsection{Bone Biology}

\subsubsection{Bone Function and Properties}

Bone is a connective tissue with unique properties and functions that support the human body. With its mineralized extracellular matrix, collagen packed outer shell and regions of porous bone, bones, in general, are able to be rigid and strong yet maintain some flexibility (Bilezikian, et al. 2008). These properties go hand in hand with its support, protection, movement and metabolic functions. Bones come in various shapes and sizes throughout the human body and provide the framework that holds the human body up, helps it move, and protects the internal organs. For example, bones in the human skull help protect the brain while bones that make up the rib cage protect organs like the heart and lungs. Bones also act as lever arms that allow the human body to move and perform basic tasks. Skeletal muscle is attached to bone via tendons, which is why bones are able

to act as a mechanical support system for muscle activity that transfers forces and enables motion. Acting as a source of inorganic ions like calcium and phosphate, bone participates in calcium homeostasis for the human body, releasing minerals into the bloodstream as needed (Marieb 2005). Bone is able to perform its versatile mechanical, protective and metabolic functions so effectively because of its structure.

\subsubsection{Bone Structure}

There are two main types of bone, cortical (compact) and trabecular (cancellous), each with their own unique structure. Cortical bone, with a porosity of about 5 to 10 percent, is the denser of the two and makes up the outermost layer of bone (Figure 1). The primary structural unit of cortical bone is the osteon. Each osteon is shaped like a 
tube and contains concentric layers of packed collagen fibrils called lamellae. Lamellae are also cylindrical in shape and are aligned along the long axis of the bone giving it some strength. At the junctions of the lamellae lie lacunae or spaces in which mature bone cells called osteocytes reside. Canaliculi are small canals that connect lacunae to each other as well as to the central Haversian canal containing blood vessels and nerve fibers. The processes of the osteocytes also jut into these canaliculi connecting them together. Volkmann's canals are a second type of canal that run perpendicular to Haversian canals and connect these Haversion canals to each other as well as to the membrane that lines the outer bone surface or periosteum. The endosteum is the thin, inner membrane that lines the medullary cavity, whose walls are composed of trabecular bone.

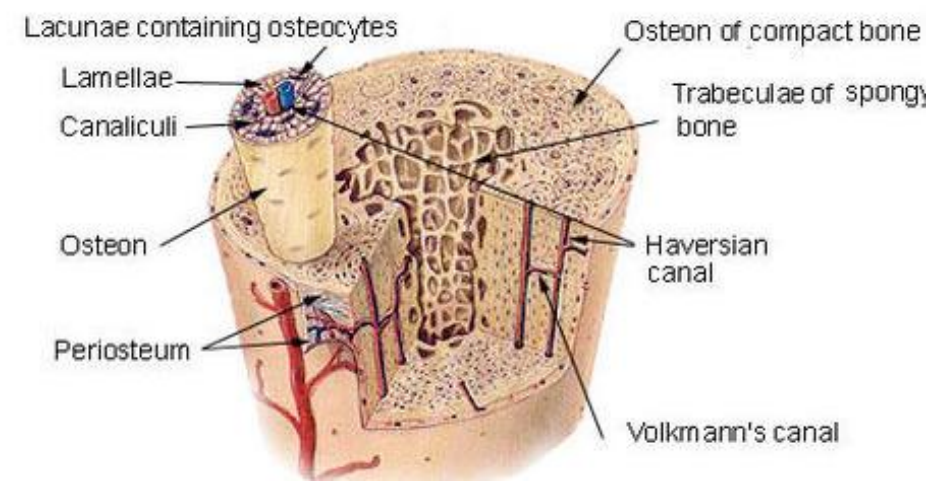

Figure 1. Cortical and trabecular bone structure (International Osteoporosis Foundation, 2011)

Trabecular bone, with porosities ranging from 50 to 90 percent, is much lighter than cortical bone and uses this structure to perform its primarily metabolic functions. Trabecular bone is made of trabeculae, beam or strut like structures that are irregularly arranged along lines of stress giving the bone a spongy appearance and providing some strength and resistance. Trabeculae also contain irregularly arranged lamellae and 
osteocytes that are connected to each other by processes residing in canaliculi. Due to its porous nature, many of the voids in trabecular bone are filled with marrow where blood cells are produced (Marieb 2005).

\subsubsection{Bone Matrix}

Bone is primarily made up of bone matrix. Bone matrix is strengthened by calcium deposits and is made up of organic and inorganic components. Approximately $90 \%$ of the organic extracellular components are type I collagen and $10 \%$ are proteoglycans, numerous proteins and cellular components. The large amount of collagen seen in the organic part of the matrix is what helps give bones their elasticity and tensile strength. The inorganic part of the matrix is made of hydroxyapatite, which accounts for most of the weight in the matrix and thus is responsible for providing much of the hardness and compressive strength seen in bone. When bone is being created, osteoblasts secrete bone matrix around blood vessels. As the matrix hardens, these cells get trapped inside and develop into osteocytes. Even though this formed bone matrix is hard and impervious to nutrients, the canaliculi and cell to cell communication via gap junctions allow the containing cells to receive the nutrients needed.

\subsubsection{Bone Cells}

Bones contain four different cell types within: osteoblasts, osteocytes, osteoclasts and bone lining cells. Osteoblasts, osteoclasts and bone lining cells can be found on the surfaces of bone while osteocytes are embedded within the bone matrix.

Osteoblasts, much like osteocytes and bone lining cells, develop from osteoprogenitor cells. Osteoblasts are mononuclear, cuboidal, fully differentiated cells whose primary job is to create bone matrix by laying down osteoid. Osteoid is produced 
at a rate of 1 micron per day. About ten to twenty percent of these osteoblasts will become embedded in the bone matrix (Noble 2008).

Opposite of osteoblasts are osteoclasts, large, multinucleated bone cells which resorb bone rather than lay down new bone. Osteoclasts resorb bone at a rate of about tens of microns per day by demineralizing the bone and dissolving the present collagen (Martin, et al. 1998). There are two important areas of its plasma membrane, the ruffled border and the clear zone. The ruffled border is the central area in the plasma membrane where bone resorption takes place. The clear zone is the area of the membrane that surrounds the ruffled border and attaches the osteoclast to the bone matrix (Bilezikian, et al. 2008).

Osteocytes, are the most common cell type, of the four, found in bone; there are about 10 times more osteocytes than there are osteoblasts (Aarden, et al. 1994). Osteocytes, as previously mentioned, are formed when an osteoblast gets embedded in the bone matrix it secretes. When the osteoblast first starts getting embedded in the matrix, that part of the matrix is still relatively weak. As other osteoblasts continue laying down bone, the embedded osteoblast gets further secured in the matrix as the matrix starts to calcify and the osteoblast starts changing shape and reducing in size.

Specifically, the number of organelles is reduced in the mitochondria, golgi apparatus and endoplasmic reticulum (Bell, et al. 2008). At this point, the osteoblast becomes an osteocyte. Osteocytes are stellate shaped and are located within lacunae and communicate with other cells extracellularly via the canaliculi throughout the matrix and intracellularly with other osteocytes via cytoplasmic processes utilizing gap junctions (Aarden, et al. 1994). Osteocytes, in response to loading, can produce a number of molecules that may 
be involved in osteogenesis or may undergo apoptosis, or cell death, if a lot of localized remodeling is occurring. It has been thought that osteocytes may also be involved in targeting osteoblasts and osteoclasts for bone remodeling due to sensing applied loads and their related strains (Noble 2003).

A second type of cell that can result from osteoblasts are bone lining cells. Theses long, elongated cells are inactive and neither lay down bone nor resorb it and are spread out on newly formed surfaces of bone after remodeling has stopped. The cells will detach when osteoclasts start resorbing bone. Bone lining cells are also thought to regulate the influx and outflux of various ions (Bilezikian, et al. 2008).

\subsection{Bone Remodeling}

\subsubsection{Modeling vs. Remodeling}

Over the human life span there are two very important processes that occur related to bone. The first, modeling, takes place when humans are young and involves creating bone. This phase is all about bone formation over bone resorption as it is more important to build and shape the mineralized tissue when there is little. For bone modeling, bone can be resorbed in some places and placed down in others, independent of each other (Martin, et al. 1998). The second process, remodeling, involves maintaining and repairing these bones and occurs over the entire human life span by removing and replacing a fraction of the bone every year; microscopic damage caused by fatigue or loading is repaired and prevented by bone remodeling. Unlike bone modeling, bone remodeling doesn't usually affect the shape or size of the bone. In this phase, bone resorption and bone formation are coupled so that all the bone taken away can be equally replaced by new bone at the same site. This is a local event in which local factors recruit 
and regulate the necessary cells and is carried out by a groups of osteoblasts and osteoclasts called a basic multicellular units or BMUs (Bilezikian, et al. 2008). A BMU, shown in Figure 2, consists of about ten osteoclasts, hundreds of osteoblasts and a central capillary to supply nutrients. BMUs go through a few stages throughout the remodeling process, shown in Figure 3.

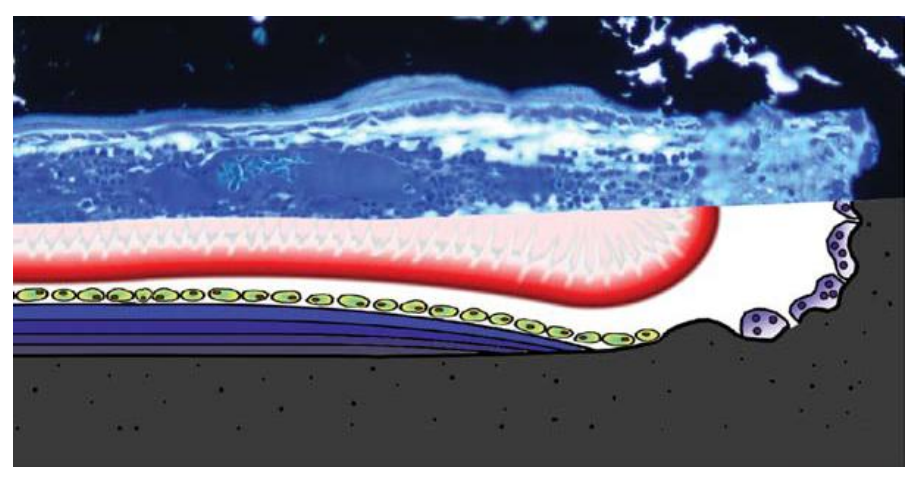

Figure 2. The structure of a Basic Multicellular Unit (BMU): The upper portion shows a longitudinal section through an active BMU while the lower portion displays a cartoon showing how the osteoclasts and osteoblasts work. The blue osteoclasts can be seen resorbing bone, while the green osteoblasts follow laying down unmineralized osteoid, stained blue, that slowly becomes mineralized, which can be seen stained black. (Robling, et al. 2006).

\subsubsection{Process}

The first stage, activation, happens when osteoclasts are signaled to form by local factors and start resorbing bone. This leads to the resorption stage where osteoclasts, at the front of the BMU, start removing bone moving forward at rate of about 40 micrometers per day; osteoclasts remove bone in a cone like shape for cortical bone and forms flat grooves if removing bone on a bone surface or in trabecular bone. The diameter of the region dug out by osteoclasts reaches about 250 to 300 micrometers, defining the approximate size of the secondary osteon to be formed (Robling, et al. 2006). After resorption comes the reversal stage, a ten day transition period, in which a cement line is formed on top of the resorption space by mononuclear cells and connects 
the old bone to the new bone that will be put down on top. Next, is the formation stage and occurs much slower than the resorption stage. Formation takes about 3 months to complete while it took only 3 weeks for the resorption phase. During this time, osteoblasts lay down osteoid, unmineralized matrix, upon which will be mineralized over time. Each BMU leaves space for a Haversion canal in the bone so nutrients can be delivered. The last stage is the resting stage, or quiescence, and involves the osteoblasts either becoming embedded in the matrix to form osteocytes or becoming bone lining cells, thus finishing the completion of a secondary osteon (Martin, et al. 1998).

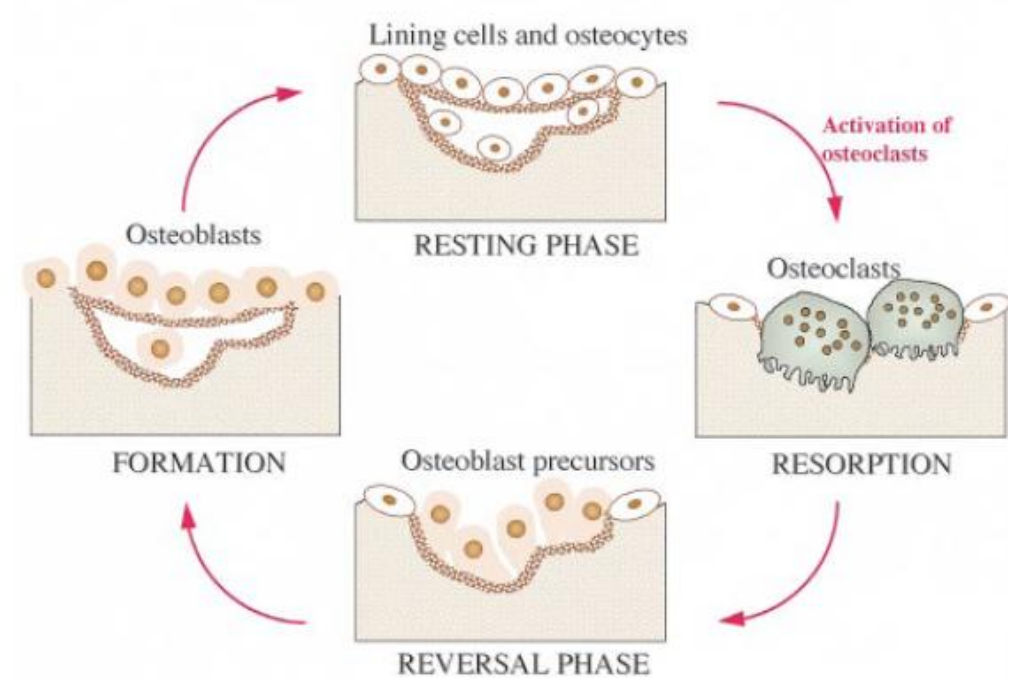

Figure 3. The cycle of bone remodeling (Hill 1998).

\subsubsection{Purpose}

The structure and function of bone are recognized as entities that work hand in hand. Bones are not just able to handle the normal loading conditions that occur every day but are able to adjust to any additional stresses that may be placed. This thought process was described by Julius Wolff. Wolff's Law stated that bones will alter their structure in response to a loading condition in order to better accommodate that load or lack thereof (Bilezikian, et al. 2008). This describes what we see in bone remodeling. The 
loading of bone, and subsequent damage caused, as well as the disuse of bone has major effects over the structure of the bone and is responsible for remodeling taking place.

Disuse of bone causes more bone to be removed with not as much bone being formed during the remodeling process resulting in an overall loss of bone mass.

Mechanical loading on the other can cause more bone to be formed in response. As bone becomes damaged, osteoclasts are signaled to remove the damaged bone and osteoblasts are signaled to lay down the necessary new bone. A study involving the loading of rat forelimbs showed that increasing the loading frequency increased bone formation (Robling, et al. 2006). So, the loading conditions, including the amount of load, the frequency it is applied and the duration of the load, all play a role in the bone remodeling process. Overloading bone can cause microdamage within the bone, which bone remodeling will try to repair. However, if the bone is overloaded too much, damage may be incurred faster than the bone can repair it. If this continues, larger microcracks can form and propagate causing stress fractures.

\subsubsection{Fatigue Microdamage}

Throughout our lives, our bones are constantly being subjected to multiple loads every day. Much like any other structure, as these loads are applied over and over again, fatigue microdamage occurs within the bone and is seen visually as microcracks. Frost was the first one to describe microdamage in vivo. Physiologic strains and stresses form microdamage and continued loading increases its presence. As the microdamage increases, the material and structural properties get further weakened until the microcracks grow larger and spread farther leading to the eventual failure of the bone in the form of a fatigue fracture. Luckily, bone contains within it the ability to repair this 
fatigue damage in the form of bone remodeling (Robling, et al. 2006). There is evidence that microdamage is associated with recruiting BMUs that will target specific areas where bone remodeling is needed. In a study, by Burr and colleagues, remodeling BMUs in dogs were shown to be likely associated with fatigue induced microcracks (Burr, et al. 1985). Another study showed that bone remodeling could be initiated by inducing microdamage in rats, which don't normally remodel their cortical bone (Bentolila, et al. 1998). These studies indicate a positive correlation between apoptotic osteocytes and the recruitment of osteoclasts involved in BMU remodeling by showing that microdamage was associated with apoptotic osteocytes and resorption cavities (Robling, et al. 2006). For this reason, continued research has been performed regarding osteocyte apoptosis, osteocytes as mechanosensors and osteocytes themselves and how they may be involved in the remodeling process.

\subsection{The Osteocyte}

\subsubsection{Mechanosensors}

As previously described, osteocytes are formed when inactive osteoblasts become embedded in the bone matrix. These osteocytes reside within spaces called lacunae that are connected to each other by canals called canaliculi. The processes of the osteocytes jut into these cancaliculi, creating pathways throughout the bone matrix. Gap junctions are present at the ends of these osteocyte processes allowing osteocytes to connect with each other. This entire network allows communication between other cells and the transfer of nutrients to occur intracellularly as well as extracellularly (Figure 4). Because of this large network of connectivity and the sheer amount of osteocytes spread throughout the bone matrix, osteocytes are considered the most popular theory in terms of 
which bone cell dominates the mechanosensory activity and may be involved in activating the bone remodeling process.

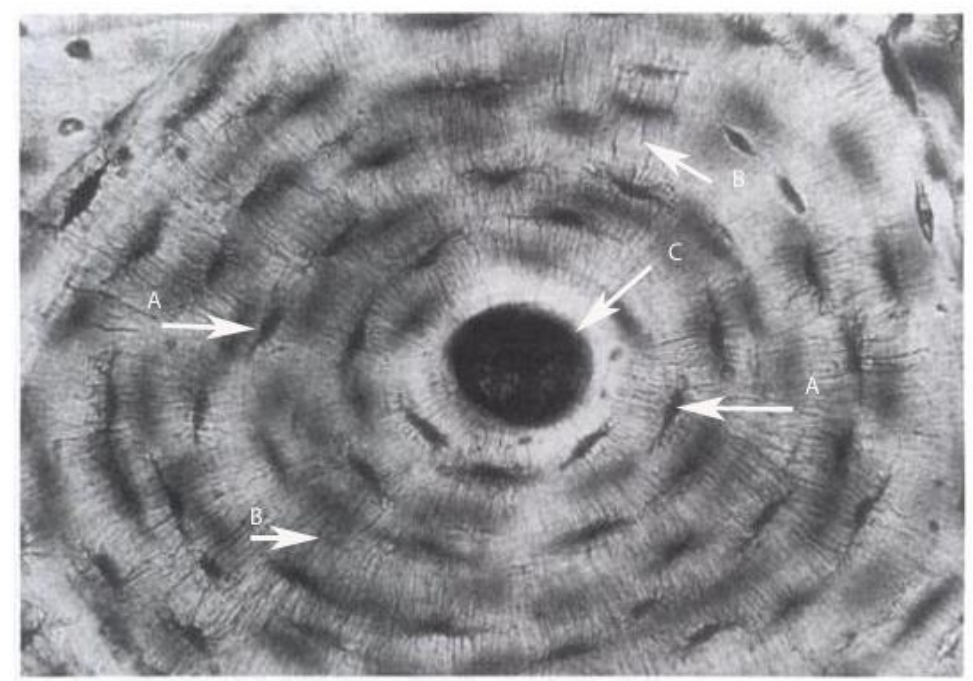

Figure 4. Osteocyte network comprised of osteocyte lacunae (A) that are connected via canaliculi $(B)$ to allow for communication within the network. In the middle, resides a Haversian space (C) (Martin, et al. 1998).

Although many of the inner workings of osteocytes, in regards to their mechanosensory capabilities and ability to support or initiate bone remodeling, remain unknown, we do know that strain plays an important role. Bones are able to take on various loads at different rates and can lay down new bone when the loading felt is increased or resorb bone in the case of disuse. Strains in bone are experienced near osteocyte lacunae. In theory, cells can feel up to seven times the deformation compared to the strain in the tissue itself (Robling, et al. 2006). Because cellular responses within bone control the formation and resorption of bone needed for bone remodeling, a common theory is that the strains experienced by osteocytes are then translated into cellular signals to make this happen, meaning that the osteocytes act as mechanotransducers (Bonewald 2006). Various studies have already provided some evidence to support this theory. In a study of turkey ulna, loading caused an increase in 
G6PD, a marker for cell metabolism, in osteocytes relative to local strain magnitudes (Skerry, et al. 1989). However, osteocytes are most likely responding to strain derived fluid flow rather than strain directly caused by mechanical loading (Bilezikian, et al. 2008). Osteocyte lacunae may also acts as pumps pushing fluid through the canaliculi because of the strain concentrations located adjacent to them (Robling, et al. 2006). Another study, showed that nitric oxide (NO), a free radical involved in promoting bone formation and inhibiting bone resorption, was generated in osteocytes in response to mechanical strain caused by flow-derived shear stress (Bakker et al. 2001). As mechanical loads are applied to the bone, interstitial fluid can flow extracellularly throughout the bone and osteocytes can use this fluid flow to sense strain information and initiate the necessary cellular response (Figure 5). The means in which osteocytes actually elicit this cellular response is also unclear. One theory suggests that osteocytes control the bone architecture by using the strain experienced in the bone as a feedback mechanism to maintain programmed physiological levels of strain (Lanyon 1993; Hedgecock, et al. 2007). Another way in which osteocytes may send signals for bone resorption or formation is through osteocyte apoptosis (Noble, et al. 1997; Power, et al. 2002; Bentolila, et al. 1998; Hedgecock, et al. 2007).

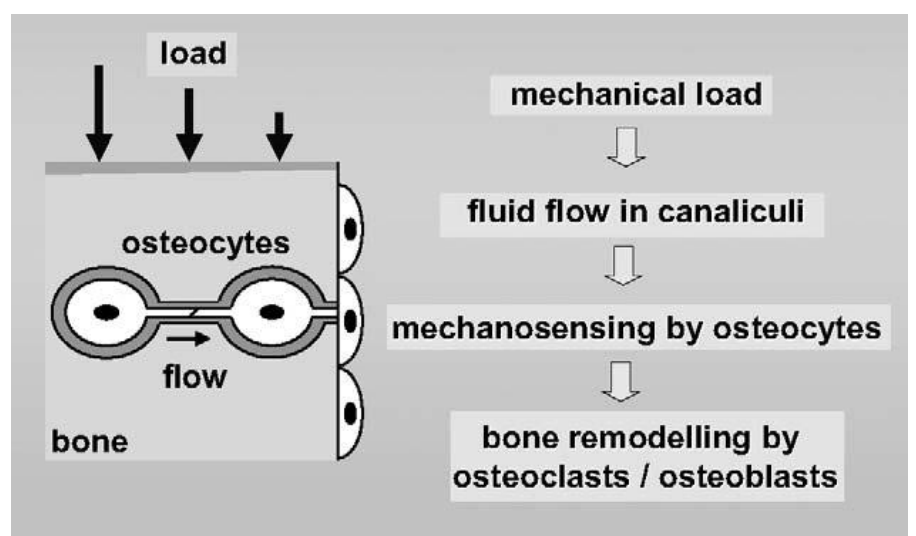

Figure 5. Mechanotransduction in bone (Klein-Nulend, et al. 1995). 


\subsection{Osteocyte Apoptosis}

Apoptosis is a form of programmed cell death or suicide. Apoptosis is a physiological form of cell death that occurs in both pathological and healthy bone. The process of apoptosis is typically initiated by either proteins released by the mitochondria or by activation of a cell surface death receptor in the tumor necrosis factor (TNF) family (Hock, et al. 2001). Cells that undergo apoptosis, separate from their neighbors, shrink and break into small pieces called apoptotic bodies (Noble 2003). In the nucleus, chromatin starts to clump up around the nuclear membrane. As this nuclear DNA is continually cleaved, the nucleus disappears and these clumps fill up the cytoplasm until eventually breaking the cell into multiple, membrane-bound apoptotic bodies (Bilezikian, et al. 2008). As this process is occurring, fluid is leaving the cell which is what causes the cell to shrink and separate from its surroundings. These formed apoptotic bodies are phagocytosed by specialized cells through a non-inflammatory process (Cardoso, et al. 2009). In bone, the majority of osteocytes are phagocytosed by osteoclasts near resorption sites (Bronckers, et al. 1996). There is another type of cell death, however, and that is necrosis. Necrosis typically affects groups of cells, and unlike apoptosis, causes their nuclei to swell, spill their cellular contents and attract inflammatory cells. Death by necrosis is much faster than apoptosis, is not energy dependent and not as controllable as apoptosis (Noble 2003). 


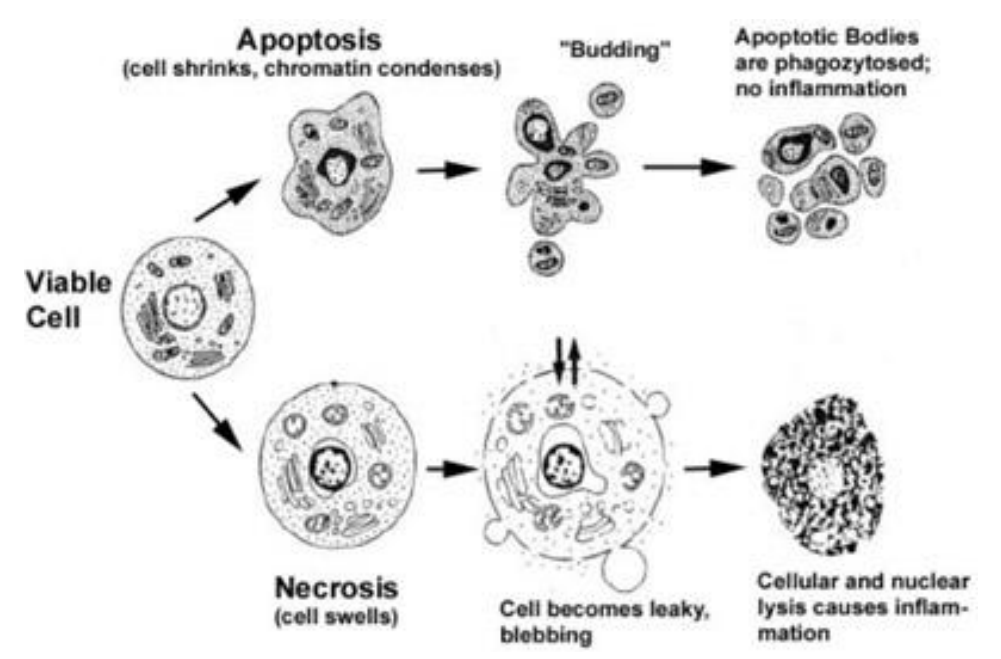

Figure 6. The difference between necrotic and apoptotic cells (Gewies 2003).

\subsubsection{Apoptosis and Bone Remodeling}

Osteocytes and their connective, canalicular system provide the means to detect any changes occurring throughout the bone and initiate bone remodeling to complete the necessary repairs. One of the ways in which this may be made possible is through apoptotic osteocytes and their role in bone remodeling. Apoptotic osteocytes have been shown to lead to increased resorption of bone material, indicating that the death of osteocytes is important in osteoclast recruitment during bone remodeling (Henriksen, et al. 2009). In one study, Bronckers et al. showed that, in developing bone, the majority of apoptotic osteocytes were located at sites with high levels of bone resorption (Bronckers, et al. 1996). A study using a rabbit tibial lengthening model showed that apoptotic osteocytes were localized in regions with osteoclast activity indicating a close relationship between bone remodeling and apoptosis ( $\mathrm{Li}$, et al. 2003).

Many studies have shown there to be a U-shaped relationship between strain and apoptosis seen in osteocytes (Jilka, et al. 2007; Noble, et al. 2003). This means that limbs that experience physiological levels of strain show low levels of apoptotic osteocytes. Conversely, limbs experiencing unloading or levels of strain high enough to induce 
microdamage, the two opposite ends of the spectrum, show increased levels of apoptotic osteocytes (Jilka, et al. 2007). Thus, microdamage caused by overloading or fatigue loading in bone also plays an important role in bone remodeling as well as how it connects apoptotic osteocytes to bone remodeling.

A study by Verborgt et al. was performed to attempt to show a relationship between osteocyte apoptosis, bone microdamage and bone resorption. In this study, the ulnae of adult rats were fatigue loaded and sections were stained to be able to determine which cells were undergoing apoptosis. Apoptotic osteocytes were found in regions surrounding microcracks as well as in bone surrounding resorption spaces. However, bone that was distant to the microcracks or resorption areas showed no differences when compared to the controls. These results were consistent from 1 day after loading to 10 days after loading. Additionally, increases in empty lacunae and decreases in normal osteocytes were observed over time. This study shows a strong correlation between microdamage, resorption and apoptotic osteocytes (Verborgt, et al. 2000). A similar study performed by Noble et al., attempted to study the role of apoptotic osteocytes on bone remodeling related to loading as well. This was done by loading rats with varying levels of strain from low to high. The rats had a loading regiment that involved loading them on days 1-5 and days 8-12. The rats that were loaded with high enough levels of strain to cause some damage resulted in an eight-fold increase in apoptotic osteocytes 7 days after the overloading. Next, 14 days after the loading, new Haversian canals were formed. Finally, 28 days after the overloading, the infilling of the resorption spaces was seen (Noble, et al. 2003). Thus, for this study, the formation of Haversian canals never preceded the presence of apoptotic osteocytes, supporting the hypothesis that apoptotic 
osteocytes may be the mechanism behind bone remodeling. Rats that were loaded with low levels of strain also showed higher levels of apoptotic osteocytes relative to physiologic levels of strain. This data also seems to support a U-shaped relationship between apoptosis in osteocytes and strain and provides evidence that this U-shaped relationship may be used to influence bone remodeling (Noble, et al. 2003).

A study by Hedgecock et al. correlated the regional variability in remodeling with the regional variability in osteocyte apoptosis in rabbit tibia midshafts. Histomorphometric analyses of the tibias showed that the remodeling parameters were the lowest in the cranial quadrant compared to the other quadrants. TUNEL staining was also performed in the tibias to see the regional variability of apoptosis within the samples. The densities of apoptotic osteocytes found in the cranial quadrant were seen to be lower than the densities in the medial quadrant. Also, the densities of osteocyte lacunae, empty lacunae and total osteocytes were seen to be higher in the lateral quadrants compared to the caudal quadrants. From this data, a strong statistically significant correlation was found between the remodeling parameters and the apoptotic osteocyte density. Although osteocyte density and lacunar density did not correlate with remodeling parameters like the density of apoptotic osteocytes did, the authors suggested that cell viability could be another factor added when correlating with remodeling parameters (Hedgecock, et al. 2007).

A study by Jessica Chan compared the variations associated with bone remodeling factors and densities of apoptotic osteocytes at different regions and quadrants within unloaded murine tibias. Bone samples were TUNEL stained to detect apoptotic osteocytes and subsequently analyzed. The levels of bone morphogenic protein 
antagonists, noggin and gremlin, were measured and compared with the amount of apoptotic osteocytes found for each quadrant and region within the tibia. This study found higher densities of apoptotic osteocytes as well as higher levels of BMP antagonists in the midshaft compared to the other regions. There was also found to be a positive linear correlation between apoptotic osteocytes and gremlin and a negative linear correlation between noggin and percentage of apoptotic osteocytes (Chan 2011).

\subsection{Study Goals (And Previous Studies)}

This study continues the work done by Jessica Chan, as previously described, by incorporating bones that have been cyclically loaded. The objective of this study is to calculate the density of apoptotic and viable osteocytes, filtered by region, quadrant and a combination of both, in loaded and unloaded murine cortical bone and attempt to point out any statistically significant differences that may be present between the loaded and unloaded data. This study will focus on the tibias taken from the left hind limbs of murine specimens, which were mechanically loaded for a time period of either 2 or 5 weeks. Densities of osteocytes will be compared between three regions (proximal, midshaft and distal) and four anatomic quadrants (cranial, lateral, caudal, and medial) present throughout the limb as well as between loaded and unloaded specimens. It is hypothesized that osteocyte apoptosis will increase in the loaded limbs for both the 2 week and 5 week periods as a result of the additional cyclic stress placed on the bones. In addition, regional variations in apoptotic osteocytes are expected to be enhanced as a result of the increased loading in the limbs for both the 2 week and 5 week periods, with the most variation expected to be seen within the 5 week loaded samples due to the further loading seen by the samples. 


\section{MATERIALS AND METHODS}

Twelve C57 Black 6 Taconic mice (C57Bl/6) were procured at 7 to 9 weeks of age (Taconic, Oxnard, CA), and were housed in microisolation chambers located at the California Polytechnic State University vivarium. A previous study showed that skeletal maturity in male and female $\mathrm{C} 57 \mathrm{Bl} / 6$ mice is reached between 3 and 6 months of age by recording any changes in body weight, length of tibiae, bone density, bone modulus and bone composition over a 12 month period (Somerville, et al. 2004). For this reason, the mice used in this study were mechanically loaded once they reached 20 to 25 weeks of age and were subsequently sacrificed at around 6 months of age, which means they would have reached young adulthood and full skeletal maturity. The loading protocol used in this study was approved by the animal care committee.

\subsection{Mechanical Loading}

Of the twelve mice procured, 4 mice were to be mechanically loaded for a period of 2 weeks and the other 8 mice for a period of 5 weeks. For each of the mice, the left tibia was mechanically loaded for the designated amount of time while the right tibia was used as a control and was not loaded throughout this process; in between loading bouts, mice experienced normal loading due to daily motion in their cages. However, due to user error, three of the mice had to be prematurely sacrificed and were not used as data in this study. Therefore, for this study, 3 mice were mechanically loaded for 2 weeks and 6 mice were mechanically loaded for 5 weeks using a Bose Enduratec 3220, Enduratec signal box and WinTest PCI control system with its relevant WinTest software. In order to use the loading equipment the mice needed to be successfully anesthetized beforehand. 
This was done by placing the mice in an isolation chamber with 4 to 5 percent isoflurane being input at 3 liters per minute. This anesthesia equipment can be seen in Figure 7.

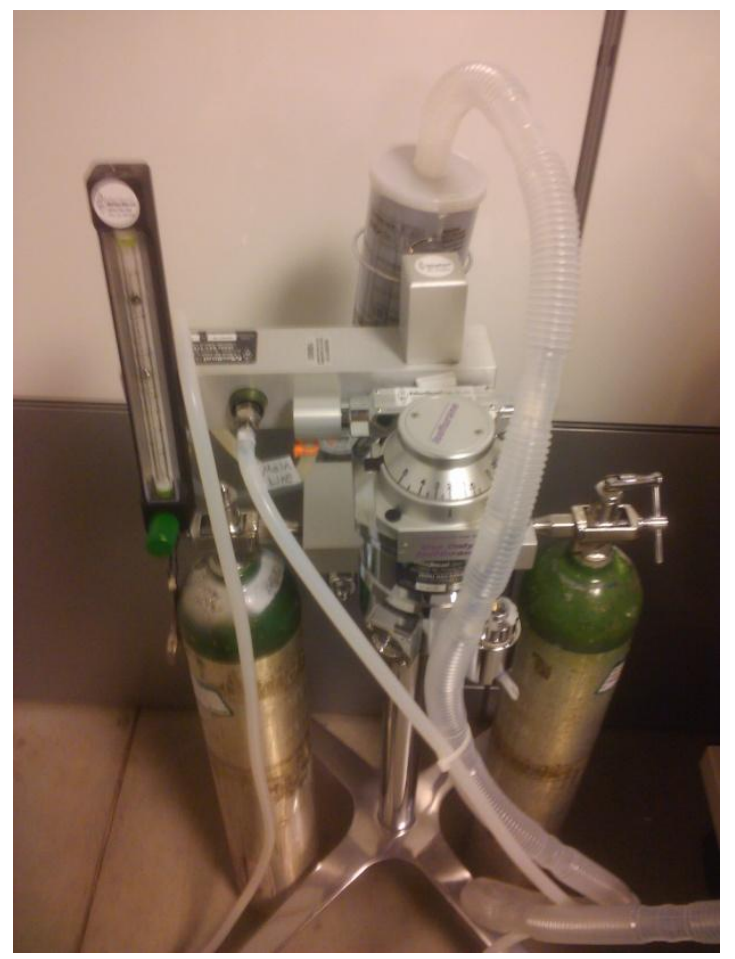

\section{Figure 7. Equipment used to provide isoflurane anesthesia to subjects.}

Once anesthetized, the mice were placed on the loading fixture and attached to a nose cone channeling $2 \%$ isoflurane at 1 liter per minute (Verborgt, et al. 2000). The loading fixture, as seen in Figure 8, is a ramp that supports most of their body weight with a shallow groove indented into the fixture that allows the left hindlimb to be secured in one spot so the loading plunger can apply the compressive force. 


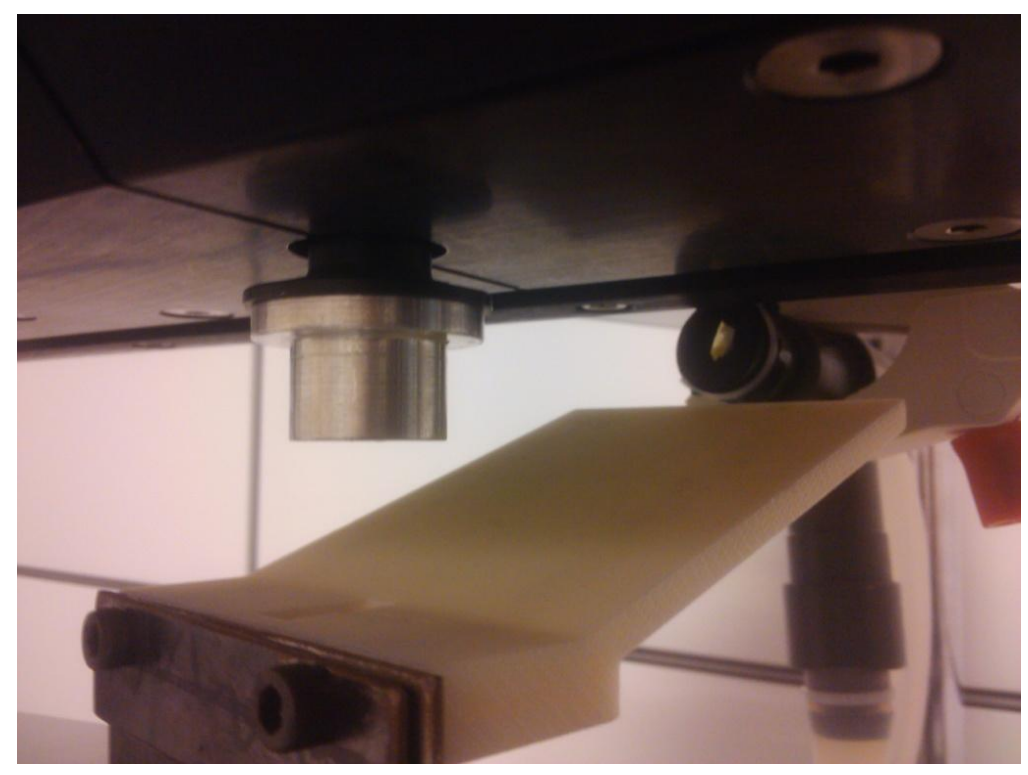

Figure 8. Loading fixture used to support and secure the mouse during the loading process.

With the mouse anesthetized and secured in the fixture, the Enduratec and

WinTest equipment can then be used to cyclically apply a mechanical load to the left tibia of each mouse. This is achieved by creating a sinusoidal waveform within the WinTest program as can be seen in Figures 9 and 10.

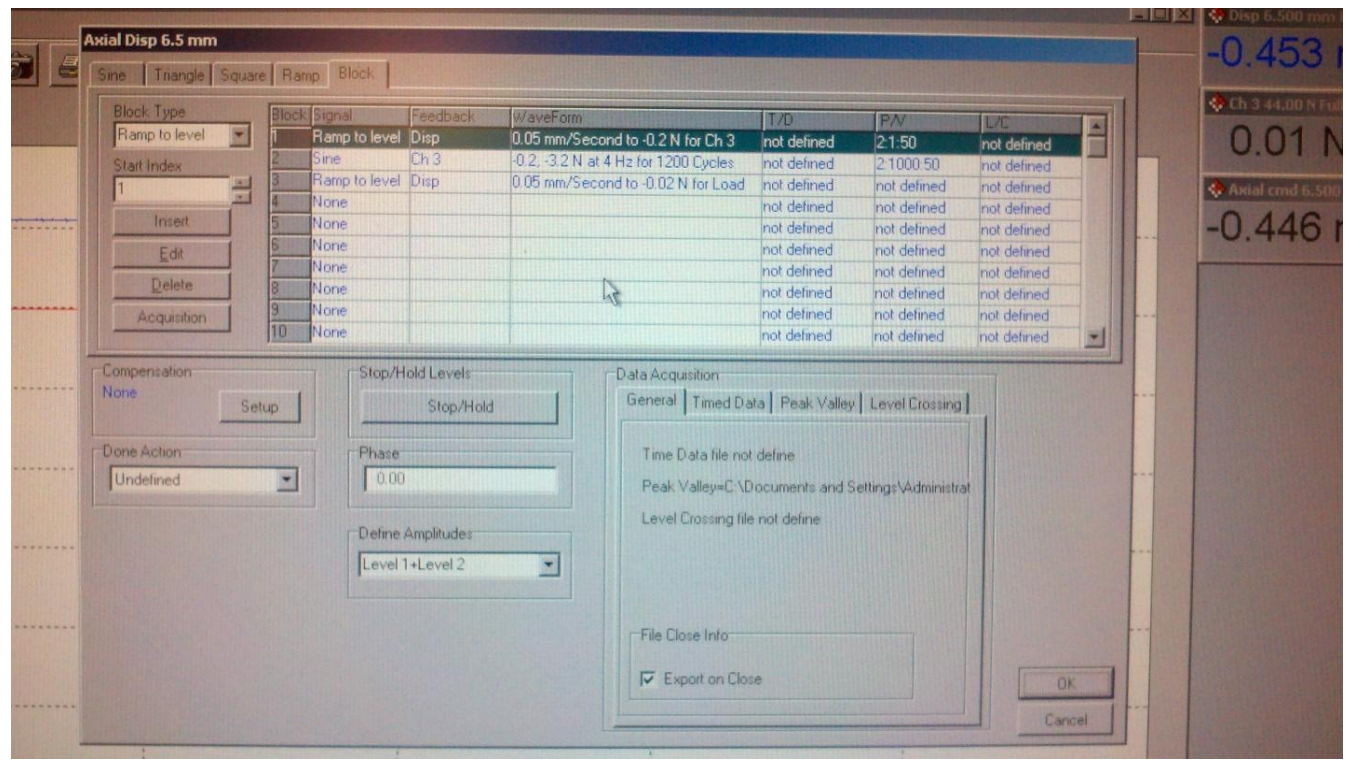

Figure 9. Interface in WinTest program that shows the cyclical loading procedure. 


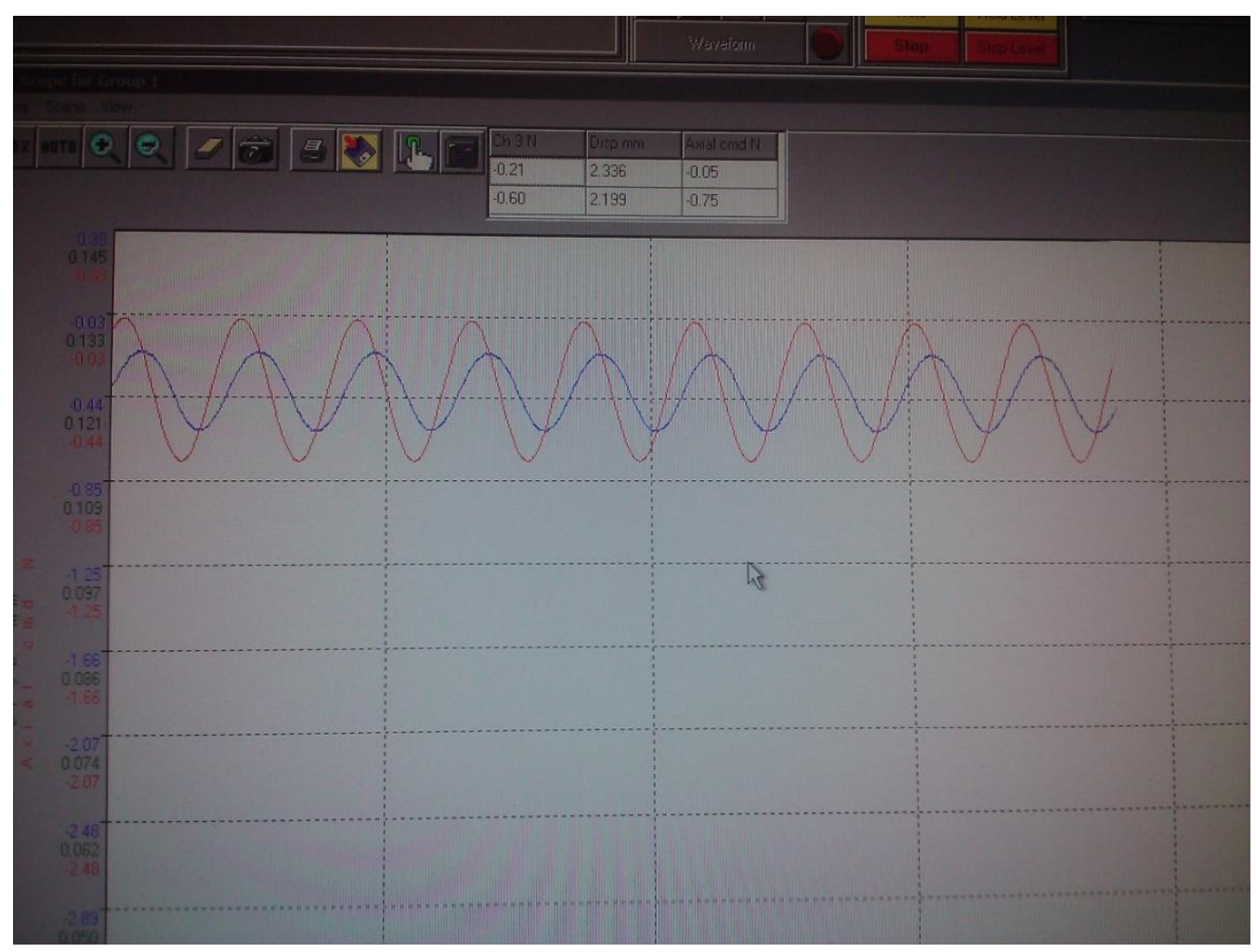

Figure 10. Sinusoidal waveform observed while running the cyclical loading procedure.

When the program was run, the subject's left tibia was ramped up to the preload of $0.2 \mathrm{~N}$ of compression by displacing the plunger onto the tibia at $0.05 \mathrm{~mm}$ per second. A sinusoidal waveform cycles the force applied between 1.0 Newton of compression and 3.2 Newtons of compression at $4 \mathrm{~Hz}$ for 1200 cycles before finally ramping back down to 0.02 Newtons of compression at the end of the mechanical loading. The force values and number of cycles were chosen to produce fatigue loading, well below the amount need to cause any fracture, within the murine bone (Noble, et al. 2003; Verborgt, et al. 2000). A frequency of $4 \mathrm{~Hz}$ was chosen to be similar to previous cyclical loading experiments and matches normal murine stride frequency (Noble, et al. 2003; Verborgt, et al. 2000;

Mosley, et al. 1997). After the loading process was complete, each mouse was monitored throughout the week to ensure that there were no abnormalities and that neither limb was 
being favored over the other. The mice loading protocol in its entirety can be seen in Appendix A.

\subsection{Specimen Sacrifice, Fixation and Decalcification}

After 2 and 5 weeks of loading, each respective group was sacrificed. Each mouse was successfully euthanized via cervical dislocation. After euthanization, each of the right and left tibias, were resected and placed in sealed microcentrifuge tubes filled with a fixative, Histochoice. Tibiae were then fixated by immersion fixation over the next 3 to 4 days and subsequently transferred into a decalcifation solution for another 3 to 4 days prior to sample embedding. The decalcification solution was composed of 150 grams disodium EDTA dehydrate and 15 grams $\mathrm{NaOH}$. Water was added until the $\mathrm{pH}$ of the solution reached 7.4 (between $700-800 \mathrm{ml}$ ), yielding an approximate 15\% EDTA solution.

\subsection{Sample Processing}

Following sacrifice, tissue immersion fixation, and decalcification, the tissue samples were embedded in paraffin wax using the Shandon Excelsior ES system (Thermo Fisher Scientific, Waltham, MA). Next, the embedded tissue blocks were secured on the Leica RM2255 rotary microtome (Leica Microsystems, Bannockburn, IL) and seven micron thick sections were cut from the block. Using tweezers, the sections were then carefully floated in a warm distilled water bath (Boekel Scientific, Feasterville, PA) and subsequently placed onto microscope slides (Thermo Fisher Scientific). Three sections were placed on each microscope slide and were allowed to air dry for 24 hours before the staining process. The full protocols used for the microtome and staining processes are listed in Appendices B and C, respectively. To prepare for staining, slides were incubated in a $40^{\circ} \mathrm{C}$ oven for twenty to thirty minutes or until the paraffin wax became more 
transparent and malleable. For each staining process completed, half of the sections were stained using the DeadEnd Colorimetric TUNEL (Terminal deoxynucleotidyl transferase (TdT)-mediated deoxyuridine triphosphate nick-end labeling) System (Promega Corp., Madison, WI) to identify cellular DNA fragmentation that is characteristic of osteocyte apoptosis. The other half of the sections were stained with a created $2.0 \%$ methyl green solution that reveals non-apoptotic nuclei within each cross section. The methyl green solution was created by first mixing 2.72 grams of sodium acetate into $200 \mathrm{ml}$ of distilled water, then adjusting the $\mathrm{pH}$ of the mixture to 4.2 using glacial acetic acid, and finally dissolving 4.0 g methyl green (Aldrich Chemical Co., St. Louis, MO) into the resulting mixture. Microtomed sections were split between two stains to ensure that both viable and apoptotic osteocytes would be clearly visible throughout the counting process. To ensure likeness between cross-sections, the sections used for the TUNEL staining were directly adjacent to the sections used for the methyl green staining and, thus, were approximately only seven to thirty microns apart relative to original tissue placement.

\subsection{TUNEL staining and Osteocyte Apoptosis}

The first step in the TUNEL staining process is to deparaffinize sections by immersing the slides in xylene for 5 minutes. The tissue section were then rehydrated by graded ethanol washes: 8 minutes in 100\%, 3 minutes in $95 \%, 3$ minutes in $85 \%, 3$ minutes in $70 \%$, and 3 minutes in 50\% ethanol. The sections were then allowed to air dry for 20 minutes. After drying, the sections were rinsed for 5 minutes in phosphate buffered saline (PBS), refixed in Histochoice for 15 minutes and rinsed again in PBS for 10 minutes. To help permeabilize the tissue sections, 100 microliters of a $20 \mu \mathrm{g} / \mathrm{mL}$ proteinase $\mathrm{K}$ solution was used to cover the tissue sections for 10 minutes at room 
temperature. After another PBS rinse, Histochoice refixing and second PBS rinse, 100 microliters of equilibration buffer was placed on each slide to cover the sections for 10 minutes. A rTdT reaction mix was created by mixing 98 parts equilibration buffer with 1 part biotinylated nucleotide mix and 1 part rTdT enzyme. After gently blotting away the previously equilibrated areas with tissue paper, 100 microliters of the $\mathrm{rTdT}$ reaction mix was added to each slide and then covered with a plastic coverslip to evenly distribute the reagent. The slides were then incubated for 1 hour in a humidifying chamber at $37^{\circ} \mathrm{C}$ to allow the end-labeling reaction to occur. Following incubation, coverslips were removed and the slides were immersed in a $2 \mathrm{x}$ sodium-chloride sodium-citrate (SSC) wash to terminate the reaction. Three subsequent 5 minute rinses in PBS were then performed to remove unincorporated biotinylated nucleotides. A $0.3 \%$ hydrogen peroxide in PBS mix was created and slides were allowed to sit in the mixture for 5 minutes to block endogenous peroxidases. Again, the slides were rinsed three times in PBS for five minutes each. The streptavidin HRP solution was diluted with PBS and 100 microliters of the mixture was added to each slide and allowed to sit for 30 minutes. After three PBS rinses, the DAB components (DAB substrate 20x buffer and DAB 20xchromagen) were mixed with deionized water and hydrogen peroxide 20x just before use. Once mixed, 100 microliters of the DAB mixture were added to each slide and allowed to develop until there was a light brown background. Finally, slides were rinsed several times in deionized water, excess liquid was removed and then the slides were mounted with Permount (Thermo Fischer Scientific).

To perform the methyl green stain, sections were deparaffinized by immersing the slides in xylene for 5 minutes. The tissue sections were rehydrated by graded ethanol 
washes: 8 minutes in 100\%, 3 minutes in $95 \%, 3$ minutes in $85 \%, 3$ minutes in $70 \%$, and 3 minutes in $50 \%$ ethanol. The sections were then allowed to air dry for 20 minutes. After drying, the sections were rinsed in deionized water for 5 minutes, allowed to sit in the $2 \%$ methyl green solution (Aldrich Chemical Co., St. Louis, MO) for 30 seconds, and then rinsed again in distilled water. Excess liquid was removed and then the slides were mounted with Permount (Thermo Fischer Scientific).

\subsection{Image Capture, Processing, and Analysis}

To quantify osteocyte apoptosis and perform subsequent analyses, slides were observed under full-spectrum white light using a BX41 polarizing light microscope (Olympus Optical Co., Ltd., Center Valley, PA) at 40x magnification. Images were captured using a Retiga EXi color camera (QImaging, Surrey, BC, Canada) and the Q Capture Pro imaging program (QImaging). After capturing all of the necessary images, Adobe Photoshop was used to combine all of the images taken from a specific crosssection into a single image so that there was only one image for each cross section. Three cross sections of each stain, TUNEL and methyl green, were taken from each region, distal, midshaft and proximal, within the right and left tibias of all 9 subjects amounting to a grand total of 324 cross sections captured and created. A Ronchi ruler with known lines at a size of 150 lines per mm was used to calibrate the images at 40x magnification. Image analysis was performed using Image J (Wayne Rashband(NIH)) where images were calibrated with the Ronchi ruler, yielding total field dimensions of $0.23 \mathrm{~mm}$ by 0.17 mm.

Regarding analysis, the area for each bone cross-section and the quadrants therein

contained, were calculated using the freehand selection tool within Image J. Two types of 
osteocytes were counted for each stain. For the TUNEL stain, osteocytes in lacunae with their nuclei stained brown (Figure 11) were counted as apoptotic osteocytes. For the methyl green stain, osteocytes in lacunae with their nuclei stained blue (Figure 12) were counted as viable osteocytes.

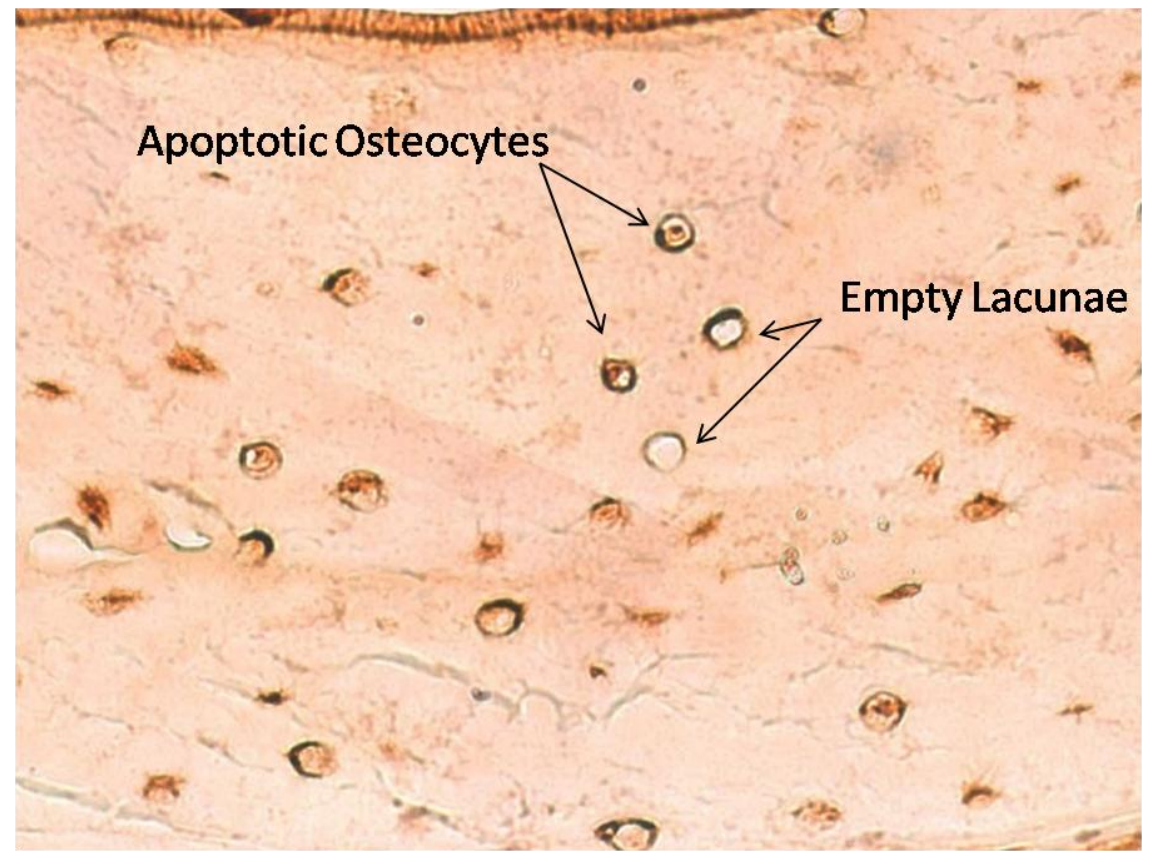

Figure 11. TUNEL stained image showing stained osteocytes and empty lacunae.

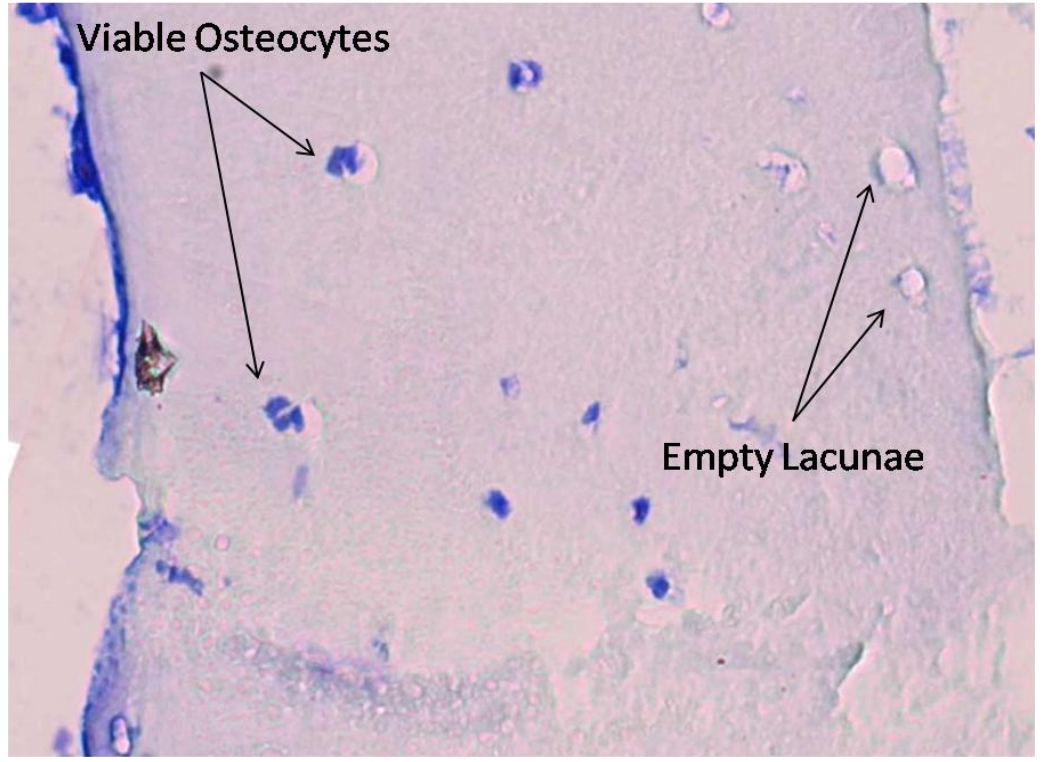

Figure 12. Methyl green stained image showing stained osteocytes and empty lacunae. 
The total number of cells in each cross-section were counted in each anatomic quadrant (Cranial, Lateral, Caudal, Medial) and in each region (Proximal, Midshaft, Distal) along the tibia for all subjects (Figure 13). To ensure that only cells in-plane were counted, stained cells were only counted if they had a clearly defined lacunar wall. The amount of apoptotic and viable osteocytes present in each subject was expressed by calculating four different terms: the apoptotic osteocyte density (number of TUNEL stained cells per cross-sectional area), percent apoptotic osteocytes (number of TUNEL stained cells as a percent of the total cells counted in the cross section), viable osteocyte density (number of methyl green stained cells per cross-sectional area) and percent viable osteocytes (number of methyl green stained cells as a percent of the total cells counted in the cross section).
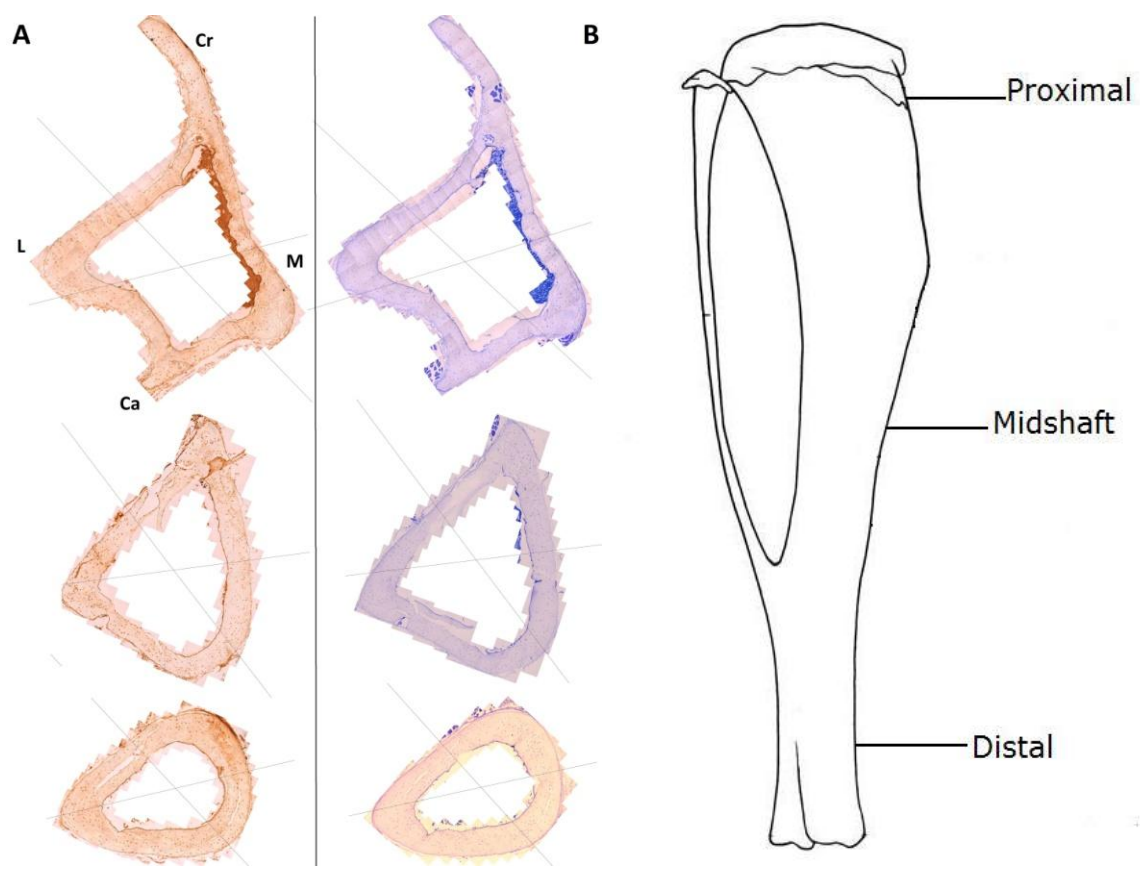

Figure 13. An example of what cross-sectional views across 3 regions of murine tibia look like stacked on top of each other, with samples on the left side(A) being TUNEL stained cross-sections, and samples directly to the right (B) being methyl green stained cross-sections $(\mathrm{Cr}=$ cranial, $\mathrm{Ca}=$ caudal, $\mathrm{M}=$ medial, $\mathrm{L}=$ =lateral $)$. To the right of the cross-sections is an image of a tibia and fibula divided regionally to show the corresponding regions in which each cross-section sample was taken from. 


\subsection{Statistical Analysis}

For this study, the statistical software Minitab 16 (Minitab) was used to analyze and compare all data collected using general linear models (GLM, ANOVA); pairwise comparisons were made using the Tukey method. Firstly, the four groups of tibias, 2 week loaded left tibias, 2 week control right tibias, 5 week loaded left tibias and 5 week control right tibias, were analyzed individually to see if there were any statistically significant differences to be seen within each group independent of the others. Next, the groups of tibias were compared between each other. Comparisons were made between the 2 week loaded and 2 week control samples, the 5 week loaded and 5 week control samples, the 2 week loaded and 5 week loaded samples, and the 2 week control and 5 week control samples. For all data analyzed, differences in apoptotic osteocyte density, percentage of apoptotic osteocytes, viable osteocyte density and percentage of viable osteocytes were determined. These four variables were analyzed in each quadrant (Cranial, Lateral, Caudal, Medial), region (Proximal, Midshaft, Distal), and combination of both. Data was considered to be statistically significant if its related p-value was less than 0.05 . 


\section{RESULTS}

\subsection{Individual statistics for left tibias loaded for 2 weeks}

Below are the statistics for all of the 2 week loaded left tibias, including a summary, analysis by quadrant, analysis by region and combinations of the latter two. For each statistical analysis, apoptotic osteocyte density, percentage of apoptotic osteocytes, viable osteocyte density and percentage of viable osteocytes were the variables considered. Mean values, standard deviations and relevant p-values are shown, with p-values less than 0.05 indicating statistically significant data.

A statistically significant lower percentage of apoptotic osteocytes can be seen in the lateral quadrants of 2 week loaded bones compared to the cranial and medial quadrants, when averaged across all regions. When specifically looking in the proximal region, the lateral quadrant had significantly lower percentage of apoptotic osteocytes than all other quadrants and a lower apoptotic osteocyte density compared to the medial quadrant. The caudal quandrant also showed a significantly lower percentage of apoptotic osteocytes when compared to the medial quadrant, within the proximal region. Only analyzing samples within the midshaft region showed that the percentage of apoptotic osteocytes within the lateral quadrant was lower than the medial quadrant. Looking within just the distal region showed that the percentage of viable osteocytes was significantly higher in the cranial quadrant compared to the lateral quadrant. No statistically significant differences between regions were seen when averaged across all quadrants. The only regional difference seen for 2 week loaded subjects, when looking only at data from medial quadrants, was that the distal region had a significantly less percentage of apoptotic osteocytes compared to the proximal region. 
Table 1. Apoptotic osteocyte density, viable osteocyte density, percentage of apoptotic osteocytes, and percentage of viable osteocytes for left tibias in all subjects that were loaded for 2 weeks. Standard deviations in parentheses.

2 Week Loaded Mean

\begin{tabular}{|l|l|l|l|l|}
\hline SUBJECT & $\begin{array}{l}\text { APOPTOTIC } \\
\text { OSTEOCYTE } \\
\text { DENSITY } \\
\left(\# / \mathbf{m m}^{\mathbf{2}}\right)\end{array}$ & $\begin{array}{l}\text { PERCENTAGE } \\
\text { APOPTOTIC } \\
\text { OSTEOCYTES } \\
(\boldsymbol{\%})\end{array}$ & $\begin{array}{l}\text { VIABLE } \\
\text { OSTEOCYTE } \\
\text { DENSITY } \\
\left(\# / \mathbf{m m}^{\mathbf{2}}\right)\end{array}$ & $\begin{array}{l}\text { PERCENTAGE } \\
\text { VIABLE } \\
\text { OSTEOCYTES } \\
(\boldsymbol{\%})\end{array}$ \\
\hline $\mathbf{2 W L 1}$ & 84.274 & 31.6416 & 166.157 & 41.8833 \\
\hline $\mathbf{2 W L 2}$ & 129.092 & 38.7803 & 268.705 & 54.2325 \\
\hline $\mathbf{2 W L 3}$ & 162.850 & 41.2053 & 232.974 & 48.2845 \\
\hline Overall & $125.4(39.4)$ & $37.21(4.97)$ & $222.6(52.1)$ & $48.13(6.18)$ \\
\hline
\end{tabular}

Table 2. Quadrantal differences of apoptotic osteocyte density, viable osteocyte density, percentage of apoptotic osteocytes, and percentage of viable osteocytes for left tibias in all subjects that were loaded for 2 weeks. Standard deviations in parentheses.

2 Week Loaded Quadrant

\begin{tabular}{|l|c|c|c|c|}
\hline Quadrant & $\begin{array}{l}\text { Apoptotic } \\
\text { Osteocyte } \\
\text { Density }\end{array}$ & $\begin{array}{l}\text { \% Apoptotic } \\
\text { Osteocytes }\end{array}$ & $\begin{array}{l}\text { Viable } \\
\text { Osteocyte } \\
\text { Density }\end{array}$ & $\begin{array}{l}\text { \% Viable } \\
\text { Osteocytes }\end{array}$ \\
\hline Cranial(Cr) & $150.1(38.4)$ & $42.03(6.40)$ & $258.3(63.3)$ & $53.54(7.96)$ \\
\hline Lateral(L) & $88.8(40.7)$ & $26.62(5.80)$ & $139.82(12.08)$ & $33.41(1.79)$ \\
\hline Caudal(Cd) & $112.1(46.8)$ & $33.89(7.47)$ & $211.4(52.1)$ & $45.61(6.39)$ \\
\hline Medial(M) & $146.1(34.6)$ & $43.42(1.92)$ & $244.7(109.0)$ & $51.73(11.52)$ \\
\hline Cr-L & .3162 & .0461 & .2252 & .0514 \\
\hline Cr-Cd & .6711 & .3726 & .8340 & .6129 \\
\hline Cr-M & .9993 & .9905 & .9945 & .9912 \\
\hline L-Cd & .8915 & .4611 & .5984 & .2896 \\
\hline L-M & .3662 & .0306 & .3087 & .0770 \\
\hline Cd-M & .7374 & .2581 & .9303 & .7704 \\
\hline
\end{tabular}


Table 3. Mean quadrantal data gathered from the proximal region for apoptotic osteocyte density, viable osteocyte density, percentage of apoptotic osteocytes, and percentage of viable osteocytes for left tibias in all subjects that were loaded for 2 weeks. Standard deviations in parentheses.

2 Week Loaded Proximal Quadrant

\begin{tabular}{|l|c|c|c|c|}
\hline Quadrant & $\begin{array}{l}\text { Apoptotic } \\
\text { Osteocyte } \\
\text { Density }\end{array}$ & $\begin{array}{l}\text { \% Apoptotic } \\
\text { Osteoctyes }\end{array}$ & $\begin{array}{l}\text { Viable } \\
\text { Osteocyte } \\
\text { Density }\end{array}$ & $\begin{array}{l}\text { \% Viable } \\
\text { Osteocytes }\end{array}$ \\
\hline Cranial(Cr) & $139.26(26.7)$ & $42.49(4.23)$ & $248.18(118.0)$ & $54.36(14.24)$ \\
\hline Lateral(L) & $73.68(47.6)$ & $22.37(3.88)$ & $113.62(61.2)$ & $30.82(12.34)$ \\
\hline Caudal(Cd) & $119.79(25.9)$ & $35.97(4.43)$ & $185.28(30.6)$ & $46.44(8.26)$ \\
\hline Medial(M) & $178.15(40.5)$ & $51.88(6.50)$ & $193.30(62.0)$ & $54.82(17.6)$ \\
\hline Cr-L & .2001 & .0043 & .2029 & .2231 \\
\hline Cr-Cd & .9105 & .4105 & .7387 & .8878 \\
\hline Cr-M & .5818 & .1630 & .8068 & 1.000 \\
\hline L-Cd & .4526 & .0368 & .6598 & .5264 \\
\hline L-M & .0321 & .0003 & .5865 & .2110 \\
\hline Cd-M & .2757 & .0166 & .9991 & .8708 \\
\hline
\end{tabular}

Table 4. Mean quadrantal data gathered from the midshaft region for apoptotic osteocyte density, viable osteocyte density, percentage of apoptotic osteocytes, and percentage of viable osteocytes for left tibias in all subjects that were loaded for 2 weeks. Standard deviations in parentheses.

2 Week Loaded Midshaft Quadrant

\begin{tabular}{|l|c|c|c|c|}
\hline Quadrant & $\begin{array}{l}\text { Apoptotic } \\
\text { Osteocyte } \\
\text { Density }\end{array}$ & $\begin{array}{l}\text { \%Apoptotic } \\
\text { Osteoctyes }\end{array}$ & $\begin{array}{l}\text { Viable } \\
\text { Osteocyte } \\
\text { Density }\end{array}$ & $\begin{array}{l}\text { \% Viable } \\
\text { Osteocytes }\end{array}$ \\
\hline Cranial(Cr) & $169.52(67.1)$ & $40.59(4.18)$ & $236.57(68.0)$ & $49.54(8.58)$ \\
\hline Lateral(L) & $71.92(34.1)$ & $25.75(6.21)$ & $109.51(53.8)$ & $28.75(8.46)$ \\
\hline Caudal(Cd) & $104.01(55.5)$ & $33.25(8.37)$ & $192.70(114.6)$ & $40.36(10.80)$ \\
\hline Medial(M) & $157.92(62.4)$ & $41.00(2.56)$ & $256.64(168.4)$ & $46.93(14.93)$ \\
\hline Cr-L & .2238 & .0534 & .5296 & .1737 \\
\hline Cr-Cd & .5184 & .4498 & .9602 & .7419 \\
\hline Cr-M & .9939 & .9997 & .9958 & .9908 \\
\hline L-Cd & .8946 & .4319 & .7950 & .5924 \\
\hline L-M & .3102 & .0472 & .4164 & .2561 \\
\hline Cd-M & .6580 & .4072 & .8914 & .8817 \\
\hline
\end{tabular}


Table 5. Mean quadrantal data gathered from the distal region for apoptotic osteocyte density, viable osteocyte density, percentage of apoptotic osteocytes, and percentage of viable osteocytes for left tibias in all subjects that were loaded for 2 weeks. Standard deviations in parentheses.

2 Week Loaded Distal Quadrant

\begin{tabular}{|l|c|c|c|c|}
\hline Quadrant & $\begin{array}{l}\text { Apoptotic } \\
\text { Osteocyte } \\
\text { Density }\end{array}$ & $\begin{array}{l}\text { \%Apoptotic } \\
\text { Osteoctyes }\end{array}$ & $\begin{array}{l}\text { Viable } \\
\text { Osteocyte } \\
\text { Density }\end{array}$ & $\begin{array}{l}\text { \% Viable } \\
\text { Osteocytes }\end{array}$ \\
\hline Cranial(Cr) & $141.53(24.6)$ & $43.01(11.61)$ & $290.43(47.3)$ & $56.72(4.66)$ \\
\hline Lateral(L) & $120.86(64.2)$ & $31.75(12.99)$ & $196.34(23.2)$ & $40.67(1.78)$ \\
\hline Caudal(Cd) & $112.62(62.2)$ & $32.43(10.07)$ & $256.25(35.3)$ & $50.03(3.32)$ \\
\hline Medial(M) & $102.34(18.4)$ & $37.39(6.00)$ & $284.29(112.9)$ & $53.44(8.14)$ \\
\hline Cr-L & .9479 & .5801 & .3484 & .0193 \\
\hline Cr-Cd & .8747 & .6247 & .9139 & .4190 \\
\hline Cr-M & .7456 & .9105 & .9994 & .8548 \\
\hline L-Cd & .9963 & .9998 & .6813 & .1853 \\
\hline L-M & .9615 & .9099 & .3999 & .0582 \\
\hline Cd-M & .9929 & .9360 & .9492 & .8402 \\
\hline
\end{tabular}

Table 6. Regional differences of apoptotic osteocyte density, viable osteocyte density, percentage of apoptotic osteocytes, and percentage of viable osteocytes for left tibias in all subjects that were loaded for 2 weeks. Standard deviations in parentheses.

2 Week Loaded Region

\begin{tabular}{|l|l|l|l|l|}
\hline Region & $\begin{array}{l}\text { Apoptotic } \\
\text { Osteocyte } \\
\text { Density }\end{array}$ & $\begin{array}{l}\text { \%Apoptotic } \\
\text { Osteocytes }\end{array}$ & $\begin{array}{l}\text { Viable } \\
\text { Osteocyte } \\
\text { Density }\end{array}$ & $\begin{array}{l}\text { \%Viable } \\
\text { Osteocytes }\end{array}$ \\
\hline Distal(D) & $123.53(42.6)$ & $37.06(8.04)$ & $262.57(50.0)$ & $51.66(3.72)$ \\
\hline Midshaft(MS) & $129.12(48.0)$ & $36.67(2.95)$ & $206.56(90.3)$ & $44.08(9.63)$ \\
\hline Proximal(P) & $123.56(29.8)$ & $37.90(4.46)$ & $198.71(65.2)$ & $48.65(9.80)$ \\
\hline D-MS & .9847 & .9959 & .6185 & .5325 \\
\hline D-P & 1.000 & .9812 & .5431 & .8968 \\
\hline MS-P & .9848 & .9603 & .9898 & .7827 \\
\hline
\end{tabular}


Table 7. Mean regional data gathered from the cranial quadrant for apoptotic osteocyte density, viable osteocyte density, percentage of apoptotic osteocytes, and percentage of viable osteocytes for left tibias in all subjects that were loaded for 2 weeks. Standard deviations in parentheses.

2 Week Loaded Cranial Region

\begin{tabular}{|l|l|l|l|c|}
\hline Region & $\begin{array}{l}\text { Apoptotic } \\
\text { Osteocyte } \\
\text { Density }\end{array}$ & $\begin{array}{l}\text { \%Apoptotic } \\
\text { Osteocytes }\end{array}$ & $\begin{array}{l}\text { Viable } \\
\text { Osteocyte } \\
\text { Density }\end{array}$ & $\begin{array}{l}\text { \% Viable } \\
\text { Osteocytes }\end{array}$ \\
\hline Distal(D) & $141.53(24.6)$ & $43.01(11.61)$ & $290.43(47.3)$ & $56.72(4.66)$ \\
\hline Midshaft(MS) & $169.52(67.1)$ & $40.59(4.18)$ & $236.57(68.0)$ & $49.54(8.58)$ \\
\hline Proximal(P) & $139.26(26.7)$ & $42.49(4.23)$ & $248.18(118)$. & $54.36(14.24)$ \\
\hline D-MS & .7290 & .9192 & .7210 & .6704 \\
\hline D-P & .9978 & .9961 & .8142 & .9551 \\
\hline MS-P & .6933 & .9489 & .9841 & .8294 \\
\hline
\end{tabular}

Table 8. Mean regional data gathered from the lateral quadrant for apoptotic osteocyte density, viable osteocyte density, percentage of apoptotic osteocytes, and percentage of viable osteocytes for left tibias in all subjects that were loaded for 2 weeks. Standard deviations in parentheses.

2 Week Loaded Lateral Region

\begin{tabular}{|l|c|l|l|c|}
\hline Region & $\begin{array}{l}\text { Apoptotic } \\
\text { Osteocyte } \\
\text { Density }\end{array}$ & $\begin{array}{l}\text { \% Apoptotic } \\
\text { Osteocytes }\end{array}$ & $\begin{array}{l}\text { Viable } \\
\text { Osteocyte } \\
\text { Density }\end{array}$ & $\begin{array}{l}\text { \% Viable } \\
\text { Osteocytes }\end{array}$ \\
\hline Distal(D) & $120.86(64.2)$ & $31.75(12.99)$ & $196.34(23.2)$ & $40.67(1.78)$ \\
\hline Midshaft(MS) & $71.92(34.1)$ & $25.75(6.21)$ & $109.51(53.8)$ & $28.75(8.46)$ \\
\hline Proximal(P) & $73.68(47.6)$ & $22.37(3.88)$ & $113.62(61.2)$ & $30.82(12.34)$ \\
\hline D-MS & .4977 & .6866 & .1548 & .2875 \\
\hline D-P & .5203 & .4293 & .1765 & .4048 \\
\hline MS-P & .9990 & .8829 & .9942 & .9544 \\
\hline
\end{tabular}


Table 9. Mean regional data gathered from the caudal quadrant for apoptotic osteocyte density, viable osteocyte density, percentage of apoptotic osteocytes, and percentage of viable osteocytes for left tibias in all subjects that were loaded for 2 weeks. Standard deviations in parentheses.

2 Week Loaded Caudal Region

\begin{tabular}{|l|c|c|c|c|}
\hline Region & $\begin{array}{l}\text { Apoptotic } \\
\text { Osteocyte } \\
\text { Density }\end{array}$ & $\begin{array}{l}\text { \% Apoptotic } \\
\text { Osteocytes }\end{array}$ & $\begin{array}{l}\text { Viable } \\
\text { Osteocyte } \\
\text { Density }\end{array}$ & $\begin{array}{l}\text { \% Viable } \\
\text { Osteocytes }\end{array}$ \\
\hline Distal(D) & $112.62(62.2)$ & $32.43(10.07)$ & $256.25(35.3)$ & $50.03(3.32)$ \\
\hline Midshaft(MS) & $104.01(55.5)$ & $33.25(8.37)$ & $192.70(114.6)$ & $40.36(10.8)$ \\
\hline Proximal(P) & $119.79(25.9)$ & $35.97(4.43)$ & $185.28(30.6)$ & $46.44(8.26)$ \\
\hline D-MS & .9763 & .9913 & .5540 & .3697 \\
\hline D-P & .9835 & .8535 & .4868 & .8532 \\
\hline MS-P & .9232 & .9098 & .9911 & .6475 \\
\hline
\end{tabular}

Table 10. Mean regional data gathered from the medial quadrant for apoptotic osteocyte density, viable osteocyte density, percentage of apoptotic osteocytes, and percentage of viable osteocytes for left tibias in all subjects that were loaded for 2 weeks. Standard deviations in parentheses.

2 Week Loaded Medial Region

\begin{tabular}{|l|l|c|l|c|}
\hline Region & $\begin{array}{l}\text { Apoptotic } \\
\text { Osteocyte } \\
\text { Density }\end{array}$ & $\begin{array}{l}\text { \%Apoptotic } \\
\text { Osteocytes }\end{array}$ & $\begin{array}{l}\text { Viable } \\
\text { Osteocyte } \\
\text { Density }\end{array}$ & $\begin{array}{l}\text { \% Viable } \\
\text { Osteocytes }\end{array}$ \\
\hline Distal(D) & $102.34(18.4)$ & $37.39(6.00)$ & $284.29(112.9)$ & $53.44(8.14)$ \\
\hline Midshaft(MS) & $157.92(62.4)$ & $41.00(2.56)$ & $256.64(168.4)$ & $46.93(14.93)$ \\
\hline Proximal(P) & $178.15(40.5)$ & $51.88(6.50)$ & $193.30(62.0)$ & $54.82(17.6)$ \\
\hline D-MS & .3400 & .6984 & .9590 & .8434 \\
\hline D-P & .1704 & .0361 & .6540 & .9921 \\
\hline MS-P & .8455 & .1015 & .8078 & .7812 \\
\hline
\end{tabular}




\subsection{Individual statistics for right tibias used as 2 week controls}

Below are the statistics for all of the 2 week unloaded right tibias used as controls, including a summary, analysis by quadrant, analysis by region and combinations of the latter two. For each statistical analysis, apoptotic osteocyte density, percentage of apoptotic osteocytes, viable osteocyte density and percentage of viable osteocytes were the variables considered. Mean values, standard deviations and relevant p-values are shown, with p-values less than 0.05 indicating statistically significant data.

For 2 week unloaded tibias, the percentage of apoptotic and viable osteocytes within the lateral quadrants were significantly lower than the medial quadrants, when averaged across all regions. The caudal quadrants showed a lower percentage of apoptotic osteocytes compared to the medial quadrants when averaged across all regions as well. When analyzing only within the proximal region, the lateral quadrant showed a significantly lower percentage of apoptotic osteocytes compared to all other quadrants. The caudal quadrant showed a lower percentage of apoptotic osteocytes as well when compared to the cranial and medial quadrants. The apoptotic osteocyte density of the lateral and the caudal quadrants were both significantly lower than that of the medial quadrant. When looking at data only within the midshaft region, the percentage of viable osteocytes was significantly lower in the lateral quadrant when compared to the cranial and medial while the caudal quadrant was only lower than the medial. No statistically significant differences were seen between regions when they were averaged across all quadrants; the percentage of apoptotic osteocytes in the proximal region was lower than that in the distal region, when solely looking at lateral quadrants. 
Table 11. Apoptotic osteocyte density, viable osteocyte density, percentage of apoptotic osteocytes, and percentage of viable osteocytes for right tibias used as controls in all subjects that were loaded for 2 weeks. Standard deviations in parentheses.

2 Week Control Mean

\begin{tabular}{|c|c|c|c|c|}
\hline SUBJECT & $\begin{array}{l}\text { APOPTOTIC } \\
\text { OSTEOCYTE } \\
\text { DENSITY } \\
\left(\# / \mathrm{mm}^{2}\right)\end{array}$ & $\begin{array}{l}\text { PERCENTAGE } \\
\text { APOPTOTIC } \\
\text { OSTEOCYTES } \\
(\%)\end{array}$ & $\begin{array}{l}\text { VIABLE } \\
\text { OSTEOCYTE } \\
\text { DENSITY } \\
\left(\# / \mathbf{m m}^{2}\right)\end{array}$ & $\begin{array}{l}\text { PERCENTAGE } \\
\text { VIABLE } \\
\text { OSTEOCYTES } \\
(\%)\end{array}$ \\
\hline 2WR1 & 86.712 & 30.2028 & 234.962 & 50.6915 \\
\hline 2WR2 & 128.724 & 35.1610 & 309.972 & 58.2828 \\
\hline 2WR3 & 154.713 & 34.8880 & 322.758 & 56.7443 \\
\hline Dverall & $123.4(34.3)$ & $33.42(2.79)$ & $289.2(47.4)$ & $5.24(4.01)$ \\
\hline
\end{tabular}

Table 12. Quadrantal differences of apoptotic osteocyte density, viable osteocyte density, percentage of apoptotic osteocytes, and percentage of viable osteocytes for right tibias used as controls in all subjects that were loaded for 2 weeks. Standard deviations in parentheses.

2 Week Control Quadrant

\begin{tabular}{|l|c|c|c|c|}
\hline Quadrant & $\begin{array}{l}\text { Apoptotic } \\
\text { Osteocyte } \\
\text { Density }\end{array}$ & $\begin{array}{l}\text { \%Apoptotic } \\
\text { Osteocytes }\end{array}$ & $\begin{array}{l}\text { Viable } \\
\text { Osteocyte } \\
\text { Density }\end{array}$ & $\begin{array}{l}\text { \% Viable } \\
\text { Osteocytes }\end{array}$ \\
\hline Cranial(Cr) & $128.08(34.1)$ & $36.20(2.08)$ & $305.68(62.2)$ & $59.06(6.36)$ \\
\hline Lateral(L) & $107.65(31.1)$ & $28.30(3.83)$ & $242.22(34.7)$ & $46.37(1.55)$ \\
\hline Caudal(Cd) & $112.28(33.9)$ & $30.21(2.91)$ & $277.54(52.9)$ & $52.05(5.01)$ \\
\hline Medial(M) & $167.96(40.6)$ & $38.92(4.06)$ & $344.32(35.6)$ & $61.03(6.19)$ \\
\hline Cr-L & .8894 & .0745 & .4175 & .0651 \\
\hline Cr-Cd & .9436 & .1992 & .8861 & .3992 \\
\hline Cr-M & .5376 & .7507 & .7592 & .9637 \\
\hline L-Cd & .9984 & .8917 & .8030 & .5598 \\
\hline L-M & .2305 & .0184 & .1144 & .0337 \\
\hline Cd-M & .2843 & .0488 & .3782 & .2214 \\
\hline
\end{tabular}


Table 13. Mean quadrantal data gathered from the proximal region for apoptotic osteocyte density, viable osteocyte density, percentage of apoptotic osteocytes, and percentage of viable osteocytes for right tibias used as controls in all subjects that were loaded for 2 weeks. Standard deviations in parentheses.

2 Week Control Proximal Quadrant

\begin{tabular}{|l|c|c|c|c|}
\hline Quadrant & $\begin{array}{l}\text { Apoptotic } \\
\text { Osteocyte } \\
\text { Density }\end{array}$ & $\begin{array}{l}\text { \% Apoptotic } \\
\text { Osteoctyes }\end{array}$ & $\begin{array}{l}\text { Viable } \\
\text { Osteocyte } \\
\text { Density }\end{array}$ & $\begin{array}{l}\text { \% Viable } \\
\text { Osteocytes }\end{array}$ \\
\hline Cranial(Cr) & $119.69(7.01)$ & $37.96(2.02)$ & $314.25(20.9)$ & $60.82(0.92)$ \\
\hline Lateral(L) & $64.08(23.4)$ & $20.74(2.88)$ & $194.92(47.2)$ & $41.14(7.09)$ \\
\hline Caudal(Cd) & $87.54(4.45)$ & $29.74(1.01)$ & $252.90(52.5)$ & $49.47(5.94)$ \\
\hline Medial(M) & $168.77(35.7)$ & $39.63(4.38)$ & $312.88(92.7)$ & $58.51(13.4)$ \\
\hline Cr-L & .0552 & .0004 & .1405 & .0708 \\
\hline Cr-Cd & .3351 & .0314 & .6050 & .3809 \\
\hline Cr-M & .0928 & .8879 & 1.000 & .9846 \\
\hline L-Cd & .5757 & .0200 & .6440 & .6151 \\
\hline L-M & .0016 & .0002 & .1461 & .1156 \\
\hline Cd-M & .0079 & .0119 & .6208 & .5561 \\
\hline
\end{tabular}

Table 14. Mean quadrantal data gathered from the midshaft region for apoptotic osteocyte density, viable osteocyte density, percentage of apoptotic osteocytes, and percentage of viable osteocytes for right tibias used as controls in all subjects that were loaded for 2 weeks. Standard deviations in parentheses.

2 Week Control Midshaft Quadrant

\begin{tabular}{|l|c|c|l|c|}
\hline Quadrant & $\begin{array}{l}\text { Apoptotic } \\
\text { Osteocyte } \\
\text { Density }\end{array}$ & $\begin{array}{l}\text { \% Apoptotic } \\
\text { Osteoctyes }\end{array}$ & $\begin{array}{l}\text { Viable } \\
\text { Osteocyte } \\
\text { Density }\end{array}$ & $\begin{array}{l}\text { \% Viable } \\
\text { Osteocytes }\end{array}$ \\
\hline Cranial(Cr) & $133.45(46.1)$ & $36.55(6.04)$ & $291.28(113.2)$ & $58.95(7.50)$ \\
\hline Lateral(L) & $115.74(41.0)$ & $28.43(7.06)$ & $238.32(27.8)$ & $43.87(1.80)$ \\
\hline Caudal(Cd) & $115.72(46.9)$ & $29.34(5.27)$ & $270.63(79.6)$ & $49.77(3.04)$ \\
\hline Medial(M) & $172.28(58.3)$ & $37.96(6.36)$ & $421.17(65.7)$ & $63.17(4.14)$ \\
\hline Cr-L & .9683 & .4294 & .8375 & .0170 \\
\hline Cr-Cd & .9681 & .5213 & .9873 & .1489 \\
\hline Cr-M & .7637 & .9919 & .2496 & .6913 \\
\hline L-Cd & 1.000 & .9978 & .9548 & .4494 \\
\hline L-M & .5173 & .3079 & .0792 & .0041 \\
\hline Cd-M & .5170 & .3831 & .1613 & .0312 \\
\hline
\end{tabular}


Table 15. Mean quadrantal data gathered from the distal region for apoptotic osteocyte density, viable osteocyte density, percentage of apoptotic osteocytes, and percentage of viable osteocytes for right tibias used as controls in all subjects that were loaded for 2 weeks. Standard deviations in parentheses.

2 Week Control Distal Quadrant

\begin{tabular}{|l|l|c|c|c|}
\hline Quadrant & $\begin{array}{l}\text { Apoptotic } \\
\text { Osteocyte } \\
\text { Density }\end{array}$ & $\begin{array}{l}\text { \% Apoptotic } \\
\text { Osteoctyes }\end{array}$ & $\begin{array}{l}\text { Viable } \\
\text { Osteocyte } \\
\text { Density }\end{array}$ & $\begin{array}{l}\text { \% Viable } \\
\text { Osteocytes }\end{array}$ \\
\hline Cranial(Cr) & $131.09(54.8)$ & $34.08(3.96)$ & $311.52(82.5)$ & $57.40(11.25)$ \\
\hline Lateral(L) & $143.13(36.0)$ & $35.72(5.44)$ & $293.43(67.2)$ & $54.09(9.46)$ \\
\hline Caudal(Cd) & $133.58(57.0)$ & $31.55(5.84)$ & $309.09(48.5)$ & $56.91(6.88)$ \\
\hline Medial(M) & $162.81(42.1)$ & $39.17(3.84)$ & $298.90(38.3)$ & $61.43(6.88)$ \\
\hline Cr-L & .9894 & .9745 & .9829 & .9655 \\
\hline Cr-Cd & .9999 & .9166 & 1.000 & .9999 \\
\hline Cr-M & .8505 & .5965 & .9940 & .9414 \\
\hline L-Cd & .9946 & .7255 & .9887 & .9781 \\
\hline L-M & .9570 & .8200 & .9995 & .7421 \\
\hline Cd-M & .8777 & .2915 & .9968 & .9203 \\
\hline
\end{tabular}

Table 16. Regional differences of apoptotic osteocyte density, viable osteocyte density, percentage of apoptotic osteocytes, and percentage of viable osteocytes for right tibias used as controls in all subjects that were loaded for 2 weeks. Standard deviations in parentheses.

2 Week Control Region

\begin{tabular}{|l|l|l|l|c|}
\hline Region & $\begin{array}{l}\text { Apoptotic } \\
\text { Osteocyte } \\
\text { Density }\end{array}$ & $\begin{array}{l}\text { \%Apoptotic } \\
\text { Osteocytes }\end{array}$ & $\begin{array}{l}\text { Viable } \\
\text { Osteocyte } \\
\text { Density }\end{array}$ & $\begin{array}{l}\text { \% Viable } \\
\text { Osteocytes }\end{array}$ \\
\hline Distal(D) & $138.65(49.4)$ & $34.19(4.82)$ & $305.10(61.4)$ & $57.41(8.62)$ \\
\hline Midshaft(MS) & $127.87(47.9)$ & $33.16(5.05)$ & $290.88(76.4)$ & $54.39(2.97)$ \\
\hline Proximal(P) & $103.63(11.37)$ & $32.90(1.36)$ & $271.71(21.5)$ & $53.92(1.24)$ \\
\hline D-MS & .9430 & .9495 & .9518 & .7749 \\
\hline D-P & .5674 & .9229 & .7691 & .7153 \\
\hline MS-P & .7518 & .9968 & .9147 & .9937 \\
\hline
\end{tabular}


Table 17. Mean regional data gathered from the cranial quadrant for apoptotic osteocyte density, viable osteocyte density, percentage of apoptotic osteocytes, and percentage of viable osteocytes for right tibias used as controls in all subjects that were loaded for 2 weeks. Standard deviations in parentheses.

2 Week Control Cranial Region

\begin{tabular}{|l|l|l|c|c|}
\hline Region & $\begin{array}{l}\text { Apoptotic } \\
\text { Osteocyte } \\
\text { Density }\end{array}$ & $\begin{array}{l}\text { \%Apoptotic } \\
\text { Osteocytes }\end{array}$ & $\begin{array}{l}\text { Viable } \\
\text { Osteocyte } \\
\text { Density }\end{array}$ & $\begin{array}{l}\text { \% Viable } \\
\text { Osteocytes }\end{array}$ \\
\hline Distal(D) & $131.09(54.8)$ & $34.08(3.96)$ & $311.52(82.5)$ & $57.40(11.25)$ \\
\hline Midshaft(MS) & $133.45(46.1)$ & $36.55(6.04)$ & $291.28(113.2)$ & $58.95(7.50)$ \\
\hline Proximal(P) & $119.69(7.01)$ & $37.96(2.02)$ & $314.25(20.9)$ & $60.82(0.92)$ \\
\hline D-MS & .9973 & .7728 & .9510 & .9683 \\
\hline D-P & .9403 & .5490 & .9991 & .8579 \\
\hline MS-P & .9146 & .9169 & .9375 & .9545 \\
\hline
\end{tabular}

Table 18. Mean regional data gathered from the lateral quadrant for apoptotic osteocyte density, viable osteocyte density, percentage of apoptotic osteocytes, and percentage of viable osteocytes for right tibias used as controls in all subjects that were loaded for 2 weeks. Standard deviations in parentheses.

2 Week Control Lateral Region

\begin{tabular}{|l|c|c|l|c|}
\hline Region & $\begin{array}{l}\text { Apoptotic } \\
\text { Osteocyte } \\
\text { Density }\end{array}$ & $\begin{array}{l}\text { \%Apoptotic } \\
\text { Osteocytes }\end{array}$ & $\begin{array}{l}\text { Viable } \\
\text { Osteocyte } \\
\text { Density }\end{array}$ & $\begin{array}{l}\text { \% Viable } \\
\text { Osteocytes }\end{array}$ \\
\hline Distal(D) & $143.13(36.0)$ & $35.72(5.44)$ & $293.43(67.2)$ & $54.09(9.46)$ \\
\hline Midshaft(MS) & $115.74(41.0)$ & $28.43(7.06)$ & $238.32(27.8)$ & $43.87(1.80)$ \\
\hline Proximal(P) & $64.08(23.4)$ & $20.74(2.88)$ & $194.92(47.2)$ & $41.14(7.09)$ \\
\hline D-MS & .6152 & .2969 & .4224 & .2440 \\
\hline D-P & .0676 & .0338 & .1145 & .1326 \\
\hline MS-P & .2339 & .2667 & .5691 & .8818 \\
\hline
\end{tabular}


Table 19. Mean regional data gathered from the caudal quadrant for apoptotic osteocyte density, viable osteocyte density, percentage of apoptotic osteocytes, and percentage of viable osteocytes for right tibias used as controls in all subjects that were loaded for 2 weeks. Standard deviations in parentheses.

2 Week Control Caudal Region

\begin{tabular}{|l|c|c|c|c|}
\hline Region & $\begin{array}{l}\text { Apoptotic } \\
\text { Osteocyte } \\
\text { Density }\end{array}$ & $\begin{array}{l}\text { \% Apoptotic } \\
\text { Osteocytes }\end{array}$ & $\begin{array}{l}\text { Viable } \\
\text { Osteocyte } \\
\text { Density }\end{array}$ & $\begin{array}{l}\text { \% Viable } \\
\text { Osteocytes }\end{array}$ \\
\hline Distal(D) & $133.58(57.0)$ & $31.55(5.84)$ & $309.09(48.5)$ & $56.91(6.88)$ \\
\hline Midshaft(MS) & $115.72(46.9)$ & $29.34(5.27)$ & $270.63(79.6)$ & $49.77(3.04)$ \\
\hline Proximal(P) & $87.54(4.45)$ & $29.74(1.01)$ & $252.90(52.5)$ & $49.47(5.94)$ \\
\hline D-MS & .8683 & .8293 & .7376 & .3233 \\
\hline D-P & .4355 & .8806 & .5404 & .2986 \\
\hline MS-P & .7120 & .9938 & .9348 & .9976 \\
\hline
\end{tabular}

Table 20. Mean regional data gathered from the medial quadrant for apoptotic osteocyte density, viable osteocyte density, percentage of apoptotic osteocytes, and percentage of viable osteocytes for right tibias used as controls in all subjects that were loaded for 2 weeks. Standard deviations in parentheses.

2 Week Control Medial Region

\begin{tabular}{|l|l|l|l|c|}
\hline Region & $\begin{array}{l}\text { Apoptotic } \\
\text { Osteocyte } \\
\text { Density }\end{array}$ & $\begin{array}{l}\text { \% Apoptotic } \\
\text { Osteocytes }\end{array}$ & $\begin{array}{l}\text { Viable } \\
\text { Osteocyte } \\
\text { Density }\end{array}$ & $\begin{array}{l}\text { \% Viable } \\
\text { Osteocytes }\end{array}$ \\
\hline Distal(D) & $162.81(42.1)$ & $39.17(3.84)$ & $298.90(38.3)$ & $61.43(6.88)$ \\
\hline Midshaft(MS) & $172.28(58.3)$ & $37.96(6.36)$ & $421.17(65.7)$ & $63.17(4.14)$ \\
\hline Proximal(P) & $168.77(35.7)$ & $39.63(4.38)$ & $312.88(92.7)$ & $58.51(13.4)$ \\
\hline D-MS & .9663 & .9532 & .1571 & .9698 \\
\hline D-P & .9865 & .9929 & .9671 & .9180 \\
\hline MS-P & .9953 & .9127 & .2147 & .8080 \\
\hline
\end{tabular}




\subsection{Individual statistics for left tibias loaded for 5 weeks}

Below are the statistics for all of the 5 week loaded left tibias, including a summary, analysis by quadrant, analysis by region and combinations of the latter two. For each statistical analysis, apoptotic osteocyte density, percentage of apoptotic osteocytes, viable osteocyte density and percentage of viable osteocytes were the variables considered. Mean values, standard deviations and relevant $\mathrm{p}$-values are shown, with $\mathrm{p}$-values less than 0.05 indicating statistically significant data.

For 5 week loaded data averaged across all regions, the lateral quadrants showed significantly lower percentages of viable osteocytes when compared to all other quadrants and significantly lower density of viable osteocytes when compared to the cranial quadrants. When looking at samples only taken from proximal regions, the lateral quadrants showed significantly lower percentages and densities of viable osteocytes compared to all other quadrants. These proximal lateral quadrants also showed lower percentages and densities of apoptotic osteocytes compared to the medial quadrants in the same region. Only analyzing samples within the midshaft region showed that there were significantly less percentages of viable osteocytes in the lateral quadrants compared to the medial quadrants. Looking only at samples within the distal region showed that there were significantly lower percentages of viable osteocytes in the lateral quadrants compared to the cranial and medial quadrants.

When averaged across all quadrants, midshaft samples showed higher viable osteocyte densities than the distal and proximal regions. When looking only within the cranial quadrant, distal samples showed significantly less viable osteocyte densities than midshaft samples. Isolating lateral quadrant samples showed significantly higher densities of apoptotic osteocytes, percentages of apoptotic osteocytes and densities of 
viable osteocytes in the midshaft compared to in the proximal region. Regional data solely from the caudal quadrant showed significantly higher apoptotic osteocyte densities in the midshaft compared to the proximal regions and significantly higher densities of viable osteocytes in the midshaft compared to both the distal and proximal regions.

Table 21. Apoptotic osteocyte density, viable osteocyte density, percentage of apoptotic osteocytes, and percentage of viable osteocytes for left tibias in all subjects that were loaded for 5 weeks. Standard deviations in parentheses.

5 Week Loaded Mean

\begin{tabular}{|l|c|c|c|c|}
\hline SUBJECT & $\begin{array}{l}\text { APOPTOTIC } \\
\text { OSTEOCYTE } \\
\text { DENSITY } \\
\left(\# / \mathbf{m m}^{2}\right)\end{array}$ & $\begin{array}{l}\text { PERCENTAGE } \\
\text { APOPTOTIC } \\
\text { OSTEOCYTES } \\
(\boldsymbol{\%})\end{array}$ & $\begin{array}{l}\text { VIABLE } \\
\text { OSTEOCYTE } \\
\text { DENSITY } \\
\left(\# / \mathbf{m m}^{\mathbf{2}}\right)\end{array}$ & $\begin{array}{l}\text { PERCENTAGE } \\
\text { VIABLE } \\
\text { OSTEOCYTES } \\
(\boldsymbol{\%})\end{array}$ \\
\hline $\mathbf{5 W L 1}$ & 254.335 & 58.0080 & 288.214 & 61.8257 \\
\hline 5WL2 & 237.385 & 60.0225 & 321.218 & 64.8525 \\
\hline 5WL3 & 276.643 & 61.7180 & 338.626 & 64.3634 \\
\hline 5WL4 & 236.360 & 62.2560 & 296.044 & 63.0723 \\
\hline 5WL5 & 253.074 & 58.8612 & 374.637 & 63.5759 \\
\hline 5WL6 & 168.333 & 54.4083 & 339.155 & 66.5362 \\
\hline Overall & $237.7(37.0)$ & $59.21(2.86)$ & $326.3(52.1)$ & $64.04(1.62)$ \\
\hline
\end{tabular}


Table 22. Quadrantal differences of apoptotic osteocyte density, viable osteocyte density, percentage of apoptotic osteocytes, and percentage of viable osteocytes for left tibias in all subjects that were loaded for 5 weeks. Standard deviations in parentheses.

5 Week Loaded Quadrant

\begin{tabular}{|l|c|c|c|c|}
\hline Quadrant & $\begin{array}{l}\text { Apoptotic } \\
\text { Osteocyte } \\
\text { Density }\end{array}$ & $\begin{array}{l}\text { \%Apoptotic } \\
\text { Osteocytes }\end{array}$ & $\begin{array}{l}\text { Viable } \\
\text { Osteocyte } \\
\text { Density }\end{array}$ & $\begin{array}{l}\text { \% Viable } \\
\text { Osteocytes }\end{array}$ \\
\hline Cranial(Cr) & $236.27(37.8)$ & $59.90(3.83)$ & $348.55(35.4)$ & $67.22(1.50)$ \\
\hline Lateral(L) & $232.46(56.8)$ & $58.00(3.47)$ & $272.02(63.1)$ & $54.68(5.81)$ \\
\hline Caudal(Cd) & $239.50(38.3)$ & $58.40(3.39)$ & $330.77(23.34)$ & $63.75(2.72)$ \\
\hline Medial(M) & $256.88(59.1)$ & $60.31(2.46)$ & $333.68(42.3)$ & $67.36(1.34)$ \\
\hline Cr-L & .9991 & .7587 & .0298 & .0000 \\
\hline Cr-Cd & .9995 & .8635 & .8927 & .3089 \\
\hline Cr-M & .8847 & .9964 & .9333 & .9999 \\
\hline L-Cd & .9944 & .9967 & .1224 & .0008 \\
\hline L-M & .8238 & .6336 & .0986 & .0000 \\
\hline Cd-M & .9264 & .7555 & .9994 & .2780 \\
\hline
\end{tabular}

Table 23. Mean quadrantal data gathered from the proximal region for apoptotic osteocyte density, viable osteocyte density, percentage of apoptotic osteocytes, and percentage of viable osteocytes for left tibias in all subjects that were loaded for 5 weeks. Standard deviations in parentheses.

5 Week Loaded Proximal Quadrant

\begin{tabular}{|l|c|c|c|c|}
\hline Quadrant & $\begin{array}{l}\text { Apoptotic } \\
\text { Osteocyte } \\
\text { Density }\end{array}$ & $\begin{array}{l}\text { \%Apoptotic } \\
\text { Osteoctyes }\end{array}$ & $\begin{array}{l}\text { Viable } \\
\text { Osteocyte } \\
\text { Density }\end{array}$ & $\begin{array}{l}\text { \% Viable } \\
\text { Osteocytes }\end{array}$ \\
\hline Cranial(Cr) & $222.01(28.9)$ & $58.68(4.20)$ & $331.65(49.7)$ & $66.40(2.15)$ \\
\hline Lateral(L) & $173.98(25.0)$ & $52.43(4.98)$ & $198.41(64.5)$ & $47.12(11.49)$ \\
\hline Caudal(Cd) & $210.18(18.24)$ & $56.97(4.00)$ & $309.71(40.4)$ & $64.43(5.67)$ \\
\hline Medial(M) & $277.59(80.9)$ & $63.09(4.59)$ & $307.77(63.3)$ & $66.61(4.91)$ \\
\hline Cr-L & .2927 & .1043 & .0025 & .0006 \\
\hline Cr-Cd & .9691 & .9089 & .9012 & .9600 \\
\hline Cr-M & .1845 & .3423 & .8770 & .9999 \\
\hline L-Cd & .5296 & .3207 & .0116 & .0018 \\
\hline L-M & .0042 & .0026 & .0133 & .0005 \\
\hline Cd-M & .0811 & .1135 & .999 & .9472 \\
\hline
\end{tabular}


Table 24. Mean quadrantal data gathered from the midshaft region for apoptotic osteocyte density, viable osteocyte density, percentage of apoptotic osteocytes, and percentage of viable osteocytes for left tibias in all subjects that were loaded for 5 weeks. Standard deviations in parentheses.

5 Week Loaded Midshaft Quadrant

\begin{tabular}{|l|c|c|c|c|}
\hline Quadrant & $\begin{array}{l}\text { Apoptotic } \\
\text { Osteocyte } \\
\text { Density }\end{array}$ & $\begin{array}{l}\text { \%Apoptotic } \\
\text { Osteoctyes }\end{array}$ & $\begin{array}{l}\text { Viable } \\
\text { Osteocyte } \\
\text { Density }\end{array}$ & $\begin{array}{l}\text { \% Viable } \\
\text { Osteocytes }\end{array}$ \\
\hline Cranial(Cr) & $255.87(71.0)$ & $62.48(4.44)$ & $392.50(54.7)$ & $67.41(3.49)$ \\
\hline Lateral(L) & $277.99(81.8)$ & $64.35(5.50)$ & $348.03(102.4)$ & $58.25(7.78)$ \\
\hline Caudal(Cd) & $287.88(68.9)$ & $62.29(3.30)$ & $382.38(54.9)$ & $63.60(5.68)$ \\
\hline Medial(M) & $287.24(114.6)$ & $60.99(5.37)$ & $383.97(112.5)$ & $68.84(5.07)$ \\
\hline Cr-L & .9698 & .9013 & .8037 & .0527 \\
\hline Cr-Cd & .9162 & .9999 & .9968 & .6626 \\
\hline Cr-M & .9206 & .9477 & .9981 & .9717 \\
\hline L-Cd & .9971 & .8732 & .8970 & .3901 \\
\hline L-M & .9976 & .6172 & .8842 & .0211 \\
\hline Cd-M & 1.000 & .9644 & 1.000 & .4080 \\
\hline
\end{tabular}

Table 25. Mean quadrantal data gathered from the distal region for apoptotic osteocyte density, viable osteocyte density, percentage of apoptotic osteocytes, and percentage of viable osteocytes for left tibias in all subjects that were loaded for 5 weeks. Standard deviations in parentheses.

5 Week Loaded Distal Quadrant

\begin{tabular}{|l|l|c|l|c|}
\hline Quadrant & $\begin{array}{l}\text { Apoptotic } \\
\text { Osteocyte } \\
\text { Density }\end{array}$ & $\begin{array}{l}\text { \% Apoptotic } \\
\text { Osteoctyes }\end{array}$ & $\begin{array}{l}\text { Viable } \\
\text { Osteocyte } \\
\text { Density }\end{array}$ & $\begin{array}{l}\text { \% Viable } \\
\text { Osteocytes }\end{array}$ \\
\hline Cranial(Cr) & $230.93(44.9)$ & $58.54(6.44)$ & $321.50(31.1)$ & $67.85(1.45)$ \\
\hline Lateral(L) & $245.40(77.7)$ & $57.22(6.52)$ & $269.62(68.5)$ & $58.67(2.89)$ \\
\hline Caudal(Cd) & $220.42(48.0)$ & $55.96(6.80)$ & $300.20(14.07)$ & $63.22(4.82)$ \\
\hline Medial(M) & $205.80(43.4)$ & $56.84(7.32)$ & $309.30(47.7)$ & $66.62(3.26)$ \\
\hline Cr-L & .9682 & .9864 & .2240 & .0006 \\
\hline Cr-Cd & .9873 & .9107 & .8454 & .1075 \\
\hline Cr-M & .8594 & .9719 & .9652 & .9170 \\
\hline L-Cd & .8614 & .9880 & .6492 & .1162 \\
\hline L-M & .6093 & .9997 & .4425 & .0027 \\
\hline Cd-M & .9673 & .9958 & .9849 & .3175 \\
\hline
\end{tabular}


Table 26. Regional differences of apoptotic osteocyte density, viable osteocyte density, percentage of apoptotic osteocytes, and percentage of viable osteocytes for left tibias in all subjects that were loaded for 5 weeks. Standard deviations in parentheses.

5 Week Loaded Region

\begin{tabular}{|l|l|l|l|c|}
\hline Region & $\begin{array}{l}\text { Apoptotic } \\
\text { Osteocyte } \\
\text { Density }\end{array}$ & $\begin{array}{l}\text { \% Apoptotic } \\
\text { Osteocytes }\end{array}$ & $\begin{array}{l}\text { Viable } \\
\text { Osteocyte } \\
\text { Density }\end{array}$ & $\begin{array}{l}\text { \% Viable } \\
\text { Osteocytes }\end{array}$ \\
\hline Distal(D) & $225.88(41.0)$ & $57.08(5.41)$ & $302.42(19.36)$ & $64.32(2.00)$ \\
\hline Midshaft(MS) & $272.75(68.7)$ & $62.78(3.77)$ & $377.70(52.9)$ & $64.97(3.61)$ \\
\hline Proximal(P) & $214.44(24.9)$ & $57.78(2.74)$ & $298.83(49.0)$ & $62.82(3.85)$ \\
\hline D-MS & .2459 & .0727 & .0219 & .9363 \\
\hline D-P & .9122 & .9534 & .9886 & .7102 \\
\hline MS-P & .1263 & .1230 & .0165 & .5032 \\
\hline
\end{tabular}

Table 27. Mean regional data gathered from the cranial quadrant for apoptotic osteocyte density, viable osteocyte density, percentage of apoptotic osteocytes, and percentage of viable osteocytes for left tibias in all subjects that were loaded for 5 weeks. Standard deviations in parentheses.

5 Week Loaded Cranial Region

\begin{tabular}{|l|l|l|l|c|}
\hline Region & $\begin{array}{l}\text { Apoptotic } \\
\text { Osteocyte } \\
\text { Density }\end{array}$ & $\begin{array}{l}\text { \% Apoptotic } \\
\text { Osteocytes }\end{array}$ & $\begin{array}{l}\text { Viable } \\
\text { Osteocyte } \\
\text { Density }\end{array}$ & $\begin{array}{l}\text { \% Viable } \\
\text { Osteocytes }\end{array}$ \\
\hline Distal(D) & $230.93(44.9)$ & $58.54(6.44)$ & $321.50(31.1)$ & $67.85(1.45)$ \\
\hline Midshaft(MS) & $255.87(71.0)$ & $62.48(4.44)$ & $392.50(54.7)$ & $67.41(3.49)$ \\
\hline Proximal(P) & $222.01(28.9)$ & $58.68(4.20)$ & $331.65(49.7)$ & $66.40(2.15)$ \\
\hline D-MS & .6836 & .4022 & .0448 & .9490 \\
\hline D-P & .9514 & .9989 & .9239 & .5878 \\
\hline MS-P & .5036 & .4259 & .0905 & .7718 \\
\hline
\end{tabular}


Table 28. Mean regional data gathered from the lateral quadrant for apoptotic osteocyte density, viable osteocyte density, percentage of apoptotic osteocytes, and percentage of viable osteocytes for left tibias in all subjects that were loaded for 5 weeks. Standard deviations in parentheses.

5 Week Loaded Lateral Region

\begin{tabular}{|l|l|l|l|c|}
\hline Region & $\begin{array}{l}\text { Apoptotic } \\
\text { Osteocyte } \\
\text { Density }\end{array}$ & $\begin{array}{l}\text { \%Apoptotic } \\
\text { Osteocytes }\end{array}$ & $\begin{array}{l}\text { Viable } \\
\text { Osteocyte } \\
\text { Density }\end{array}$ & $\begin{array}{l}\text { \% Viable } \\
\text { Osteocytes }\end{array}$ \\
\hline Distal(D) & $245.40(77.7)$ & $57.22(6.52)$ & $269.62(68.5)$ & $58.67(2.89)$ \\
\hline Midshaft(MS) & $277.99(81.8)$ & $64.35(5.50)$ & $348.03(102.4)$ & $58.25(7.78)$ \\
\hline Proximal(P) & $173.98(25.0)$ & $52.43(4.98)$ & $198.41(64.5)$ & $47.12(11.49)$ \\
\hline D-MS & .6811 & .1106 & .2405 & .9956 \\
\hline D-P & .1862 & .3396 & .3028 & .0665 \\
\hline MS-P & .0411 & .0067 & .0147 & .0783 \\
\hline
\end{tabular}

Table 29. Mean regional data gathered from the caudal quadrant for apoptotic osteocyte density, viable osteocyte density, percentage of apoptotic osteocytes, and percentage of viable osteocytes for left tibias in all subjects that were loaded for 5 weeks. Standard deviations in parentheses.

5 Week Loaded Caudal Region

\begin{tabular}{|l|c|c|l|c|}
\hline Region & $\begin{array}{l}\text { Apoptotic } \\
\text { Osteocyte } \\
\text { Density }\end{array}$ & $\begin{array}{l}\text { \%Apoptotic } \\
\text { Osteocytes }\end{array}$ & $\begin{array}{l}\text { Viable } \\
\text { Osteocyte } \\
\text { Density }\end{array}$ & $\begin{array}{l}\text { \% Viable } \\
\text { Osteocytes }\end{array}$ \\
\hline Distal(D) & $220.42(48.0)$ & $55.96(6.80)$ & $300.20(14.07)$ & $63.22(4.82)$ \\
\hline Midshaft(MS) & $287.88(68.9)$ & $62.29(3.30)$ & $382.38(54.9)$ & $63.60(5.68)$ \\
\hline Proximal(P) & $210.18(18.24)$ & $56.97(4.00)$ & $309.71(40.4)$ & $64.43(5.67)$ \\
\hline D-MS & .0781 & .1004 & .0078 & .9919 \\
\hline D-P & .9322 & .9341 & .9120 & .9213 \\
\hline MS-P & .0400 & .1829 & .0177 & .9620 \\
\hline
\end{tabular}


Table 30. Mean regional data gathered from the medial quadrant for apoptotic osteocyte density, viable osteocyte density, percentage of apoptotic osteocytes, and percentage of viable osteocytes for left tibias in all subjects that were loaded for 5 weeks. Standard deviations in parentheses.

5 Week Loaded Medial Region

\begin{tabular}{|l|c|c|c|c|}
\hline Region & $\begin{array}{l}\text { Apoptotic } \\
\text { Osteocyte } \\
\text { Density }\end{array}$ & $\begin{array}{l}\text { \% Apoptotic } \\
\text { Osteocytes }\end{array}$ & $\begin{array}{l}\text { Viable } \\
\text { Osteocyte } \\
\text { Density }\end{array}$ & $\begin{array}{l}\text { \% Viable } \\
\text { Osteocytes }\end{array}$ \\
\hline Distal(D) & $205.80(43.4)$ & $56.84(7.32)$ & $309.30(47.7)$ & $66.62(3.26)$ \\
\hline Midshaft(MS) & $287.24(114.6)$ & $60.99(5.37)$ & $383.97(112.5)$ & $68.84(5.07)$ \\
\hline Proximal(P) & $277.59(80.9)$ & $63.09(4.59)$ & $307.77(63.3)$ & $66.61(4.91)$ \\
\hline D-MS & .2508 & .4578 & .2651 & .6743 \\
\hline D-P & .3338 & .1895 & .9994 & 1.000 \\
\hline MS-P & .9788 & .8119 & .2522 & .6719 \\
\hline
\end{tabular}

\subsection{Individual statistics for right tibias used as 5 week controls}

Below are the statistics for all of the 5 week unloaded right tibias used as controls, including a summary, analysis by quadrant, analysis by region and combinations of the latter two. For each statistical analysis, apoptotic osteocyte density, percentage of apoptotic osteocytes, viable osteocyte density and percentage of viable osteocytes were the variables considered. Mean values, standard deviations and relevant $\mathrm{p}$-values are shown, with p-values less than 0.05 indicating statistically significant data.

No statistically significant data differences were seen between quadrants, when averaged across all regions, or between regions, when averaged across all quadrants. The only statistically significant difference seen showed higher viable osteocyte densities in midshafts compared to samples in the proximal region, when analyzing within the medial quadrant only. 
Table 31. Apoptotic osteocyte density, viable osteocyte density, percentage of apoptotic osteocytes, and percentage of viable osteocytes for right tibias used as controls in all subjects that were loaded for 5 weeks. Standard deviations in parentheses.

5 Week Control Mean

\begin{tabular}{|l|c|c|c|c|}
\hline SUBJECT & $\begin{array}{l}\text { APOPTOTIC } \\
\text { OSTEOCYTE } \\
\text { DENSITY } \\
\left(\# / \mathbf{m m}^{2}\right)\end{array}$ & $\begin{array}{l}\text { PERCENTAGE } \\
\text { APOPTOTIC } \\
\text { OSTEOCYTES } \\
(\boldsymbol{\%})\end{array}$ & $\begin{array}{l}\text { VIABLE } \\
\text { OSTEOCYTE } \\
\text { DENSITY } \\
\left(\# / \text { mm }^{2}\right)\end{array}$ & $\begin{array}{l}\text { PERCENTAGE } \\
\text { VIABLE } \\
\text { OSTEOCYTES } \\
(\boldsymbol{\%})\end{array}$ \\
\hline 5WR1 & 132.827 & 41.1027 & 351.098 & 60.0203 \\
\hline 5WR2 & 148.814 & 35.8902 & 399.276 & 57.1673 \\
\hline 5WR3 & 125.390 & 32.8866 & 392.888 & 60.4484 \\
\hline 5WR4 & 186.986 & 46.9419 & 300.056 & 68.5789 \\
\hline 5WR5 & 169.658 & 43.1078 & 271.562 & 72.1905 \\
\hline 5WR6 & 126.423 & 33.8280 & 389.805 & 64.6432 \\
\hline Overall & $148.3(25.3)$ & $38.96(5.62)$ & $350.8(53.8)$ & $63.84(5.72)$ \\
\hline
\end{tabular}

Table 32. Quadrantal differences of apoptotic osteocyte density, viable osteocyte density, percentage of apoptotic osteocytes, and percentage of viable osteocytes for right tibias used as controls in all subjects that were loaded for 5 weeks. Standard deviations in parentheses.

5 Week Control Quadrant

\begin{tabular}{|l|l|c|c|c|}
\hline Quadrant & $\begin{array}{l}\text { Apoptotic } \\
\text { Osteocyte } \\
\text { Density }\end{array}$ & $\begin{array}{l}\text { \%Apoptotic } \\
\text { Osteocytes }\end{array}$ & $\begin{array}{l}\text { Viable } \\
\text { Osteocyte } \\
\text { Density }\end{array}$ & $\begin{array}{l}\text { \% Viable } \\
\text { Osteocytes }\end{array}$ \\
\hline Cranial(Cr) & $151.11(17.04)$ & $41.24(4.74)$ & $358.88(83.2)$ & $66.72(3.11)$ \\
\hline Lateral(L) & $154.51(36.2)$ & $36.82(6.58)$ & $319.53(27.5)$ & $57.41(10.05)$ \\
\hline Caudal(Cd) & $141.49(28.4)$ & $37.35(6.70)$ & $368.86(59.6)$ & $64.33(7.15)$ \\
\hline Medial(M) & $154.90(45.1)$ & $38.35(6.07)$ & $336.28(58.0)$ & $64.63(6.75)$ \\
\hline Cr-L & .9980 & .5964 & .6770 & .1466 \\
\hline Cr-Cd & .9581 & .6867 & .9916 & .9384 \\
\hline Cr-M & .9972 & .8415 & .9151 & .9575 \\
\hline L-Cd & .9046 & .9987 & .5054 & .3673 \\
\hline L-M & 1.000 & .9715 & .9626 & .3316 \\
\hline Cd-M & .8971 & .9916 & .7872 & .9999 \\
\hline
\end{tabular}


Table 33. Mean quadrantal data gathered from the proximal region for apoptotic osteocyte density, viable osteocyte density, percentage of apoptotic osteocytes, and percentage of viable osteocytes for right tibias used as controls in all subjects that were loaded for 5 weeks. Standard deviations in parentheses.

5 Week Control Proximal Quadrant

\begin{tabular}{|l|l|c|c|c|}
\hline Quadrant & $\begin{array}{l}\text { Apoptotic } \\
\text { Osteocyte } \\
\text { Density }\end{array}$ & $\begin{array}{l}\text { \%Apoptotic } \\
\text { Osteoctyes }\end{array}$ & $\begin{array}{l}\text { Viable } \\
\text { Osteocyte } \\
\text { Density }\end{array}$ & $\begin{array}{l}\text { \% Viable } \\
\text { Osteocytes }\end{array}$ \\
\hline Cranial(Cr) & $150.31(18.42)$ & $42.06(4.85)$ & $312.83(88.0)$ & $64.48(3.61)$ \\
\hline Lateral(L) & $135.35(48.8)$ & $35.54(8.14)$ & $265.19(37.4)$ & $54.35(11.81)$ \\
\hline Caudal(Cd) & $132.08(25.1)$ & $38.56(6.21)$ & $350.45(97.9)$ & $66.50(9.72)$ \\
\hline Medial(M) & $165.20(61.2)$ & $38.51(9.86)$ & $268.59(73.3)$ & $59.62(9.94)$ \\
\hline Cr-L & .9261 & .4532 & .7152 & .2644 \\
\hline Cr-Cd & .8758 & .8497 & .8352 & .9812 \\
\hline Cr-M & .9272 & .8450 & .7583 & .8022 \\
\hline L-Cd & .9991 & .8972 & .2587 & .1402 \\
\hline L-M & .6179 & .9011 & .9998 & .7607 \\
\hline Cd-M & .5368 & 1.000 & .2908 & .5841 \\
\hline
\end{tabular}

Table 34. Mean quadrantal data gathered from the midshaft region for apoptotic osteocyte density, viable osteocyte density, percentage of apoptotic osteocytes, and percentage of viable osteocytes for right tibias used as controls in all subjects that were loaded for 5 weeks. Standard deviations in parentheses.

5 Week Control Midshaft Quadrant

\begin{tabular}{|l|c|l|l|c|}
\hline Quadrant & $\begin{array}{l}\text { Apoptotic } \\
\text { Osteocyte } \\
\text { Density }\end{array}$ & $\begin{array}{l}\text { \%Apoptotic } \\
\text { Osteoctyes }\end{array}$ & $\begin{array}{l}\text { Viable } \\
\text { Osteocyte } \\
\text { Density }\end{array}$ & $\begin{array}{l}\text { \% Viable } \\
\text { Osteocytes }\end{array}$ \\
\hline Cranial(Cr) & $164.57(27.5)$ & $40.87(7.98)$ & $408.90(123.1)$ & $67.21(4.17)$ \\
\hline Lateral(L) & $191.78(69.1)$ & $39.62(8.77)$ & $365.40(99.9)$ & $58.69(11.38)$ \\
\hline Caudal(Cd) & $155.41(25.9)$ & $38.86(7.33)$ & $396.47(83.9)$ & $64.60(6.96)$ \\
\hline Medial(M) & $155.11(10.82)$ & $37.32(6.66)$ & $397.45(95.8)$ & $65.21(5.78)$ \\
\hline Cr-L & .6421 & .9920 & .8794 & .2397 \\
\hline Cr-Cd & .9779 & .9687 & .9965 & .9317 \\
\hline Cr-M & .9758 & .8557 & .9973 & .9675 \\
\hline L-Cd & .4088 & .9982 & .9510 & .5416 \\
\hline L-M & .4018 & .9546 & .9466 & .4596 \\
\hline Cd-M & 1.000 & .9855 & 1.000 & .9990 \\
\hline
\end{tabular}


Table 35. Mean quadrantal data gathered from the distal region for apoptotic osteocyte density, viable osteocyte density, percentage of apoptotic osteocytes, and percentage of viable osteocytes for right tibias used as controls in all subjects that were loaded for 5 weeks. Standard deviations in parentheses.

5 Week Control Distal Quadrant

\begin{tabular}{|l|c|c|c|c|}
\hline Quadrant & $\begin{array}{l}\text { Apoptotic } \\
\text { Osteocyte } \\
\text { Density }\end{array}$ & $\begin{array}{l}\text { \%Apoptotic } \\
\text { Osteoctyes }\end{array}$ & $\begin{array}{l}\text { Viable } \\
\text { Osteocyte } \\
\text { Density }\end{array}$ & $\begin{array}{l}\text { \% Viable } \\
\text { Osteocytes }\end{array}$ \\
\hline Cranial(Cr) & $138.46(35.3)$ & $40.80(10.09)$ & $354.90(89.4)$ & $68.47(6.75)$ \\
\hline Lateral(L) & $136.41(26.3)$ & $35.30(6.60)$ & $328.00(64.6)$ & $59.19(9.15)$ \\
\hline Caudal(Cd) & $136.99(60.2)$ & $34.62(10.86)$ & $359.66(81.8)$ & $61.89(9.12)$ \\
\hline Medial(M) & $144.39(79.4)$ & $39.21(11.13)$ & $342.81(65.2)$ & $69.06(8.48)$ \\
\hline Cr-L & .9999 & .7686 & .9267 & .2565 \\
\hline Cr-Cd & 1.000 & .7008 & .9995 & .5414 \\
\hline Cr-M & .9975 & .9920 & .9925 & .9994 \\
\hline L-Cd & 1.000 & .9994 & .8873 & .9443 \\
\hline L-M & .9941 & .9005 & .9864 & .2113 \\
\hline Cd-M & .9953 & .8503 & .9802 & .4710 \\
\hline
\end{tabular}

Table 36. Regional differences of apoptotic osteocyte density, viable osteocyte density, percentage of apoptotic osteocytes, and percentage of viable osteocytes for right tibias used as controls in all subjects that were loaded for 5 weeks. Standard deviations in parentheses.

5 Week Control Region

\begin{tabular}{|l|c|c|l|c|}
\hline Region & $\begin{array}{l}\text { Apoptotic } \\
\text { Osteocyte } \\
\text { Density }\end{array}$ & $\begin{array}{l}\text { \%Apoptotic } \\
\text { Osteocytes }\end{array}$ & $\begin{array}{l}\text { Viable } \\
\text { Osteocyte } \\
\text { Density }\end{array}$ & $\begin{array}{l}\text { \% Viable } \\
\text { Osteocytes }\end{array}$ \\
\hline Distal(D) & $139.09(45.8)$ & $37.63(8.96)$ & $350.68(71.9)$ & $64.41(7.51)$ \\
\hline Midshaft(MS) & $163.32(22.7)$ & $39.67(7.46)$ & $394.35(83.1)$ & $64.55(5.68)$ \\
\hline Proximal(P) & $142.64(22.93)$ & $39.58(5.51)$ & $307.31(69.6)$ & $62.56(6.33)$ \\
\hline D-MS & .4179 & .8836 & .5838 & .9993 \\
\hline D-P & .9803 & .8937 & .5881 & .8774 \\
\hline MS-P & .5242 & .9997 & .1447 & .8601 \\
\hline
\end{tabular}


Table 37. Mean regional data gathered from the cranial quadrant for apoptotic osteocyte density, viable osteocyte density, percentage of apoptotic osteocytes, and percentage of viable osteocytes for right tibias used as controls in all subjects that were loaded for 5 weeks. Standard deviations in parentheses.

5 Week Control Cranial Region

\begin{tabular}{|l|c|c|c|c|}
\hline Region & $\begin{array}{l}\text { Apoptotic } \\
\text { Osteocyte } \\
\text { Density }\end{array}$ & $\begin{array}{l}\text { \% Apoptotic } \\
\text { Osteocytes }\end{array}$ & $\begin{array}{l}\text { Viable } \\
\text { Osteocyte } \\
\text { Density }\end{array}$ & $\begin{array}{l}\text { \% Viable } \\
\text { Osteocytes }\end{array}$ \\
\hline Distal(D) & $138.46(35.3)$ & $40.80(10.09)$ & $354.90(89.4)$ & $68.47(6.75)$ \\
\hline Midshaft(MS) & $164.57(27.5)$ & $40.87(7.98)$ & $408.90(123.1)$ & $67.21(4.17)$ \\
\hline Proximal(P) & $150.31(18.42)$ & $42.06(4.85)$ & $312.83(88.0)$ & $64.48(3.61)$ \\
\hline D-MS & .2685 & .9999 & .6354 & .9015 \\
\hline D-P & .7469 & .9594 & .7568 & .3785 \\
\hline MS-P & .6585 & .9637 & .2602 & .6249 \\
\hline
\end{tabular}

Table 38. Mean regional data gathered from the lateral quadrant for apoptotic osteocyte density, viable osteocyte density, percentage of apoptotic osteocytes, and percentage of viable osteocytes for right tibias used as controls in all subjects that were loaded for 5 weeks. Standard deviations in parentheses.

5 Week Control Lateral Region

\begin{tabular}{|l|l|l|l|c|}
\hline Region & $\begin{array}{l}\text { Apoptotic } \\
\text { Osteocyte } \\
\text { Density }\end{array}$ & $\begin{array}{l}\text { \%Apoptotic } \\
\text { Osteocytes }\end{array}$ & $\begin{array}{l}\text { Viable } \\
\text { Osteocyte } \\
\text { Density }\end{array}$ & $\begin{array}{l}\text { \% Viable } \\
\text { Osteocytes }\end{array}$ \\
\hline Distal(D) & $136.41(26.3)$ & $35.30(6.60)$ & $328.00(64.6)$ & $59.19(9.15)$ \\
\hline Midshaft(MS) & $191.78(69.1)$ & $39.62(8.77)$ & $365.40(99.9)$ & $58.69(11.38)$ \\
\hline Proximal(P) & $135.35(48.8)$ & $35.54(8.14)$ & $265.19(37.4)$ & $54.35(11.81)$ \\
\hline D-MS & .1799 & .6194 & .6487 & .9965 \\
\hline D-P & .9993 & .9985 & .3140 & .7243 \\
\hline MS-P & .1697 & .6507 & .0709 & .7706 \\
\hline
\end{tabular}


Table 39. Mean regional data gathered from the caudal quadrant for apoptotic osteocyte density, viable osteocyte density, percentage of apoptotic osteocytes, and percentage of viable osteocytes for right tibias used as controls in all subjects that were loaded for 5 weeks. Standard deviations in parentheses.

5 Week Control Caudal Region

\begin{tabular}{|l|l|l|l|c|}
\hline Region & $\begin{array}{l}\text { Apoptotic } \\
\text { Osteocyte } \\
\text { Density }\end{array}$ & $\begin{array}{l}\text { \%Apoptotic } \\
\text { Osteocytes }\end{array}$ & $\begin{array}{l}\text { Viable } \\
\text { Osteocyte } \\
\text { Density }\end{array}$ & $\begin{array}{l}\text { \% Viable } \\
\text { Osteocytes }\end{array}$ \\
\hline Distal(D) & $136.99(60.2)$ & $34.62(10.86)$ & $359.66(81.8)$ & $61.89(9.12)$ \\
\hline Midshaft(MS) & $155.41(25.9)$ & $38.86(7.33)$ & $396.47(83.9)$ & $64.60(6.96)$ \\
\hline Proximal(P) & $132.08(25.1)$ & $38.56(6.21)$ & $350.45(97.9)$ & $66.50(9.72)$ \\
\hline D-MS & .7163 & .6623 & .7539 & .8523 \\
\hline D-P & .9760 & .7002 & .9821 & .6357 \\
\hline MS-P & .5898 & .9978 & .6460 & .9240 \\
\hline
\end{tabular}

Table 40. Mean regional data gathered from the medial quadrant for apoptotic osteocyte density, viable osteocyte density, percentage of apoptotic osteocytes, and percentage of viable osteocytes for right tibias used as controls in all subjects that were loaded for 5 weeks. Standard deviations in parentheses.

5 Week Control Medial Region

\begin{tabular}{|l|c|c|l|c|}
\hline Region & $\begin{array}{l}\text { Apoptotic } \\
\text { Osteocyte } \\
\text { Density }\end{array}$ & $\begin{array}{l}\text { \%Apoptotic } \\
\text { Osteocytes }\end{array}$ & $\begin{array}{l}\text { Viable } \\
\text { Osteocyte } \\
\text { Density }\end{array}$ & $\begin{array}{l}\text { \%Viable } \\
\text { Osteocytes }\end{array}$ \\
\hline Distal(D) & $144.39(79.4)$ & $39.21(11.13)$ & $342.81(65.2)$ & $69.06(8.48)$ \\
\hline Midshaft(MS) & $155.11(10.82)$ & $37.32(6.66)$ & $397.45(95.8)$ & $65.21(5.78)$ \\
\hline Proximal(P) & $165.20(61.2)$ & $38.51(9.86)$ & $268.59(73.3)$ & $59.62(9.94)$ \\
\hline D-MS & .9457 & .9361 & .4739 & .7043 \\
\hline D-P & .8122 & .9910 & .2667 & .1510 \\
\hline MS-P & .9518 & .9741 & .0328 & .4856 \\
\hline
\end{tabular}




\subsection{Comparison Between 2 Week Loaded Left Tibias and Unloaded Right Tibia Controls}

Below are the statistics for all of the 2 week loaded left tibias compared against all of the 2 week unloaded right tibias used as controls, including a summary, analysis by quadrant, analysis by region and combinations of the latter two. For each statistical analysis, apoptotic osteocyte density, percentage of apoptotic osteocytes, viable osteocyte density and percentage of viable osteocytes were the variables considered. Mean values, standard deviations and relevant $\mathrm{p}$-values are shown, with p-values less than 0.05 indicating statistically significant data.

When comparing the 2 week loaded data against the unloaded data, only one statistically significant difference was found; the percentage of apoptotic osteocytes in the medial quadrant of the proximal region for the 2 week loaded bones was significantly higher than in the 2 week unloaded bones. 
Table 41. Quadrantal differences of apoptotic osteocyte density, viable osteocyte density, percentage of apoptotic osteocytes, and percentage of viable osteocytes between loaded left tibias and control right tibias in all subjects that were loaded for 2 weeks. Standard deviations in parentheses.

2 Week Loaded/2 Week Control Quadrant

\begin{tabular}{|c|c|c|c|c|}
\hline Quadrant & $\begin{array}{l}\text { Apoptotic } \\
\text { Osteocyte } \\
\text { Density }\end{array}$ & $\begin{array}{l}\text { \% Apoptotic } \\
\text { Osteocytes }\end{array}$ & $\begin{array}{l}\text { Viable } \\
\text { Osteocyte } \\
\text { Density }\end{array}$ & $\begin{array}{l}\text { \% Viable } \\
\text { Osteocytes }\end{array}$ \\
\hline $2 \mathrm{WL} \_C r a n i a l\left(\mathrm{Cr}_{2 \mathrm{WL}}\right)$ & $150.1(38.4)$ & $42.03(6.40)$ & $258.3(63.3)$ & $53.54(7.96)$ \\
\hline 2WL_Lateral $\left(\mathbf{L}_{2 \mathrm{WL}}\right)$ & $88.8(40.7)$ & $26.62(5.80)$ & $139.82(12.08)$ & $33.41(1.79)$ \\
\hline 2WL_Caudal $\left(\mathrm{Cd}_{2 \mathrm{WL}}\right)$ & $112.1(46.8)$ & $33.89(7.47)$ & $211.4(52.1)$ & $45.61(6.39)$ \\
\hline 2WL_Medial( $\left(M_{2 W L}\right)$ & 146.1(34.6) & 43.42(1.92) & $244.7(109.0)$ & $51.73(11.52)$ \\
\hline 2WR_Cranial $\left(\mathrm{Cr}_{2 \mathrm{WR}}\right)$ & $128.08(34.1)$ & $36.20(2.08)$ & $305.68(62.2)$ & $59.06(6.36)$ \\
\hline 2WR_Lateral(L $\left.\mathrm{L}_{2 \mathrm{WR}}\right)$ & $107.65(31.1)$ & $28.30(3.83)$ & $242.22(34.7)$ & $46.37(1.55)$ \\
\hline 2WR_Caudal $\left(\mathrm{Cd}_{2 \mathrm{WR}}\right)$ & $112.28(33.9)$ & $30.21(2.91)$ & $277.54(52.9)$ & $52.05(5.01)$ \\
\hline 2WR_Medial(M $\left(M_{2 \mathrm{WR}}\right)$ & $167.96(40.6)$ & $38.92(4.06)$ & $344.32(35.6)$ & 61.03(6.19) \\
\hline $\mathrm{Cr}_{2 \mathrm{WL}}-\mathrm{Cr}_{2 \mathrm{wR}}$ & .9953 & .7897 & .9709 & 9631 \\
\hline $\mathbf{L}_{2} \mathrm{WL}_{\mathbf{L}}-\mathbf{L}_{2 \mathrm{WR}}$ & 9982 & .9998 & 4406 & 2993 \\
\hline $\mathrm{Cd}_{2 \mathrm{WL}}-\mathrm{Cd}_{2 \mathrm{WR}}$ & 1.000 & .9748 & .8570 & .9207 \\
\hline $\mathbf{M}_{2 \mathrm{WL}}-\mathbf{M}_{2 \mathrm{WR}}$ & 9955 & .9298 & 4732 & .6691 \\
\hline
\end{tabular}


Table 42. Mean quadrantal data gathered from the proximal region for apoptotic osteocyte density, viable osteocyte density, percentage of apoptotic osteocytes, and percentage of viable osteocytes compared between loaded left tibias and control right tibias in all subjects that were loaded for 2 weeks. Standard deviations in parentheses.

2 Week Loaded/2 Week Control Proximal Quadrant

\begin{tabular}{|c|c|c|c|c|}
\hline Quadrant & $\begin{array}{l}\text { Apoptotic } \\
\text { Osteocyte } \\
\text { Density }\end{array}$ & $\begin{array}{l}\text { \% Apoptotic } \\
\text { Osteocytes }\end{array}$ & $\begin{array}{l}\text { Viable } \\
\text { Osteocyte } \\
\text { Density }\end{array}$ & $\begin{array}{l}\text { \% Viable } \\
\text { Osteocytes }\end{array}$ \\
\hline 2WL_Cranial $\left(\mathrm{Cr}_{2 \mathrm{WL}}\right)$ & $139.26(26.7)$ & $42.49(4.23)$ & $248.18(118.0)$ & $54.36(14.24)$ \\
\hline 2WL_Lateral( $\left.\mathrm{L}_{2 \mathrm{WL}}\right)$ & $73.68(47.6)$ & $22.37(3.88)$ & $113.62(61.2)$ & $30.82(12.34)$ \\
\hline 2WL_Caudal $\left(\mathrm{Cd}_{2 \mathrm{WL}}\right)$ & $119.79(25.9)$ & $35.97(4.43)$ & $185.28(30.6)$ & $46.44(8.26)$ \\
\hline 2WL_Medial( $\left(M_{2 W L}\right)$ & $178.15(40.5)$ & $51.88(6.50)$ & $193.30(62.0)$ & $54.82(17.6)$ \\
\hline 2WR_Cranial $\left(\mathrm{Cr}_{2 \mathrm{WR}}\right)$ & $119.69(7.01)$ & $37.96(2.02)$ & $314.25(20.9)$ & $60.82(0.92)$ \\
\hline 2WR_Lateral( $\left.\mathrm{L}_{2 \mathrm{WR}}\right)$ & $64.08(23.4)$ & $20.74(2.88)$ & $194.92(47.2)$ & $41.14(7.09)$ \\
\hline 2WR_Caudal $\left(\mathrm{Cd}_{2 \mathrm{WR}}\right)$ & $87.54(4.45)$ & $29.74(1.01)$ & $252.90(52.5)$ & $49.47(5.94)$ \\
\hline 2WR_Medial( $\left(M_{2 W R}\right)$ & $168.77(35.7)$ & $39.63(4.38)$ & $312.88(92.7)$ & $58.51(13.4)$ \\
\hline $\mathrm{Cr}_{2 \mathrm{WL}}-\mathrm{Cr}_{2 \mathrm{wR}}$ & .9906 & .8489 & .9211 & .9955 \\
\hline $\mathbf{L}_{2 W L}-\mathbf{L}_{2 W R}$ & .9999 & .9995 & .8097 & .9400 \\
\hline $\mathrm{Cd}_{2 W L}-\mathrm{Cd}_{2 \mathrm{WR}}$ & .8788 & .5610 & .9121 & 1.000 \\
\hline$M_{2 W L}-M_{2 W R}$ & .9999 & .0285 & .4167 & .9999 \\
\hline
\end{tabular}


Table 43. Mean quadrantal data gathered from the midshaft region for apoptotic osteocyte density, viable osteocyte density, percentage of apoptotic osteocytes, and percentage of viable osteocytes compared between loaded left tibias and control right tibias in all subjects that were loaded for 2 weeks. Standard deviations in parentheses.

2 Week Loaded/2 Week Control Midshaft Quadrant

\begin{tabular}{|c|c|c|c|c|}
\hline Quadrant & $\begin{array}{l}\text { Apoptotic } \\
\text { Osteocyte } \\
\text { Density }\end{array}$ & $\begin{array}{l}\text { \% Apoptotic } \\
\text { Osteocytes }\end{array}$ & $\begin{array}{l}\text { Viable } \\
\text { Osteocyte } \\
\text { Density }\end{array}$ & $\begin{array}{l}\text { \% Viable } \\
\text { Osteocytes }\end{array}$ \\
\hline 2WL_Cranial $\left(\mathrm{Cr}_{2 \mathrm{WL}}\right)$ & $169.52(67.1)$ & $40.59(4.18)$ & $236.57(68.0)$ & $49.54(8.58)$ \\
\hline 2WL_Lateral( $\left.\mathbf{L}_{2 W L}\right)$ & $71.92(34.1)$ & $25.75(6.21)$ & $109.51(53.8)$ & $28.75(8.46)$ \\
\hline 2WL_Caudal $\left(\mathrm{Cd}_{2 \mathrm{WL}}\right)$ & $104.01(55.5)$ & $33.25(8.37)$ & $192.70(114.6)$ & $40.36(10.80)$ \\
\hline 2WL_Medial( $\left(M_{2 W L}\right)$ & $157.92(62.4)$ & $41.00(2.56)$ & $256.64(168.4)$ & $46.93(14.93)$ \\
\hline 2WR_Cranial $\left(\mathrm{Cr}_{2 \mathrm{WR}}\right)$ & $133.45(46.1)$ & $36.55(6.04)$ & $291.28(113.2)$ & $58.95(7.50)$ \\
\hline 2WR_Lateral( $\left.\mathbf{L}_{2 W R}\right)$ & $115.74(41.0)$ & $28.43(7.06)$ & $238.32(27.8)$ & $43.87(1.80)$ \\
\hline 2WR_Caudal $\left(\mathrm{Cd}_{2 \mathrm{WR}}\right)$ & $115.72(46.9)$ & $29.34(5.27)$ & $270.63(79.6)$ & $49.77(3.04)$ \\
\hline 2WR_Medial( $\left(M_{2 W R}\right)$ & $172.28(58.3)$ & $37.96(6.36)$ & $421.17(65.7)$ & $63.17(4.14)$ \\
\hline $\mathrm{Cr}_{2 \mathrm{WL}}-\mathrm{Cr}_{2 \mathrm{wR}}$ & .9875 & .9888 & .9958 & .9603 \\
\hline $\mathbf{L}_{2 W L}-\mathbf{L}_{2 W R}$ & .9638 & .9991 & .7168 & .4041 \\
\hline $\mathrm{Cd}_{2 \mathrm{WL}}-\mathrm{Cd}_{2 \mathrm{WR}}$ & 1.000 & .9906 & .9682 & .8598 \\
\hline$M_{2 W L}-M_{2 W R}$ & 1.000 & .9980 & .4507 & .3244 \\
\hline
\end{tabular}


Table 44. Mean quadrantal data gathered from the distal region for apoptotic osteocyte density, viable osteocyte density, percentage of apoptotic osteocytes, and percentage of viable osteocytes compared between loaded left tibias and control right tibias in all subjects that were loaded for 2 weeks. Standard deviations in parentheses.

2 Week Loaded/2 Week Control Distal Quadrant

\begin{tabular}{|c|c|c|c|c|}
\hline Quadrant & $\begin{array}{l}\text { Apoptotic } \\
\text { Osteocyte } \\
\text { Density }\end{array}$ & $\begin{array}{l}\text { \% Apoptotic } \\
\text { Osteocytes }\end{array}$ & $\begin{array}{l}\text { Viable } \\
\text { Osteocyte } \\
\text { Density }\end{array}$ & $\begin{array}{l}\text { \% Viable } \\
\text { Osteocytes }\end{array}$ \\
\hline 2WL_Cranial $\left(\mathrm{Cr}_{2 \mathrm{WL}}\right)$ & $141.53(24.6)$ & $43.01(11.61)$ & $290.43(47.3)$ & $56.72(4.66)$ \\
\hline 2WL_Lateral( $\left.\mathrm{L}_{2 \mathrm{WL}}\right)$ & $120.86(64.2)$ & $31.75(12.99)$ & $196.34(23.2)$ & $40.67(1.78)$ \\
\hline 2WL_Caudal $\left(\mathrm{Cd}_{2 \mathrm{WL}}\right)$ & $112.62(62.2)$ & $32.43(10.07)$ & $256.25(35.3)$ & $50.03(3.32)$ \\
\hline 2WL_Medial(M $\left(M_{2 L L}\right)$ & $102.34(18.4)$ & $37.39(6.00)$ & $284.29(112.9)$ & $53.44(8.14)$ \\
\hline 2WR_Cranial $\left(\mathrm{Cr}_{2 \mathrm{WR}}\right)$ & $131.09(54.8)$ & $34.08(3.96)$ & $311.52(82.5)$ & $57.40(11.25)$ \\
\hline 2WR_Lateral( $\left.L_{2 W R}\right)$ & $143.13(36.0)$ & $35.72(5.44)$ & $293.43(67.2)$ & $54.09(9.46)$ \\
\hline 2WR_Caudal $\left(\mathrm{Cd}_{2 W R}\right)$ & $133.58(57.0)$ & $31.55(5.84)$ & $309.09(48.5)$ & $56.91(6.88)$ \\
\hline 2WR_Medial(M $\left(M_{2 W R}\right)$ & $162.81(42.1)$ & $39.17(3.84)$ & $298.90(38.3)$ & $61.43(6.88)$ \\
\hline $\mathrm{Cr}_{2 \mathrm{WL}}-\mathrm{Cr}_{2 \mathrm{wR}}$ & 1.000 & .8716 & .9999 & 1.000 \\
\hline $\mathbf{L}_{2 W L}-\mathbf{L}_{2 W R}$ & .9988 & .9984 & .5799 & .3569 \\
\hline $\mathrm{Cd}_{2 \mathrm{WL}}-\mathrm{Cd}_{2 \mathrm{WR}}$ & .9992 & 1.000 & .9635 & .9285 \\
\hline$M_{2 W L}-M_{2 W R}$ & .7710 & 1.000 & 1.000 & .8615 \\
\hline
\end{tabular}

Table 45. Regional differences of apoptotic osteocyte density, viable osteocyte density, percentage of apoptotic osteocytes, and percentage of viable osteocytes between loaded left tibias and control right tibias in all subjects that were loaded for 2 weeks. Standard deviations in parentheses.

2 Week Loaded/2 Week Control Region

\begin{tabular}{|c|c|c|c|c|}
\hline Quadrant & $\begin{array}{l}\text { Apoptotic } \\
\text { Osteocyte } \\
\text { Density }\end{array}$ & $\begin{array}{l}\text { \% Apoptoti } \\
\text { c } \\
\text { Osteocytes }\end{array}$ & $\begin{array}{l}\text { Viable } \\
\text { Osteocyte } \\
\text { Density } \\
\end{array}$ & $\begin{array}{l}\text { \% Viable } \\
\text { Osteocytes }\end{array}$ \\
\hline 2WL_Distal( $\left.\mathrm{D}_{2 \mathrm{WL}}\right)$ & $123.53(42.6)$ & $37.06(8.04)$ & $262.57(50.0)$ & $51.66(3.72)$ \\
\hline 2WL_Midshaft(MS $\left.{ }_{2 W L}\right)$ & $129.12(48.0)$ & $36.67(2.95)$ & $206.56(90.3)$ & $44.08(9.63)$ \\
\hline 2WL_Proximal $\left(\mathbf{P}_{2 \mathrm{WL}}\right)$ & $123.56(29.8)$ & $37.90(4.46)$ & $198.71(65.2)$ & $48.65(9.80)$ \\
\hline 2WR_Distal( $\left(D_{2 W R}\right)$ & $138.65(49.4)$ & $34.19(4.82)$ & $305.10(61.4)$ & $57.41(8.62)$ \\
\hline 2WR_Midshaft(MS $\left(\mathrm{SWR}_{2}\right)$ & $127.87(47.9)$ & $33.16(5.05)$ & $290.88(76.4)$ & $54.39(2.97)$ \\
\hline 2WR_Proximal( $\left(\mathbf{P}_{2 \mathrm{WR}}\right)$ & $103.63(11.37)$ & $32.90(1.36)$ & $271.71(21.5)$ & $53.92(1.24)$ \\
\hline$D_{2 \mathrm{WL}}-D_{2 \mathrm{wR}}$ & .9969 & .9761 & .9607 & .9038 \\
\hline $\mathbf{M S}_{2 \mathrm{WL}}-\mathbf{M S}_{2 \mathrm{WR}}$ & 1.000 & .9450 & .6130 & .4870 \\
\hline $\mathbf{P}_{2 \mathrm{WL}}-\mathbf{P}_{\mathbf{2 W R}}$ & .9889 & .8047 & .7344 & .9301 \\
\hline
\end{tabular}


Table 46. Mean regional data gathered from the cranial quadrant for apoptotic osteocyte density, viable osteocyte density, percentage of apoptotic osteocytes, and percentage of viable osteocytes compared between loaded left tibias and control right tibias in all subjects that were loaded for 2 weeks. Standard deviations in parentheses.

2 Week Loaded/2 Week Control Cranial Region

\begin{tabular}{|c|c|c|c|c|}
\hline Quadrant & $\begin{array}{l}\text { Apoptotic } \\
\text { Osteocyte } \\
\text { Density }\end{array}$ & $\begin{array}{l}\text { \% Apoptotic } \\
\text { Osteocytes }\end{array}$ & $\begin{array}{l}\text { Viable } \\
\text { Osteocyte } \\
\text { Density }\end{array}$ & $\begin{array}{l}\text { \% Viable } \\
\text { Osteocytes }\end{array}$ \\
\hline 2WL_Distal( $\left(D_{2 \mathrm{WL}}\right)$ & $141.53(24.6)$ & 43.01(11.61) & $290.43(47.3)$ & $56.72(4.66)$ \\
\hline 2WL_Midshaft $\left(M_{2 W L}\right)$ & $169.52(67.1)$ & $40.59(4.18)$ & $236.57(68.0)$ & 49.54(8.58) \\
\hline $2 \mathrm{WL} \_$Proximal $\left(\mathbf{P}_{2 \mathrm{WL}}\right)$ & $139.26(26.7)$ & $42.49(4.23)$ & $248.18(118)$. & $54.36(14.24)$ \\
\hline 2WR_Distal( $\left(D_{2 W R}\right)$ & $131.09(54.8)$ & $34.08(3.96)$ & $311.52(82.5)$ & $57.40(11.25)$ \\
\hline 2WR_Midshaft $\left(\mathrm{MS}_{2 \mathrm{WR}}\right)$ & $133.45(46.1)$ & $36.55(6.04)$ & $291.28(113.2)$ & $58.95(7.50)$ \\
\hline 2WR_Proximal $\left(\mathbf{P}_{2 \mathrm{WR}}\right)$ & $119.69(7.01)$ & $37.96(2.02)$ & $314.25(20.9)$ & $60.82(0.92)$ \\
\hline $\mathbf{D}_{2 \mathrm{WL}}-\mathrm{D}_{2 \mathrm{wR}}$ & 9996 & .5112 & .9995 & 1.000 \\
\hline $\mathbf{M S}_{2 \mathrm{WL}}-\mathbf{M S} \mathbf{S}_{\mathbf{2 W R}}$ & .8983 & .9612 & .9597 & .7873 \\
\hline $\mathbf{P}_{2 \mathrm{WI}}$ & .9920 & .9385 & 9157 & 9438 \\
\hline
\end{tabular}

Table 47. Mean regional data gathered from the lateral quadrant for apoptotic osteocyte density, viable osteocyte density, percentage of apoptotic osteocytes, and percentage of viable osteocytes compared between loaded left tibias and control right tibias in all subjects that were loaded for 2 weeks. Standard deviations in parentheses.

2 Week Loaded/2 Week Control Lateral Region

\begin{tabular}{|c|c|c|c|c|}
\hline Quadrant & $\begin{array}{l}\text { Apoptotic } \\
\text { Osteocyte } \\
\text { Density }\end{array}$ & $\begin{array}{l}\text { \% Apoptotic } \\
\text { Osteocytes }\end{array}$ & $\begin{array}{l}\text { Viable } \\
\text { Osteocyte } \\
\text { Density }\end{array}$ & $\begin{array}{l}\text { \% Viable } \\
\text { Osteocytes }\end{array}$ \\
\hline 2WL_Distal( $\left(D_{2 W L}\right)$ & $120.86(64.2)$ & $31.75(12.99)$ & $196.34(23.2)$ & $40.67(1.78)$ \\
\hline 2WL_Midshaft $\left(\mathrm{MS}_{2 \mathrm{WL}}\right)$ & $71.92(34.1)$ & $25.75(6.21)$ & 109.51(53.8) & $28.75(8.46)$ \\
\hline 2WL_Proximal $\left(\mathbf{P}_{2 \mathrm{WL}}\right)$ & $73.68(47.6)$ & $22.37(3.88)$ & $113.62(61.2)$ & $30.82(12.34)$ \\
\hline 2WR_Distal $\left(\mathbf{D}_{2 \mathrm{WR}}\right)$ & $143.13(36.0)$ & $35.72(5.44)$ & $293.43(67.2)$ & $54.09(9.46)$ \\
\hline 2WR_Midshaft $\left(M_{2} S_{2 R}\right)$ & $115.74(41.0)$ & $28.43(7.06)$ & $238.32(27.8)$ & $43.87(1.80)$ \\
\hline 2WR_Proximal $\left(\mathbf{P}_{2 \mathrm{WR}}\right)$ & $64.08(23.4)$ & $20.74(2.88)$ & 194.92(47.2) & 41.14(7.09) \\
\hline $\mathbf{D}_{2 \mathrm{WL}}-\mathrm{D}_{2 \mathrm{wR}}$ & .9859 & 9813 & .2292 & .3523 \\
\hline $\mathbf{M S}_{\mathbf{2 W L}}-\mathbf{M S}_{2}$ & .8050 & .9969 & .0665 & 2447 \\
\hline $\mathbf{P}_{2 \mathrm{WI}}$ & 9997 & 9997 & .3898 & 6082 \\
\hline
\end{tabular}


Table 48. Mean regional data gathered from the caudal quadrant for apoptotic osteocyte density, viable osteocyte density, percentage of apoptotic osteocytes, and percentage of viable osteocytes compared between loaded left tibias and control right tibias in all subjects that were loaded for 2 weeks. Standard deviations in parentheses.

2 Week Loaded/2 Week Control Caudal Region

\begin{tabular}{|c|c|c|c|c|}
\hline Quadrant & $\begin{array}{l}\text { Apoptotic } \\
\text { Osteocyte } \\
\text { Density }\end{array}$ & $\begin{array}{l}\text { \%Apoptotic } \\
\text { Osteocytes }\end{array}$ & $\begin{array}{l}\text { Viable } \\
\text { Osteocyte } \\
\text { Density }\end{array}$ & $\begin{array}{l}\text { \% Viable } \\
\text { Osteocytes }\end{array}$ \\
\hline 2WL_Distal( $\left(D_{2 W L}\right)$ & $112.62(62.2)$ & $32.43(10.07)$ & $256.25(35.3)$ & $50.03(3.32)$ \\
\hline 2WL_Midshaft(MS $2 W L)$ & $104.01(55.5)$ & $33.25(8.37)$ & $192.70(114.6)$ & $40.36(10.8)$ \\
\hline 2WL_Proximal $\left(\mathbf{P}_{2 \mathrm{WL}}\right)$ & $119.79(25.9)$ & $35.97(4.43)$ & $185.28(30.6)$ & $46.44(8.26)$ \\
\hline 2WR_Distal( $\left.\mathrm{D}_{2 \mathrm{WR}}\right)$ & $133.58(57.0)$ & $31.55(5.84)$ & $309.09(48.5)$ & $56.91(6.88)$ \\
\hline 2WR_Midshaft(MS $\left(\mathrm{MWR}_{2 \mathrm{R}}\right)$ & $115.72(46.9)$ & $29.34(5.27)$ & $270.63(79.6)$ & $49.77(3.04)$ \\
\hline 2WR_Proximal( $\left(\mathbf{P}_{2 W R}\right)$ & $87.54(4.45)$ & $29.74(1.01)$ & $252.90(52.5)$ & $49.47(5.94)$ \\
\hline$D_{2 W L}-D_{2 w R}$ & .9926 & 1.000 & .9192 & .8206 \\
\hline $\mathbf{M S}_{2 W L}-\mathbf{M S}_{2 W R}$ & .9995 & .9731 & .7104 & .5759 \\
\hline $\mathbf{P}_{2 W L}-P_{2 W R}$ & .9526 & .8407 & .8096 & .9934 \\
\hline
\end{tabular}

Table 49. Mean regional data gathered from the medial quadrant for apoptotic osteocyte density, viable osteocyte density, percentage of apoptotic osteocytes, and percentage of viable osteocytes compared between loaded left tibias and control right tibias in all subjects that were loaded for 2 weeks. Standard deviations in parentheses.

2 Week Loaded/2 Week Control Medial Region

\begin{tabular}{|c|c|c|c|c|}
\hline Quadrant & $\begin{array}{l}\text { Apoptotic } \\
\text { Osteocyte } \\
\text { Density }\end{array}$ & $\begin{array}{l}\text { \% Apoptotic } \\
\text { Osteocytes }\end{array}$ & $\begin{array}{l}\text { Viable } \\
\text { Osteocyte } \\
\text { Density }\end{array}$ & $\begin{array}{l}\text { \% Viable } \\
\text { Osteocytes }\end{array}$ \\
\hline 2WL_Distal( $\left(D_{2 W L}\right)$ & $102.34(18.4)$ & $37.39(6.00)$ & $284.29(112.9)$ & $53.44(8.14)$ \\
\hline 2WL_Midshaft(MS $\left.{ }_{2 W L}\right)$ & $157.92(62.4)$ & $41.00(2.56)$ & $256.64(168.4)$ & $46.93(14.93)$ \\
\hline 2WL_Proximal( $\left(\mathbf{P}_{2 \mathrm{WL}}\right)$ & $178.15(40.5)$ & $51.88(6.50)$ & $193.30(62.0)$ & $54.82(17.6)$ \\
\hline 2WR_Distal( $\left(D_{2 W R}\right)$ & $162.81(42.1)$ & $39.17(3.84)$ & $298.90(38.3)$ & $61.43(6.88)$ \\
\hline 2WR_Midshaft(MS MWR $\left._{2}\right)$ & $172.28(58.3)$ & $37.96(6.36)$ & $421.17(65.7)$ & $63.17(4.14)$ \\
\hline 2WR_Proximal $\left(\mathbf{P}_{2 \mathrm{WR}}\right)$ & $168.77(35.7)$ & $39.63(4.38)$ & $312.88(92.7)$ & $58.51(13.4)$ \\
\hline $\mathbf{D}_{2 \mathrm{WL}}-\mathbf{D}_{2 \mathrm{wR}}$ & .5935 & .9978 & 1.000 & .9570 \\
\hline $\mathbf{M S}_{2 \mathrm{WL}}-\mathbf{M S}_{2 \mathrm{WR}}$ & .9985 & .9753 & .3827 & .5691 \\
\hline $\mathbf{P}_{2 W L}-\mathbf{P}_{2 W R}$ & .9998 & .1045 & .6862 & .9987 \\
\hline
\end{tabular}




\subsection{Comparison Between 5 Week Loaded Left Tibias and Unloaded Right Tibia Controls}

Below are the statistics for all of the 5 week loaded left tibias compared against all of the 5 week unloaded right tibias used as controls, including a summary, analysis by quadrant, analysis by region and combinations of the latter two. For each statistical analysis, apoptotic osteocyte density, percentage of apoptotic osteocytes, viable osteocyte density and percentage of viable osteocytes were the variables considered. Mean values, standard deviations and relevant $\mathrm{p}$-values are shown, with p-values less than 0.05 indicating statistically significant data.

When comparing the 5 week loaded data against the unloaded data, the percentage of apoptotic osteocytes, in each region, quadrant and combination of the two, were higher in 5 week loaded bones when compared against the 5 week unloaded bones from the same region and quadrant. No statistically significant differences in viable osteocyte density or percentage of viable osteocytes were seen between the 5 week loaded samples and the 5 week unloaded control samples. The density of apoptotic osteocytes in each quadrant, averaged across all regions, were significantly higher in the 5 week loaded bones than their respective counterparts in the 5 week unloaded bones. The medial quadrants in proximal and midshaft samples, the caudal quadrants in midshaft samples and the lateral quadrants in distal samples showed significantly higher densities of apoptotic osteocytes in 5 week loaded bones compared to 5 week unload bones. The density of apoptotic osteocytes in the distal and midshaft regions, averaged across all quadrants, were higher in 5 week loaded bones when compared against the 5 week unloaded bones from the same region. The distal regions of cranial, lateral and caudal quadrants showed statistically significantly higher apoptotic osteocyte densities in 5 week 
loaded samples compared to 5 week unloaded samples. The 5 week loaded midshaft regions in the cranial, caudal and medial quadrants of bone showed statistically significantly higher apoptotic osteocyte densities compared to 5 week unloaded samples.

Table 50. Quadrantal differences of apoptotic osteocyte density, viable osteocyte density, percentage of apoptotic osteocytes, and percentage of viable osteocytes between loaded left tibias and control right tibias in all subjects that were loaded for 5 weeks. Standard deviations in parentheses.

5 Week Loaded/5 Week Control Quadrant

\begin{tabular}{|c|c|c|c|c|}
\hline Quadrant & $\begin{array}{l}\text { Apoptotic } \\
\text { Osteocyte } \\
\text { Density }\end{array}$ & $\begin{array}{l}\text { \% Apoptoti } \\
\text { c } \\
\text { Osteocytes }\end{array}$ & $\begin{array}{l}\text { Viable } \\
\text { Osteocyte } \\
\text { Density }\end{array}$ & $\begin{array}{l}\text { \% Viable } \\
\text { Osteocytes }\end{array}$ \\
\hline 5WL_Cranial $\left(\mathrm{Cr}_{5 \mathrm{WL}}\right)$ & $236.27(37.8)$ & $59.90(3.83)$ & $348.55(35.4)$ & $67.22(1.50)$ \\
\hline $5 \mathrm{WL} \_$Lateral $\left(\mathrm{L}_{5 \mathrm{WL}}\right)$ & $232.46(56.8)$ & $58.00(3.47)$ & $272.02(63.1)$ & $54.68(5.81)$ \\
\hline 5WL_Caudal $\left(\mathbf{C d}_{5 \mathrm{WL}}\right)$ & $239.50(38.3)$ & $58.40(3.39)$ & $330.77(23.34)$ & $63.75(2.72)$ \\
\hline 5WL_Medial $\left(M_{5 W L}\right)$ & $256.88(59.1)$ & $60.31(2.46)$ & $333.68(42.3)$ & $67.36(1.34)$ \\
\hline 5WR_Cranial(Cr ( $\left._{\text {WWR }}\right)$ & $151.11(17.04)$ & $41.24(4.74)$ & $358.88(83.2)$ & $66.72(3.11)$ \\
\hline 5WR_Lateral( $\left.\mathbf{L}_{5 \mathrm{WR}}\right)$ & $154.51(36.2)$ & $36.82(6.58)$ & $319.53(27.5)$ & $57.41(10.05)$ \\
\hline 5WR_Caudal(Cd CdWR $)$ & $141.49(28.4)$ & $37.35(6.70)$ & $368.86(59.6)$ & $64.33(7.15)$ \\
\hline 5WR_Medial(M MWR $)$ & $154.90(45.1)$ & $38.35(6.07)$ & $336.28(58.0)$ & $64.63(6.75)$ \\
\hline $\mathrm{Cr}_{5 \mathrm{WL}}-\mathrm{Cr}_{5 \mathrm{WR}}$ & 0.0221 & 0.0000 & 1.0000 & 1.0000 \\
\hline $\mathrm{L}_{5 \mathrm{WL}}-\mathrm{L}_{5 \mathrm{WR}}$ & 0.0471 & 0.0000 & 0.7685 & 0.9896 \\
\hline$C d_{5 W L}-C d_{5 W R}$ & 0.0051 & 0.0000 & 0.9102 & 1.0000 \\
\hline$M_{5 W L}-M_{5 W R}$ & 0.0032 & 0.0000 & 1.0000 & 0.9895 \\
\hline
\end{tabular}


Table 51. Mean quadrantal data gathered from the proximal region for apoptotic osteocyte density, viable osteocyte density, percentage of apoptotic osteocytes, and percentage of viable osteocytes compared between loaded left tibias and control right tibias in all subjects that were loaded for 5 weeks. Standard deviations in parentheses.

5 Week Loaded/5 Week Control Proximal Quadrant

\begin{tabular}{|c|c|c|c|c|}
\hline Quadrant & $\begin{array}{l}\text { Apoptotic } \\
\text { Osteocyte } \\
\text { Density }\end{array}$ & $\begin{array}{l}\text { \%Apoptotic } \\
\text { Osteocytes }\end{array}$ & $\begin{array}{l}\text { Viable } \\
\text { Osteocyte } \\
\text { Density }\end{array}$ & $\begin{array}{l}\text { \% Viable } \\
\text { Osteocytes }\end{array}$ \\
\hline 5WL_Cranial $\left(\mathrm{Cr}_{5 \mathrm{WL}}\right)$ & $222.01(28.9)$ & $58.68(4.20)$ & $331.65(49.7)$ & $66.40(2.15)$ \\
\hline 5WL_Lateral( $\left.\mathbf{L}_{5 W L}\right)$ & $173.98(25.0)$ & $52.43(4.98)$ & $198.41(64.5)$ & $47.12(11.49)$ \\
\hline 5WL_Caudal $\left(\mathrm{Cd}_{5 W \mathrm{~L}}\right)$ & $210.18(18.24)$ & $56.97(4.00)$ & $309.71(40.4)$ & $64.43(5.67)$ \\
\hline 5WL_Medial $\left(M_{5 W L}\right)$ & $277.59(80.9)$ & $63.09(4.59)$ & $307.77(63.3)$ & $66.61(4.91)$ \\
\hline 5WR_Cranial $\left(\mathrm{Cr}_{5 \mathrm{WR}}\right)$ & $150.31(18.42)$ & $42.06(4.85)$ & $312.83(88.0)$ & $64.48(3.61)$ \\
\hline 5WR_Lateral(L5WR) & $135.35(48.8)$ & $35.54(8.14)$ & $265.19(37.4)$ & $54.35(11.81)$ \\
\hline 5WR_Caudal $\left(\mathrm{Cd}_{5 \mathrm{WR}}\right)$ & $132.08(25.1)$ & $38.56(6.21)$ & $350.45(97.9)$ & $66.50(9.72)$ \\
\hline 5WR_Medial(M $\left.M_{5 W R}\right)$ & $165.20(61.2)$ & $38.51(9.86)$ & $268.59(73.3)$ & $59.62(9.94)$ \\
\hline $\mathrm{Cr}_{5 W L}-\mathrm{Cr}_{5 W R}$ & .1170 & .0009 & .9997 & .9999 \\
\hline $\mathbf{L}_{5 W L}-\mathbf{L}_{5 W R}$ & .7908 & .0007 & .6777 & .7899 \\
\hline $\mathrm{Cd}_{5 \mathrm{WL}}-\mathrm{Cd}_{5 \mathrm{WR}}$ & .0662 & .0002 & .9640 & .9998 \\
\hline$M_{5 W L}-M_{5 W R}$ & .0017 & 0.000 & .9708 & .8157 \\
\hline
\end{tabular}


Table 52. Mean quadrantal data gathered from the midshaft region for apoptotic osteocyte density, viable osteocyte density, percentage of apoptotic osteocytes, and percentage of viable osteocytes compared between loaded left tibias and control right tibias in all subjects that were loaded for 5 weeks. Standard deviations in parentheses.

5 Week Loaded/5 Week Control Midshaft Quadrant

\begin{tabular}{|c|c|c|c|c|}
\hline Quadrant & $\begin{array}{l}\text { Apoptotic } \\
\text { Osteocyte } \\
\text { Density }\end{array}$ & $\begin{array}{l}\text { \% Apoptoti } \\
\text { c } \\
\text { Osteocytes }\end{array}$ & $\begin{array}{l}\text { Viable } \\
\text { Osteocyte } \\
\text { Density }\end{array}$ & $\begin{array}{l}\text { \% Viable } \\
\text { Osteocytes }\end{array}$ \\
\hline 5WL_Cranial $\left(\mathrm{Cr}_{5 W L}\right)$ & $255.87(71.0)$ & $62.48(4.44)$ & $392.50(54.7)$ & $67.41(3.49)$ \\
\hline 5WL_Lateral( $\left.\mathbf{L}_{5 W L}\right)$ & $277.99(81.8)$ & $64.35(5.50)$ & $348.03(102.4)$ & $58.25(7.78)$ \\
\hline 5WL_Caudal $\left(\mathrm{Cd}_{5 \mathrm{WL}}\right)$ & $287.88(68.9)$ & $62.29(3.30)$ & $382.38(54.9)$ & $63.60(5.68)$ \\
\hline 5WL_Medial(M $\left.M_{5 W L}\right)$ & $287.24(114.6)$ & $60.99(5.37)$ & $383.97(112.5)$ & $68.84(5.07)$ \\
\hline 5WR_Cranial $\left(\mathrm{Cr}_{5 \mathrm{WR}}\right)$ & $164.57(27.5)$ & $40.87(7.98)$ & $408.90(123.1)$ & $67.21(4.17)$ \\
\hline 5WR_Lateral(L) LWR $\left._{5}\right)$ & $191.78(69.1)$ & $39.62(8.77)$ & $365.40(99.9)$ & $58.69(11.38)$ \\
\hline 5WR_Caudal $\left(\mathrm{Cd}_{5 \mathrm{WR}}\right)$ & $155.41(25.9)$ & $38.86(7.33)$ & $396.47(83.9)$ & $64.60(6.96)$ \\
\hline 5WR_Medial( $\left(M_{5 W R}\right)$ & $155.11(10.82)$ & $37.32(6.66)$ & $397.45(95.8)$ & $65.21(5.78)$ \\
\hline $\mathrm{Cr}_{5 W L}-\mathrm{Cr}_{5 W R}$ & .2884 & 0.0000 & 1.0000 & 1.0000 \\
\hline $\mathbf{L}_{5 W L}-\mathbf{L}_{5 W R}$ & .3575 & 0.0000 & 1.0000 & 1.0000 \\
\hline $\mathrm{Cd}_{5 \mathrm{WL}}-\mathrm{Cd}_{5 \mathrm{WR}}$ & .0283 & 0.0000 & 1.0000 & 1.0000 \\
\hline$M_{5 W L}-M_{5 W R}$ & .0290 & 0.0000 & 1.0000 & .9804 \\
\hline
\end{tabular}


Table 53. Mean quadrantal data gathered from the distal region for apoptotic osteocyte density, viable osteocyte density, percentage of apoptotic osteocytes, and percentage of viable osteocytes compared between loaded left tibias and control right tibias in all subjects that were loaded for 5 weeks. Standard deviations in parentheses.

5 Week Loaded/5 Week Control Distal Quadrant

\begin{tabular}{|c|c|c|c|c|}
\hline Quadrant & $\begin{array}{l}\text { Apoptotic } \\
\text { Osteocyte } \\
\text { Density }\end{array}$ & $\begin{array}{l}\text { \% Apoptotic } \\
\text { Osteocytes }\end{array}$ & $\begin{array}{l}\text { Viable } \\
\text { Osteocyte } \\
\text { Density } \\
\end{array}$ & $\begin{array}{l}\text { \% Viable } \\
\text { Osteocytes }\end{array}$ \\
\hline 5WL_Cranial $\left(\mathrm{Cr}_{5 \mathrm{WL}}\right)$ & $230.93(44.9)$ & $58.54(6.44)$ & $321.50(31.1)$ & $67.85(1.45)$ \\
\hline 5WL_Lateral $\left(\mathrm{L}_{5 \mathrm{WL}}\right)$ & $245.40(77.7)$ & $57.22(6.52)$ & $269.62(68.5)$ & $58.67(2.89)$ \\
\hline 5WL_Caudal $\left(\mathrm{Cd}_{5 \mathrm{WL}}\right)$ & $220.42(48.0)$ & $55.96(6.80)$ & $300.20(14.07)$ & $63.22(4.82)$ \\
\hline 5WL_Medial $\left(M_{5 \mathrm{WL}}\right)$ & $205.80(43.4)$ & 56.84(7.32) & $309.30(47.7)$ & $66.62(3.26)$ \\
\hline 5WR_Cranial $\left(\mathrm{Cr}_{5 \mathrm{WR}}\right)$ & $138.46(35.3)$ & $40.80(10.09)$ & $354.90(89.4)$ & $68.47(6.75)$ \\
\hline 5WR_Lateral(L5WR) & $136.41(26.3)$ & $35.30(6.60)$ & $328.00(64.6)$ & $59.19(9.15)$ \\
\hline 5WR_Caudal $\left(\mathrm{Cd}_{5 \mathrm{WR}}\right)$ & $136.99(60.2)$ & $34.62(10.86)$ & $359.66(81.8)$ & $61.89(9.12)$ \\
\hline 5WR_Medial(M MWR $)$ & $144.39(79.4)$ & $39.21(11.13)$ & $342.81(65.2)$ & $69.06(8.48)$ \\
\hline $\mathrm{Cr}_{5 \mathrm{WL}}-\mathrm{Cr}_{5 \mathrm{WR}}$ & 0957 & .0162 & .9816 & 1.0000 \\
\hline $\mathbf{L}_{5 W L}-\mathbf{L}_{5 W R}$ & .0272 & .0014 & .7369 & 1.0000 \\
\hline $\mathrm{Cd}_{5 \mathrm{WL}}-\mathrm{Cd}_{5 \mathrm{WR}}$ & .1745 & .0020 & .7191 & 1.0000 \\
\hline $\mathbf{M}_{5 \mathrm{WL}}-\mathrm{M}_{5 \mathrm{WR}}$ & .5345 & .0171 & 9813 & 9976 \\
\hline
\end{tabular}

Table 54. Regional differences of apoptotic osteocyte density, viable osteocyte density, percentage of apoptotic osteocytes, and percentage of viable osteocytes between loaded left tibias and control right tibias in all subjects that were loaded for 5 weeks. Standard deviations in parentheses.

5 Week Loaded/5 Week Control Region

\begin{tabular}{|c|c|c|c|c|}
\hline Quadrant & $\begin{array}{l}\text { Apoptotic } \\
\text { Osteocyte } \\
\text { Density }\end{array}$ & $\begin{array}{l}\text { \% Apoptotic } \\
\text { Osteocytes }\end{array}$ & $\begin{array}{l}\text { Viable } \\
\text { Osteocyte } \\
\text { Density }\end{array}$ & $\begin{array}{l}\text { \% Viable } \\
\text { Osteocytes }\end{array}$ \\
\hline 5WL_Distal $\left(D_{5 W L}\right)$ & $225.88(41.0)$ & $57.08(5.41)$ & $302.42(19.36)$ & $64.32(2.00)$ \\
\hline 5WL_Midshaft(MS $\left.{ }_{5 W L}\right)$ & $272.75(68.7)$ & $62.78(3.77)$ & $377.70(52.9)$ & $64.97(3.61)$ \\
\hline 5WL_Proximal $\left(P_{5 W L}\right)$ & $214.44(24.9)$ & $57.78(2.74)$ & $298.83(49.0)$ & $62.82(3.85)$ \\
\hline 5WR_Distal( $\left(D_{5 W R}\right)$ & $139.09(45.8)$ & $37.63(8.96)$ & $350.68(71.9)$ & $64.41(7.51)$ \\
\hline 5WR_Midshaft(MS $\left.{ }_{5 W R}\right)$ & $163.32(22.7)$ & $39.67(7.46)$ & $394.35(83.1)$ & $64.55(5.68)$ \\
\hline 5WR_Proximal $\left(\mathbf{P}_{5 \mathrm{WR}}\right)$ & $142.64(22.93)$ & $39.58(5.51)$ & $307.31(69.6)$ & $62.56(6.33)$ \\
\hline$D_{5 W L}-D_{5 W R}$ & .0115 & 0.0001 & .7468 & 1.0000 \\
\hline $\mathrm{MS}_{5 \mathrm{WL}}-\mathrm{MS}_{5 \mathrm{WR}}$ & .0009 & 0.0000 & .9968 & 1.0000 \\
\hline $\mathbf{P}_{5 W L}-P_{5 W R}$ & .0523 & 0.0002 & .9999 & 1.0000 \\
\hline
\end{tabular}


Table 55. Mean regional data gathered from the cranial quadrant for apoptotic osteocyte density, viable osteocyte density, percentage of apoptotic osteocytes, and percentage of viable osteocytes compared between loaded left tibias and control right tibias in all subjects that were loaded for 5 weeks. Standard deviations in parentheses.

5 Week Loaded/5 Week Control Cranial Region

\begin{tabular}{|c|c|c|c|c|}
\hline Quadrant & $\begin{array}{l}\text { Apoptotic } \\
\text { Osteocyte } \\
\text { Density }\end{array}$ & $\begin{array}{l}\text { \%Apoptotic } \\
\text { Osteocytes }\end{array}$ & $\begin{array}{l}\text { Viable } \\
\text { Osteocyte } \\
\text { Density }\end{array}$ & $\begin{array}{l}\text { \% Viable } \\
\text { Osteocytes }\end{array}$ \\
\hline 5WL_Distal( $\left(D_{5 W L}\right)$ & 230.93(44.9) & $58.54(6.44)$ & $321.50(31.1)$ & $67.85(1.45)$ \\
\hline 5WL_Midshaft $\left(M_{5} S_{5 L}\right)$ & $55.87(71.0)$ & $62.48(4.44)$ & $392.50(54.7)$ & 3.49) \\
\hline 5WL_Proximal $\left(P_{5 W_{L}}\right)$ & $222.01(28.9)$ & $58.68(4.20)$ & $331.65(49.7)$ & $66.40(2.15)$ \\
\hline 5WR_Distal( D $\left._{5 \mathrm{WR}}\right)$ & $138.46(35.3)$ & $40.80(10.09)$ & $354.90(89.4)$ & $68.47(6.75)$ \\
\hline 5WR_Midshaft $\left(M^{2} S_{5 R}\right)$ & $164.57(27.5)$ & 40.87(7.98) & $408.90(123.1)$ & $67.21(4.17)$ \\
\hline 5WR_Proximal $\left(\mathbf{P}_{5 \mathrm{WR}}\right)$ & $150.31(18.42)$ & $42.06(4.85)$ & $312.83(88.0)$ & $64.48(3.61)$ \\
\hline $\mathrm{D}_{5 \mathrm{WL}}-\mathrm{D}_{5 \mathrm{WR}}$ & .0065 & .0009 & .9761 & 9998 \\
\hline $\mathbf{M S}_{5 \mathrm{WL}}-\mathbf{M S}_{5 \mathrm{v}}$ & .0073 & .0001 & 9991 & 1.0000 \\
\hline wI & 0542 & .0021 & 9983 & 9581 \\
\hline
\end{tabular}

Table 56. Mean regional data gathered from the lateral quadrant for apoptotic osteocyte density, viable osteocyte density, percentage of apoptotic osteocytes, and percentage of viable osteocytes compared between loaded left tibias and control right tibias in all subjects that were loaded for 5 weeks. Standard deviations in parentheses.

5 Week Loaded/5 Week Control Lateral Region

\begin{tabular}{|c|c|c|c|c|}
\hline Quadrant & $\begin{array}{l}\text { Apoptotic } \\
\text { Osteocyte } \\
\text { Density }\end{array}$ & $\begin{array}{l}\text { \% Apoptotic } \\
\text { Osteocytes }\end{array}$ & $\begin{array}{l}\text { Viable } \\
\text { Osteocyte } \\
\text { Density }\end{array}$ & $\begin{array}{l}\text { \% Viable } \\
\text { Osteocytes }\end{array}$ \\
\hline 5WL_Distal $\left(D_{5 W L}\right)$ & $245.40(77.7)$ & $57.22(6.52)$ & $269.62(68.5)$ & $58.67(2.89)$ \\
\hline 5WL_Midshaft $\left(M_{5 W L}\right)$ & $277.99(81.8)$ & $64.35(5.50)$ & $348.03(102.4)$ & $58.25(7.78)$ \\
\hline 5WL_Proximal $\left(\mathbf{P}_{5 \mathrm{WL}}\right)$ & $173.98(25.0)$ & $52.43(4.98)$ & $198.41(64.5)$ & $47.12(11.49)$ \\
\hline 5WR_Distal $\left(D_{5 W R}\right)$ & $136.41(26.3)$ & $35.30(6.60)$ & $328.00(64.6)$ & $59.19(9.15)$ \\
\hline 5WR_Midshaft(MS $\left(M_{5 \mathrm{WR}}\right)$ & $191.78(69.1)$ & $39.62(8.77)$ & $365.40(99.9)$ & $58.69(11.38)$ \\
\hline 5WR_Proximal $\left(\mathbf{P}_{5 \mathrm{WR}}\right)$ & $135.35(48.8)$ & $35.54(8.14)$ & $265.19(37.4)$ & $54.35(11.81)$ \\
\hline$D_{5 W L}-D_{5 W R}$ & .0367 & .0001 & .7686 & 1.0000 \\
\hline $\mathbf{M S}_{5 W L}-M_{5 W R}$ & .1525 & .0000 & .9986 & 1.0000 \\
\hline $\mathbf{P}_{5 W L}-\mathbf{P}_{5 W R}$ & .8669 & .0024 & .6565 & .7815 \\
\hline
\end{tabular}


Table 57. Mean regional data gathered from the caudal quadrant for apoptotic osteocyte density, viable osteocyte density, percentage of apoptotic osteocytes, and percentage of viable osteocytes compared between loaded left tibias and control right tibias in all subjects that were loaded for 5 weeks. Standard deviations in parentheses.

5 Week Loaded/5 Week Control Caudal Region

\begin{tabular}{|c|c|c|c|c|}
\hline Quadrant & $\begin{array}{l}\text { Apoptotic } \\
\text { Osteocyte } \\
\text { Density }\end{array}$ & $\begin{array}{l}\text { \% Apoptotic } \\
\text { Osteocytes }\end{array}$ & $\begin{array}{l}\text { Viable } \\
\text { Osteocyte } \\
\text { Density }\end{array}$ & $\begin{array}{l}\text { \% Viable } \\
\text { Osteocytes }\end{array}$ \\
\hline 5WL_Distal( $\left(D_{5 W L}\right)$ & $220.42(48.0)$ & $55.96(6.80)$ & $300.20(14.07)$ & $63.22(4.82)$ \\
\hline 5WL_Midshaft(MS $\left(M_{5 W L}\right)$ & $287.88(68.9)$ & $62.29(3.30)$ & $382.38(54.9)$ & $63.60(5.68)$ \\
\hline 5WL_Proximal $\left(P_{5 W L}\right)$ & $210.18(18.24)$ & $56.97(4.00)$ & $309.71(40.4)$ & $64.43(5.67)$ \\
\hline 5WR_Distal(D DWR $)$ & $136.99(60.2)$ & $34.62(10.86)$ & $359.66(81.8)$ & $61.89(9.12)$ \\
\hline 5WR_Midshaft(MS 5WR $)$ & $155.41(25.9)$ & $38.86(7.33)$ & $396.47(83.9)$ & $64.60(6.96)$ \\
\hline 5WR_Proximal( $\left(\mathbf{P}_{5 \mathrm{WR}}\right)$ & $132.08(25.1)$ & $38.56(6.21)$ & $350.45(97.9)$ & $66.50(9.72)$ \\
\hline$D_{5 W L}-D_{5 W R}$ & .0354 & .0001 & .6649 & .9995 \\
\hline $\mathbf{M S}_{5 W L}-M_{5 W R}$ & .0003 & .0000 & .9992 & .9999 \\
\hline $\mathbf{P}_{5 W L}-P_{5 W R}$ & .0565 & .0008 & .9041 & .9959 \\
\hline
\end{tabular}

Table 58. Mean regional data gathered from the medial quadrant for apoptotic osteocyte density, viable osteocyte density, percentage of apoptotic osteocytes, and percentage of viable osteocytes compared between loaded left tibias and control right tibias in all subjects that were loaded for 5 weeks. Standard deviations in parentheses.

5 Week Loaded/5 Week Control Medial Region

\begin{tabular}{|c|c|c|c|c|}
\hline Quadrant & $\begin{array}{l}\text { Apoptotic } \\
\text { Osteocyte } \\
\text { Density }\end{array}$ & $\begin{array}{l}\text { \% Apoptotic } \\
\text { Osteocytes }\end{array}$ & $\begin{array}{l}\text { Viable } \\
\text { Osteocyte } \\
\text { Density }\end{array}$ & $\begin{array}{l}\text { \% Viable } \\
\text { Osteocytes }\end{array}$ \\
\hline 5WL_Distal $\left(D_{5 W L}\right)$ & $205.80(43.4)$ & $56.84(7.32)$ & $309.30(47.7)$ & $66.62(3.26)$ \\
\hline 5WL_Midshaft $\left(M_{5 W L}\right)$ & $287.24(114.6)$ & $60.99(5.37)$ & $383.97(112.5)$ & $68.84(5.07)$ \\
\hline 5WL_Proximal $\left(\mathbf{P}_{5 \mathrm{WL}}\right)$ & $277.59(80.9)$ & $63.09(4.59)$ & $307.77(63.3)$ & $66.61(4.91)$ \\
\hline 5WR_Distal $\left(D_{5 W R}\right)$ & $144.39(79.4)$ & $39.21(11.13)$ & $342.81(65.2)$ & $69.06(8.48)$ \\
\hline 5WR_Midshaft(MS $\left(M_{5 \mathrm{WR}}\right)$ & $155.11(10.82)$ & $37.32(6.66)$ & $397.45(95.8)$ & $65.21(5.78)$ \\
\hline 5WR_Proximal $\left(\mathbf{P}_{5 \mathrm{WR}}\right)$ & $165.20(61.2)$ & $38.51(9.86)$ & $268.59(73.3)$ & $59.62(9.94)$ \\
\hline$D_{5 W L}-D_{5 W R}$ & .6896 & .0062 & .9764 & .9873 \\
\hline $\mathbf{M S}_{5 W L}-M_{5 W R}$ & .0393 & .0002 & .9997 & .9309 \\
\hline $\mathbf{P}_{5 W L}-\mathbf{P}_{5 W R}$ & .1100 & .0001 & .9541 & .4670 \\
\hline
\end{tabular}




\subsection{Comparison Between 2 Week Loaded Left Tibias and 5 Week Loaded Left Tibias}

Below are the statistics for all of the 2 week loaded left tibias compared against all of the 5 week loaded left tibias, including a summary, analysis by quadrant, analysis by region and combinations of the latter two. For each statistical analysis, apoptotic osteocyte density, percentage of apoptotic osteocytes, viable osteocyte density and percentage of viable osteocytes were the variables considered. Mean values, standard deviations and relevant $\mathrm{p}$-values are shown, with p-values less than 0.05 indicating statistically significant data.

The lateral quadrants, isolated to each region individually and averaged across all regions; the caudal quadrants, isolated to the midshaft region and averaged across all regions; and the medial quadrants, averaged across all regions, showed significantly higher densities of apoptotic osteocytes in 5 week loaded bone compared to 2 week loaded samples. The midshaft regions, when isolated to lateral quadrants, caudal quadrants and an averaged across all quadrants, showed significantly higher densities of apoptotic osteocytes in 5 week loaded bones compared to 2 week loaded bones as well. The 5 week loaded quadrants, isolated to the proximal region, midshaft region and average across all regions, and 5 week loaded regions, isolated to the cranial quadrant, lateral quadrant, caudal quadrant and average across all quadrants, showed significantly higher percentages of apoptotic osteocytes compared to the respective quadrants or regions of the 2 week loaded samples. The lateral, caudal and medial quadrants, isolated to the distal region, and the distal and midshaft regions, both isolated to medial quadrant, also showed a significantly higher percentage of apoptotic osteocytes in the 5 week loaded samples compared to the 2 week load samples. Lateral quadrants, when averaged 
across all regions and when isolated to the midshaft region, showed significantly higher densities of viable osteocytes in 5 week loaded bones compared to 2 week loaded bones. Midshaft regions, when isolated to cranial quadrants, lateral quadrants, caudal quadrants and averaged across all quadrants, and proximal regions, isolated to the caudal quadrant, showed significantly higher densities of viable osteocytes in 5 week loaded bones compared to 2 week loaded bones as well. The 5 week loaded quadrants, isolated to the distal region, midshaft region and averaged across all regions, and the 5 week loaded regions, averaged across all quadrants, showed a significantly higher percentage of viable osteocytes compared to the respective quadrants or regions in the 2 week loaded samples. The midshafts, when isolated by each individual quadrant, and the proximal regions, isolated to the caudal quadrant, also showed a significantly less percentage of viable osteocytes in the 2 week loaded samples compared to the 5 week samples. 
Table 59. Quadrantal differences of apoptotic osteocyte density, viable osteocyte density, percentage of apoptotic osteocytes, and percentage of viable osteocytes between left tibias loaded for 2 weeks and left tibias loaded for 5 weeks. Standard deviations in parentheses.

2 Week Loaded/5 Week Loaded Quadrant

\begin{tabular}{|c|c|c|c|c|}
\hline Quadrant & $\begin{array}{l}\text { Apoptotic } \\
\text { Osteocyte } \\
\text { Density }\end{array}$ & $\begin{array}{l}\text { \% Apoptotic } \\
\text { Osteocytes }\end{array}$ & $\begin{array}{l}\text { Viable } \\
\text { Osteocyte } \\
\text { Density }\end{array}$ & $\begin{array}{l}\text { \% Viable } \\
\text { Osteocytes }\end{array}$ \\
\hline 2WL_Cranial $\left(\mathrm{Cr}_{2 \mathrm{WL}}\right)$ & $150.1(38.4)$ & $42.03(6.40)$ & $258.3(63.3)$ & $53.54(7.96)$ \\
\hline 2WL_Lateral( $\left.\mathrm{L}_{2 \mathrm{WL}}\right)$ & $88.8(40.7)$ & $26.62(5.80)$ & $139.82(12.08)$ & $33.41(1.79)$ \\
\hline 2WL_Caudal $\left(\mathrm{Cd}_{2 W L}\right)$ & $112.1(46.8)$ & $33.89(7.47)$ & $211.4(52.1)$ & $45.61(6.39)$ \\
\hline 2WL_Medial(M $\left(M_{2 W L}\right)$ & $146.1(34.6)$ & $43.42(1.92)$ & $244.7(109.0)$ & $51.73(11.52)$ \\
\hline 5WL_Cranial $\left(\mathrm{Cr}_{5 \mathrm{WL}}\right)$ & $236.27(37.8)$ & $59.90(3.83)$ & $348.55(35.4)$ & $67.22(1.50)$ \\
\hline 5WL_Lateral(L) $\left.L_{5 \mathrm{WL}}\right)$ & $232.46(56.8)$ & $58.00(3.47)$ & $272.02(63.1)$ & $54.68(5.81)$ \\
\hline 5WL_Caudal $\left(\mathrm{Cd}_{5 W L}\right)$ & $239.50(38.3)$ & $58.40(3.39)$ & $330.77(23.34)$ & $63.75(2.72)$ \\
\hline 5WL_Medial(M $\left.M_{5 W L}\right)$ & $256.88(59.1)$ & $60.31(2.46)$ & $333.68(42.3)$ & $67.36(1.34)$ \\
\hline $\mathrm{Cr}_{2 W L}-\mathrm{Cr}_{5 \mathrm{WL}}$ & .1950 & .0001 & .2539 & .0126 \\
\hline $\mathbf{L}_{2 W L}-\mathbf{L}_{5 W L}$ & .0036 & .0000 & .0230 & .0001 \\
\hline $\mathrm{Cd}_{2 \mathrm{WL}}-\mathrm{Cd}_{5 \mathrm{I}}$ & .0125 & .0000 & .0518 & .0005 \\
\hline$M_{2 W L}-M_{5 W L}$ & .0416 & .0001 & .2685 & .0031 \\
\hline
\end{tabular}


Table 60. Mean quadrantal data gathered from the proximal region for apoptotic osteocyte density, viable osteocyte density, percentage of apoptotic osteocytes, and percentage of viable osteocytes compared between left tibias loaded for 2 weeks and left tibias loaded for 5 weeks. Standard deviations in parentheses.

2 Week Loaded/5 Week Loaded Proximal Quadrant

\begin{tabular}{|c|c|c|c|c|}
\hline Quadrant & $\begin{array}{l}\text { Apoptotic } \\
\text { Osteocyte } \\
\text { Density }\end{array}$ & $\begin{array}{l}\text { \% Apoptotic } \\
\text { Osteocytes }\end{array}$ & $\begin{array}{l}\text { Viable } \\
\text { Osteocyte } \\
\text { Density }\end{array}$ & $\begin{array}{l}\text { \% Viable } \\
\text { Osteocytes }\end{array}$ \\
\hline 2WL_Cranial $\left(\mathrm{Cr}_{2 \mathrm{WL}}\right)$ & $139.26(26.7)$ & $42.49(4.23)$ & $248.18(118.0)$ & $54.36(14.24)$ \\
\hline 2WL_Lateral( $\left.\mathrm{L}_{2 W L}\right)$ & $73.68(47.6)$ & $22.37(3.88)$ & $113.62(61.2)$ & $30.82(12.34)$ \\
\hline 2WL_Caudal $\left(\mathrm{Cd}_{2 \mathrm{WL}}\right)$ & $119.79(25.9)$ & $35.97(4.43)$ & $185.28(30.6)$ & $46.44(8.26)$ \\
\hline 2WL_Medial $\left(M_{2 W L}\right)$ & $178.15(40.5)$ & $51.88(6.50)$ & $193.30(62.0)$ & $54.82(17.6)$ \\
\hline 5WL_Cranial $\left(\mathrm{Cr}_{5 \mathrm{WL}}\right)$ & $222.01(28.9)$ & $58.68(4.20)$ & $331.65(49.7)$ & $66.40(2.15)$ \\
\hline 5WL_Lateral $\left(\mathrm{L}_{5 \mathrm{WL}}\right)$ & $173.98(25.0)$ & $52.43(4.98)$ & $198.41(64.5)$ & $47.12(11.49)$ \\
\hline 5WL_Caudal $\left(\mathrm{Cd}_{5 W L}\right)$ & $210.18(18.24)$ & $56.97(4.00)$ & $309.71(40.4)$ & $64.43(5.67)$ \\
\hline 5WL_Medial $\left(M_{5 W L}\right)$ & $277.59(80.9)$ & $63.09(4.59)$ & $307.77(63.3)$ & $66.61(4.91)$ \\
\hline $\mathrm{Cr}_{2 \mathrm{WL}}-\mathrm{Cr}_{5 \mathrm{WL}}$ & .1616 & .0007 & .5521 & .6081 \\
\hline $\mathbf{L}_{2 W L}-\mathbf{L}_{5 W L}$ & .0486 & .0000 & .5331 & .2472 \\
\hline $\mathrm{Cd}_{2 W L}-\mathrm{Cd}_{5 W L}$ & .0982 & .0000 & .1211 & .1550 \\
\hline$M_{2 W L}-M_{5 W L}$ & .0517 & .0321 & .1882 & .6323 \\
\hline
\end{tabular}


Table 61. Mean quadrantal data gathered from the midshaft region for apoptotic osteocyte density, viable osteocyte density, percentage of apoptotic osteocytes, and percentage of viable osteocytes compared between left tibias loaded for 2 weeks and left tibias loaded for 5 weeks. Standard deviations in parentheses.

2 Week Loaded/5 Week Loaded Midshaft Quadrant

\begin{tabular}{|c|c|c|c|c|}
\hline Quadrant & $\begin{array}{l}\text { Apoptotic } \\
\text { Osteocyte } \\
\text { Density }\end{array}$ & $\begin{array}{l}\text { \% Apoptotic } \\
\text { Osteocytes }\end{array}$ & $\begin{array}{l}\text { Viable } \\
\text { Osteocyte } \\
\text { Density }\end{array}$ & $\begin{array}{l}\text { \% Viable } \\
\text { Osteocytes }\end{array}$ \\
\hline 2WL_Cranial $\left(\mathrm{Cr}_{2 \mathrm{WL}}\right)$ & $169.52(67.1)$ & $40.59(4.18)$ & $236.57(68.0)$ & $49.54(8.58)$ \\
\hline 2WL_Lateral $\left(\mathrm{L}_{2 \mathrm{WL}}\right)$ & $71.92(34.1)$ & $25.75(6.21)$ & $109.51(53.8)$ & $28.75(8.46)$ \\
\hline 2WL_Caudal $\left(\mathrm{Cd}_{2 \mathrm{WL}}\right)$ & $104.01(55.5)$ & $33.25(8.37)$ & $192.70(114.6)$ & $40.36(10.80)$ \\
\hline 2WL_Medial( $\left(M_{2 W L}\right)$ & $157.92(62.4)$ & $41.00(2.56)$ & $256.64(168.4)$ & $46.93(14.93)$ \\
\hline 5WL_Cranial $\left(\mathrm{Cr}_{5 \mathrm{WL}}\right)$ & $255.87(71.0)$ & $62.48(4.44)$ & $392.50(54.7)$ & $67.41(3.49)$ \\
\hline 5WL_Lateral $\left(\mathbf{L}_{5 W L}\right)$ & $277.99(81.8)$ & $64.35(5.50)$ & $348.03(102.4)$ & $58.25(7.78)$ \\
\hline 5WL_Caudal $\left(\mathrm{Cd}_{5 \mathrm{WL}}\right)$ & $287.88(68.9)$ & $62.29(3.30)$ & $382.38(54.9)$ & $63.60(5.68)$ \\
\hline 5WL_Medial(M $\left.M_{5 \mathrm{WL}}\right)$ & $287.24(114.6)$ & $60.99(5.37)$ & $383.97(112.5)$ & $68.84(5.07)$ \\
\hline $\mathrm{Cr}_{2 \mathrm{WL}}-\mathrm{Cr}_{5 \mathrm{WL}}$ & .7732 & .0000 & .2969 & .0449 \\
\hline $\mathbf{L}_{2 W L}-\mathbf{L}_{5 W L}$ & .0181 & .0000 & .0224 & .0002 \\
\hline $\mathrm{Cd}_{2 \mathrm{WL}}-\mathrm{Cd}_{5 \mathrm{WL}}$ & .0462 & .0000 & .1165 & .0039 \\
\hline$M_{2 W L}-M_{5 W L}$ & .3161 & .0001 & .5431 & .0073 \\
\hline
\end{tabular}


Table 62. Mean quadrantal data gathered from the distal region for apoptotic osteocyte density, viable osteocyte density, percentage of apoptotic osteocytes, and percentage of viable osteocytes compared between left tibias loaded for 2 weeks and left tibias loaded for 5 weeks. Standard deviations in parentheses.

2 Week Loaded/5 Week Loaded Distal Quadrant

\begin{tabular}{|c|c|c|c|c|}
\hline Quadrant & $\begin{array}{l}\text { Apoptotic } \\
\text { Osteocyte } \\
\text { Density }\end{array}$ & $\begin{array}{l}\text { \%Apoptotic } \\
\text { Osteocytes }\end{array}$ & $\begin{array}{l}\text { Viable } \\
\text { Osteocyte } \\
\text { Density } \\
\end{array}$ & $\begin{array}{l}\text { \% Viable } \\
\text { Osteocytes }\end{array}$ \\
\hline $2 \mathrm{WL}$ CCranial $\left(\mathrm{Cr}_{2 \mathrm{WL}}\right)$ & $141.53(24.6)$ & $43.01(11.61)$ & $290.43(47.3)$ & $56.72(4.66)$ \\
\hline $2 \mathrm{WL} \_$Lateral $\left(\mathrm{L}_{2 \mathrm{WL}}\right)$ & $120.86(64.2)$ & $31.75(12.99)$ & $196.34(23.2)$ & $40.67(1.78)$ \\
\hline $2 \mathrm{WL} \_$Caudal $\left(\mathrm{Cd}_{2 \mathrm{WL}}\right)$ & $112.62(62.2)$ & $32.43(10.07)$ & $256.25(35.3)$ & $50.03(3.32)$ \\
\hline 2WL_Medial $\left(M_{2 W L}\right)$ & $102.34(18.4)$ & $37.39(6.00)$ & $284.29(112.9)$ & $53.44(8.14)$ \\
\hline $5 \mathrm{WL}$-Cranial $\left(\mathrm{Cr}_{5 \mathrm{WL}}\right)$ & $230.93(44.9)$ & $58.54(6.44)$ & $321.50(31.1)$ & $67.85(1.45)$ \\
\hline 5WL_Lateral $\left(\mathrm{L}_{5 \mathrm{WL}}\right)$ & $245.40(77.7)$ & $57.22(6.52)$ & $269.62(68.5)$ & $58.67(2.89)$ \\
\hline 5WL_Caudal $\left(\mathrm{Cd}_{5 \mathrm{WL}}\right)$ & $220.42(48.0)$ & $55.96(6.80)$ & $300.20(14.07)$ & $63.22(4.82)$ \\
\hline 5WL_Medial( $\left(M_{5 \mathrm{WL}}\right)$ & $205.80(43.4)$ & $56.84(7.32)$ & $309.30(47.7)$ & $66.62(3.26)$ \\
\hline $\mathrm{Cr}_{2 \mathrm{WL}}-\mathrm{Cr}_{5 \mathrm{WL}}$ & .2893 & .1526 & 9879 & .0079 \\
\hline $\mathbf{L}_{2 W L}-\mathbf{L}_{5 W L}$ & .0451 & .0025 & 4919 & .0000 \\
\hline $\mathrm{Cd}_{2 \mathrm{WL}}-\mathrm{Cd}_{5 \mathrm{WL}}$ & .1178 & .0060 & 9230 & .0012 \\
\hline$M_{2 W L}-M_{5 W L}$ & .1481 & .0347 & 9967 & .0012 \\
\hline
\end{tabular}

Table 63. Regional differences of apoptotic osteocyte density, viable osteocyte density, percentage of apoptotic osteocytes, and percentage of viable osteocytes between left tibias loaded for $\mathbf{2}$ weeks and left tibias loaded for 5 weeks. Standard deviations in parentheses.

2 Week Loaded/5 Week Loaded Region

\begin{tabular}{|c|c|c|c|c|}
\hline Quadrant & $\begin{array}{l}\text { Apoptotic } \\
\text { Osteocyte } \\
\text { Density }\end{array}$ & $\begin{array}{l}\text { \% Apoptotic } \\
\text { Osteocytes }\end{array}$ & $\begin{array}{l}\text { Viable } \\
\text { Osteocyte } \\
\text { Density } \\
\end{array}$ & $\begin{array}{l}\text { \% Viable } \\
\text { Osteocytes }\end{array}$ \\
\hline $2 \mathrm{WL} \_$Distal $\left(\mathrm{D}_{2 \mathrm{WL}}\right)$ & $123.53(42.6)$ & $37.06(8.04)$ & $262.57(50.0)$ & $51.66(3.72)$ \\
\hline 2WL_Midshaft( $\left(\mathrm{MS}_{2 \mathrm{WL}}\right)$ & $129.12(48.0)$ & $36.67(2.95)$ & $206.56(90.3)$ & $44.08(9.63)$ \\
\hline 2WL_Proximal $\left(P_{2 W L}\right)$ & $123.56(29.8)$ & $37.90(4.46)$ & 198.71(65.2) & $48.65(9.80)$ \\
\hline 5WL_Distal $\left(D_{5 \mathrm{WL}}\right)$ & $225.88(41.0)$ & $57.08(5.41)$ & $302.42(19.36)$ & $64.32(2.00)$ \\
\hline 5WL_Midshaft(MS $\left.{ }_{5 \mathrm{WL}}\right)$ & $272.75(68.7)$ & $62.78(3.77)$ & $377.70(52.9)$ & 64.97(3.61) \\
\hline 5WL_Proximal $\left(P_{5 W L}\right)$ & 214.44(24.9) & $57.78(2.74)$ & $298.83(49.0)$ & $62.82(3.85)$ \\
\hline$D_{2 W L}-D_{5 W I}$ & 508 & 001 & .8858 & .0251 \\
\hline $\mathbf{M S}_{2 \mathrm{WL}}-\mathbf{M S}_{5}$ & .0031 & .0000 & .0018 & .0002 \\
\hline $\mathbf{P}_{2 \mathrm{WL}}-\mathbf{P}_{5 \mathrm{WL}}$ & .1023 & .0001 & .1168 & .0101 \\
\hline
\end{tabular}


Table 64. Mean regional data gathered from the cranial quadrant for apoptotic osteocyte density, viable osteocyte density, percentage of apoptotic osteocytes, and percentage of viable osteocytes compared between left tibias loaded for 2 weeks and left tibias loaded for 5 weeks. Standard deviations in parentheses.

2 Week Loaded/5 Week Loaded Cranial Region

\begin{tabular}{|c|c|c|c|c|}
\hline Quadrant & $\begin{array}{l}\text { Apoptotic } \\
\text { Osteocyte } \\
\text { Density }\end{array}$ & $\begin{array}{l}\text { \% Apoptotic } \\
\text { Osteocytes }\end{array}$ & $\begin{array}{l}\text { Viable } \\
\text { Osteocyte } \\
\text { Density }\end{array}$ & $\begin{array}{l}\text { \% Viable } \\
\text { Osteocytes }\end{array}$ \\
\hline 2WL_Distal $\left(D_{2 \mathrm{WL}}\right)$ & $141.53(24.6)$ & 43.01(11.61) & $290.43(47.3)$ & $56.72(4.66)$ \\
\hline 2WL_Midshaft $\left(\mathrm{MS}_{2 \mathrm{WL}}\right)$ & $169.52(67.1)$ & $40.59(4.18)$ & $236.57(68.0)$ & $49.54(8.58)$ \\
\hline 2WL_Proximal $\left(\mathbf{P}_{2 \mathrm{WL}}\right)$ & $139.26(26.7)$ & $42.49(4.23)$ & $248.18(118)$. & $54.36(14.24)$ \\
\hline 5WL_Distal( $\left(D_{5 W L}\right)$ & $230.93(44.9)$ & 58.54(6.44) & $321.50(31.1)$ & $67.85(1.45)$ \\
\hline 5WL_Midshaft(MS $\left.{ }_{5 \mathrm{WL}}\right)$ & $255.87(71.0)$ & $62.48(4.44)$ & $392.50(54.7)$ & 67.41(3.49) \\
\hline 5WL_Proximal $\left(P_{5 \mathrm{WL}}\right)$ & $222.01(28.9)$ & $58.68(4.20)$ & $331.65(49.7)$ & $66.40(2.15)$ \\
\hline$D_{2 W L}-D_{5 W L}$ & .1512 & .0142 & .9742 & .1078 \\
\hline $\mathbf{M S}_{2 \mathrm{WL}}-\mathbf{M S}_{\mathbf{5 W L}}$ & 1766 & .0004 & .0139 & .0030 \\
\hline $\mathbf{P}_{2 \mathrm{WL}}-\mathbf{P}_{5 \mathrm{WL}}$ & .2110 & .0100 & .3792 & .0694 \\
\hline
\end{tabular}

Table 65. Mean regional data gathered from the lateral quadrant for apoptotic osteocyte density, viable osteocyte density, percentage of apoptotic osteocytes, and percentage of viable osteocytes compared between left tibias loaded for 2 weeks and left tibias loaded for 5 weeks. Standard deviations in parentheses.

2 Week Loaded/5 Week Loaded Lateral Region

\begin{tabular}{|c|c|c|c|c|}
\hline Quadrant & $\begin{array}{l}\text { Apoptotic } \\
\text { Osteocyte } \\
\text { Density }\end{array}$ & $\begin{array}{l}\text { \% Apoptotic } \\
\text { Osteocytes }\end{array}$ & $\begin{array}{l}\text { Viable } \\
\text { Osteocyte } \\
\text { Density } \\
\end{array}$ & $\begin{array}{l}\text { \% Viable } \\
\text { Osteocytes }\end{array}$ \\
\hline 2WL_Distal( $\left(D_{2 W L}\right)$ & $120.86(64.2)$ & $31.75(12.99)$ & $196.34(23.2)$ & $40.67(1.78)$ \\
\hline 2WL_Midshaft( $\left(\mathrm{MS}_{2 W L}\right)$ & $71.92(34.1)$ & $25.75(6.21)$ & $109.51(53.8)$ & $28.75(8.46)$ \\
\hline 2WL_Proximal $\left(\mathbf{P}_{2 \mathrm{WL}}\right)$ & $73.68(47.6)$ & $22.37(3.88)$ & $113.62(61.2)$ & $30.82(12.34)$ \\
\hline 5WL_Distal( D $\left._{5 W L}\right)$ & $245.40(77.7)$ & $57.22(6.52)$ & $269.62(68.5)$ & $58.67(2.89)$ \\
\hline 5WL_Midshaft(MS (MWL $)$ & $277.99(81.8)$ & $64.35(5.50)$ & $348.03(102.4)$ & $58.25(7.78)$ \\
\hline 5WL_Proximal $\left(P_{5 W L}\right)$ & $173.98(25.0)$ & $52.43(4.98)$ & $198.41(64.5)$ & $47.12(11.49)$ \\
\hline$D_{2 W L}-D_{5 W L}$ & .0928 & .0003 & .7122 & .0583 \\
\hline $\mathbf{M S}_{2 W L}-\mathbf{M S}_{5 W L}$ & .0016 & .0000 & .0017 & .0007 \\
\hline $\mathbf{P}_{2 W L}-P_{5 W L}$ & .2487 & .0000 & .5776 & .1033 \\
\hline
\end{tabular}


Table 66. Mean regional data gathered from the caudal quadrant for apoptotic osteocyte density, viable osteocyte density, percentage of apoptotic osteocytes, and percentage of viable osteocytes compared between left tibias loaded for 2 weeks and left tibias loaded for 5 weeks. Standard deviations in parentheses.

2 Week Loaded/5 Week Loaded Caudal Region

\begin{tabular}{|c|c|c|c|c|}
\hline Quadrant & $\begin{array}{l}\text { Apoptotic } \\
\text { Osteocyte } \\
\text { Density }\end{array}$ & \begin{tabular}{|l|} 
\% Apoptotic \\
Osteocytes
\end{tabular} & $\begin{array}{l}\text { Viable } \\
\text { Osteocyte } \\
\text { Density }\end{array}$ & $\begin{array}{l}\text { \% Viable } \\
\text { Osteocytes }\end{array}$ \\
\hline 2WL_Distal(D $\left(D_{2 \mathrm{WL}}\right)$ & $112.62(62.2)$ & $32.43(10.07)$ & $256.25(35.3)$ & $50.03(3.32)$ \\
\hline 2WL_Midshaft(MS $\left(\mathrm{MSL}_{2 \mathrm{~L}}\right)$ & $104.01(55.5)$ & $33.25(8.37)$ & $192.70(114.6)$ & $40.36(10.8)$ \\
\hline 2WL_Proximal $\left(\mathbf{P}_{2 \mathrm{WL}}\right)$ & $119.79(25.9)$ & $35.97(4.43)$ & 185.28(30.6) & $46.44(8.26)$ \\
\hline 5WL_Distal((D) & $220.42(48.0)$ & $55.96(6.80)$ & $300.20(14.07)$ & $63.22(4.82)$ \\
\hline 5WL_Midshaft(MS $\left.{ }_{5 \mathrm{WL}}\right)$ & $287.88(68.9)$ & $62.29(3.30)$ & $382.38(54.9)$ & $63.60(5.68)$ \\
\hline 5WL_Proximal $\left(\mathbf{P}_{5 \mathrm{WL}}\right)$ & $210.18(18.24)$ & $56.97(4.00)$ & 309.71(40.4) & $64.43(5.67)$ \\
\hline$D_{2 W L}-D_{5 W L}$ & .0576 & .0002 & .8239 & .0693 \\
\hline $\mathbf{M S}_{\mathbf{2 W L}-\mathbf{M S}}$ & .0005 & .0000 & .0004 & .0005 \\
\hline $\mathbf{P}_{2 \mathrm{WL}}-\mathbf{P}_{5 \mathrm{WL}}$ & .1501 & .0008 & .0255 & .0067 \\
\hline
\end{tabular}

Table 67. Mean regional data gathered from the medial quadrant for apoptotic osteocyte density, viable osteocyte density, percentage of apoptotic osteocytes, and percentage of viable osteocytes compared between left tibias loaded for 2 weeks and left tibias loaded for 5 weeks. Standard deviations in parentheses.

2 Week Loaded/5 Week Loaded Medial Region

\begin{tabular}{|c|c|c|c|c|}
\hline Quadrant & $\begin{array}{l}\text { Apoptotic } \\
\text { Osteocyte } \\
\text { Density }\end{array}$ & $\begin{array}{l}\text { \%Apoptoti } \\
\text { c } \\
\text { Osteocytes }\end{array}$ & $\begin{array}{l}\text { Viable } \\
\text { Osteocyte } \\
\text { Density }\end{array}$ & $\begin{array}{l}\text { \% Viable } \\
\text { Osteocytes }\end{array}$ \\
\hline 2WL_Distal $\left(\mathrm{D}_{2 W L}\right)$ & $102.34(18.4)$ & $37.39(6.00)$ & $284.29(112.9)$ & $53.44(8.14)$ \\
\hline 2WL_Midshaft(MS $\left.{ }_{2 W L}\right)$ & $157.92(62.4)$ & $41.00(2.56)$ & $256.64(168.4)$ & $46.93(14.93)$ \\
\hline 2WL_Proximal $\left(\mathbf{P}_{2 W L}\right)$ & $178.15(40.5)$ & $51.88(6.50)$ & $193.30(62.0)$ & $54.82(17.6)$ \\
\hline 5WL_Distal( $\left(D_{5 W L}\right)$ & $205.80(43.4)$ & $56.84(7.32)$ & $309.30(47.7)$ & $66.62(3.26)$ \\
\hline 5WL_Midshaft(MS $\left.{ }_{5 W L}\right)$ & $287.24(114.6)$ & $60.99(5.37)$ & $383.97(112.5)$ & $68.84(5.07)$ \\
\hline 5WL_Proximal $\left(P_{5 W L}\right)$ & $277.59(80.9)$ & $63.09(4.59)$ & $307.77(63.3)$ & $66.61(4.91)$ \\
\hline$D_{2 W L}-D_{5 W L}$ & .4075 & .0012 & .9989 & .2769 \\
\hline $\mathbf{M S}_{2 \mathrm{WL}}-\mathbf{M S}_{5 \mathrm{WL}}$ & .1929 & .0009 & .4179 & .0158 \\
\hline $\mathbf{P}_{2 W L}-\mathbf{P}_{5 W L}$ & .4495 & .1018 & .5305 & .3900 \\
\hline
\end{tabular}




\subsection{Comparison Between 2 Week and 5 Week Unloaded Right Tibia Controls}

Below are the statistics for all of the 2 week unloaded right tibias compared against all of the 5 week unloaded right tibias used as controls, including a summary, analysis by quadrant, analysis by region and combinations of the latter two. For each statistical analysis, apoptotic osteocyte density, percentage of apoptotic osteocytes, viable osteocyte density and percentage of viable osteocytes were the variables considered. Mean values, standard deviations and relevant $p$-values are shown, with $p$-values less than 0.05 indicating statistically significant data. No statistically significant differences were seen between the 2 week unloaded controls and the 5 week unloaded controls.

Table 68. Quadrantal differences of apoptotic osteocyte density, viable osteocyte density, percentage of apoptotic osteocytes, and percentage of viable osteocytes between right tibias unloaded for 2 weeks and right tibias unloaded for 5 weeks both used as controls. Standard deviations in parentheses.

2 Week Control/5 Week Control Quadrant

\begin{tabular}{|c|c|c|c|c|}
\hline Quadrant & $\begin{array}{l}\text { Apoptotic } \\
\text { Osteocyte } \\
\text { Density }\end{array}$ & $\begin{array}{l}\text { \% Apoptotic } \\
\text { Osteocytes }\end{array}$ & $\begin{array}{l}\text { Viable } \\
\text { Osteocyte } \\
\text { Density }\end{array}$ & $\begin{array}{l}\text { \% Viable } \\
\text { Osteocytes }\end{array}$ \\
\hline 2WR_Cranial $\left(\mathrm{Cr}_{2 \mathrm{WR}}\right)$ & $128.08(34.1)$ & $36.20(2.08)$ & $305.68(62.2)$ & $59.06(6.36)$ \\
\hline 2WR_Lateral( $\left.\mathrm{L}_{2 \mathrm{WR}}\right)$ & 107.65(31.1) & $28.30(3.83)$ & $242.22(34.7)$ & $46.37(1.55)$ \\
\hline 2WR_Caudal $\left(\mathrm{Cd}_{2 \mathrm{WR}}\right)$ & $112.28(33.9)$ & $30.21(2.91)$ & $277.54(52.9)$ & $52.05(5.01)$ \\
\hline 2WR_Medial( $\left(M_{2 W R}\right)$ & $167.96(40.6)$ & $38.92(4.06)$ & $344.32(35.6)$ & $61.03(6.19)$ \\
\hline 5WR_Cranial $\left(\mathrm{Cr}_{5 \mathrm{FR}}\right)$ & 151.11(17.04) & $41.24(4.74)$ & $358.88(83.2)$ & $66.72(3.11)$ \\
\hline 5WR_Lateral( $\left.\mathbf{L}_{5 \mathrm{WR}}\right)$ & 154.51(36.2) & $36.82(6.58)$ & $319.53(27.5)$ & $57.41(10.05)$ \\
\hline 5WR_Caudal $\left(\mathrm{Cd}_{5 \mathrm{WR}}\right)$ & $141.49(28.4)$ & $37.35(6.70)$ & $368.86(59.6)$ & $64.33(7.15)$ \\
\hline 5WR_Medial $\left(M_{5 \mathrm{WR}}\right)$ & $154.90(45.1)$ & $38.35(6.07)$ & $336.28(58.0)$ & $64.63(6.75)$ \\
\hline $\mathrm{Cr}_{2 \mathrm{WR}}-\mathrm{Cr}_{5 \mathrm{WR}}$ & .9761 & .8859 & .8845 & .7336 \\
\hline $\mathbf{L}_{2} \mathrm{WR}_{\mathrm{R}}-\mathrm{L}_{5 \mathrm{WR}}$ & .5253 & .3711 & .5528 & .3097 \\
\hline $\mathrm{Cd}_{2 \mathrm{WR}}-\mathrm{Cd}_{5 \mathrm{WR}}$ & .9187 & .5882 & .3482 & 1981 \\
\hline$M_{2 W R}-M_{5 W R}$ & .9992 & 1.0000 & 1.0000 & .9939 \\
\hline
\end{tabular}


Table 69. Mean quadrantal data gathered from the proximal region for apoptotic osteocyte density, viable osteocyte density, percentage of apoptotic osteocytes, and percentage of viable osteocytes compared between right tibias unloaded for 2 weeks and right tibias unloaded for 5 weeks both used as controls. Standard deviations in parentheses.

2 Week Control/5 Week Control Proximal Quadrant

\begin{tabular}{|c|c|c|c|c|}
\hline Quadrant & $\begin{array}{l}\text { Apoptotic } \\
\text { Osteocyte } \\
\text { Density }\end{array}$ & $\begin{array}{l}\text { \% Apoptotic } \\
\text { Osteocytes }\end{array}$ & $\begin{array}{l}\text { Viable } \\
\text { Osteocyte } \\
\text { Density }\end{array}$ & $\begin{array}{l}\text { \% Viable } \\
\text { Osteocytes }\end{array}$ \\
\hline 2WR_Cranial $\left(\mathrm{Cr}_{2 \mathrm{WR}}\right)$ & $119.69(7.01)$ & $37.96(2.02)$ & $314.25(20.9)$ & $60.82(0.92)$ \\
\hline 2WR_Lateral(L $\left.\mathrm{L}_{2 \mathrm{WR}}\right)$ & $64.08(23.4)$ & $20.74(2.88)$ & $194.92(47.2)$ & $41.14(7.09)$ \\
\hline 2WR_Caudal $\left(\mathrm{Cd}_{2 \mathrm{WR}}\right)$ & $87.54(4.45)$ & $29.74(1.01)$ & $252.90(52.5)$ & $49.47(5.94)$ \\
\hline 2WR_Medial( $\left(M_{2 W R}\right)$ & $168.77(35.7)$ & $39.63(4.38)$ & $312.88(92.7)$ & $58.51(13.4)$ \\
\hline 5WR_Cranial $\left(\mathrm{Cr}_{5 \mathrm{WR}}\right)$ & $150.31(18.42)$ & $42.06(4.85)$ & $312.83(88.0)$ & $64.48(3.61)$ \\
\hline 5WR_Lateral(L) LWR $\left._{5}\right)$ & $135.35(48.8)$ & $35.54(8.14)$ & $265.19(37.4)$ & $54.35(11.81)$ \\
\hline 5WR_Caudal $\left(\mathrm{Cd}_{5 \mathrm{WR}}\right)$ & $132.08(25.1)$ & $38.56(6.21)$ & $350.45(97.9)$ & $66.50(9.72)$ \\
\hline 5WR_Medial(M $\left(M_{5 W R}\right)$ & $165.20(61.2)$ & $38.51(9.86)$ & $268.59(73.3)$ & $59.62(9.94)$ \\
\hline $\mathrm{Cr}_{2 W R}-\mathrm{Cr}_{5 W R}$ & .9377 & .9849 & 1.0000 & .9989 \\
\hline $\mathbf{L}_{2 W R}-\mathbf{L}_{5 W R}$ & .1674 & .0578 & .8654 & .4522 \\
\hline $\mathrm{Cd}_{2 W R}-\mathrm{Cd}_{5 W R}$ & .6987 & .5552 & .5660 & .1703 \\
\hline$M_{2 W R}-M_{5 W R}$ & 1.0000 & 1.0000 & .9874 & 1.0000 \\
\hline
\end{tabular}


Table 70. Mean quadrantal data gathered from the midshaft region for apoptotic osteocyte density, viable osteocyte density, percentage of apoptotic osteocytes, and percentage of viable osteocytes compared between right tibias unloaded for 2 weeks and right tibias unloaded for 5 weeks both used as controls. Standard deviations in parentheses.

2 Week Control/5 Week Control Midshaft Quadrant

\begin{tabular}{|c|c|c|c|c|}
\hline Quadrant & $\begin{array}{l}\text { Apoptotic } \\
\text { Osteocyte } \\
\text { Density }\end{array}$ & $\begin{array}{l}\text { \% Apoptoti } \\
\text { c } \\
\text { Osteocytes }\end{array}$ & $\begin{array}{l}\text { Viable } \\
\text { Osteocyte } \\
\text { Density }\end{array}$ & $\begin{array}{l}\text { \% Viable } \\
\text { Osteocytes }\end{array}$ \\
\hline 2WR_Cranial $\left(\mathrm{Cr}_{2 \mathrm{WR}}\right)$ & $133.45(46.1)$ & $36.55(6.04)$ & $291.28(113.2)$ & $58.95(7.50)$ \\
\hline 2WR_Lateral( $\left.\mathrm{L}_{2 \mathrm{WR}}\right)$ & $115.74(41.0)$ & $28.43(7.06)$ & $238.32(27.8)$ & $43.87(1.80)$ \\
\hline 2WR_Caudal $\left(\mathrm{Cd}_{2 \mathrm{WR}}\right)$ & $115.72(46.9)$ & $29.34(5.27)$ & $270.63(79.6)$ & $49.77(3.04)$ \\
\hline 2WR_Medial(M $\left(M_{2 \mathrm{WR}}\right)$ & $172.28(58.3)$ & $37.96(6.36)$ & $421.17(65.7)$ & $63.17(4.14)$ \\
\hline 5WR_Cranial $\left(\mathrm{Cr}_{5 \mathrm{WR}}\right)$ & $164.57(27.5)$ & $40.87(7.98)$ & $408.90(123.1)$ & $67.21(4.17)$ \\
\hline 5WR_Lateral(L5WR) & $191.78(69.1)$ & $39.62(8.77)$ & $365.40(99.9)$ & $58.69(11.38)$ \\
\hline 5WR_Caudal $\left(\mathrm{Cd}_{5 \mathrm{WR}}\right)$ & $155.41(25.9)$ & $38.86(7.33)$ & $396.47(83.9)$ & $64.60(6.96)$ \\
\hline 5WR_Medial(M (WWR $)$ & $155.11(10.82)$ & $37.32(6.66)$ & $397.45(95.8)$ & $65.21(5.78)$ \\
\hline $\mathrm{Cr}_{2 W R}-\mathrm{Cr}_{5 W R}$ & .9642 & .9894 & .6615 & .6854 \\
\hline $\mathbf{L}_{2 W R}-\mathbf{L}_{5 W R}$ & .2220 & .4034 & .5735 & .0798 \\
\hline $\mathrm{Cd}_{2 W R}-\mathrm{Cd}_{5 W R}$ & .8821 & 6009 & .5851 & .0796 \\
\hline$M_{2 W R}-M_{5 W R}$ & .9990 & 1.0000 & 1.0000 & 9999 \\
\hline
\end{tabular}


Table 71. Mean quadrantal data gathered from the distal region for apoptotic osteocyte density, viable osteocyte density, percentage of apoptotic osteocytes, and percentage of viable osteocytes compared between right tibias unloaded for 2 weeks and right tibias unloaded for 5 weeks both used as controls. Standard deviations in parentheses.

2 Week Control/5 Week Control Distal Quadrant

\begin{tabular}{|c|c|c|c|c|}
\hline Quadrant & $\begin{array}{l}\text { Apoptotic } \\
\text { Osteocyte } \\
\text { Density }\end{array}$ & $\begin{array}{l}\text { \%Apoptotic } \\
\text { Osteocytes }\end{array}$ & $\begin{array}{l}\text { Viable } \\
\text { Osteocyte } \\
\text { Density }\end{array}$ & $\begin{array}{l}\text { \% Viable } \\
\text { Osteocytes }\end{array}$ \\
\hline 2WR_Cranial $\left(\mathrm{Cr}_{2 \mathrm{WR}}\right)$ & $131.09(54.8)$ & $34.08(3.96)$ & $311.52(82.5)$ & $57.40(11.25)$ \\
\hline 2WR_Lateral $\left(\mathrm{L}_{2 \mathrm{WR}}\right)$ & $143.13(36.0)$ & $35.72(5.44)$ & $293.43(67.2)$ & $54.09(9.46)$ \\
\hline 2WR_Caudal $\left(\mathrm{Cd}_{2 \mathrm{WR}}\right)$ & $133.58(57.0)$ & $31.55(5.84)$ & $309.09(48.5)$ & $56.91(6.88)$ \\
\hline 2WR_Medial(M $\left(M_{2 W R}\right)$ & $162.81(42.1)$ & $39.17(3.84)$ & $298.90(38.3)$ & $61.43(6.88)$ \\
\hline 5WR_Cranial $\left(\mathrm{Cr}_{5 W R}\right)$ & $138.46(35.3)$ & $40.80(10.09)$ & $354.90(89.4)$ & $68.47(6.75)$ \\
\hline 5WR_Lateral(L) $\left.\mathbf{L}_{5 \mathrm{WR}}\right)$ & $136.41(26.3)$ & $35.30(6.60)$ & $328.00(64.6)$ & $59.19(9.15)$ \\
\hline 5WR_Caudal $\left(\mathrm{Cd}_{5 \mathrm{WR}}\right)$ & $136.99(60.2)$ & $34.62(10.86)$ & $359.66(81.8)$ & $61.89(9.12)$ \\
\hline 5WR_Medial(M MWR $\left._{5}\right)$ & $144.39(79.4)$ & $39.21(11.13)$ & $342.81(65.2)$ & $69.06(8.48)$ \\
\hline $\mathrm{Cr}_{2 W R}-\mathrm{Cr}_{5 W R}$ & 1.0000 & .9534 & .9882 & .6046 \\
\hline $\mathbf{L}_{2 W R}-\mathbf{L}_{5 W R}$ & 1.0000 & 1.0000 & .9970 & .9886 \\
\hline $\mathrm{Cd}_{2 W R}-\mathrm{Cd}_{5 \mathrm{WR}}$ & 1.0000 & .9996 & .9720 & .9902 \\
\hline $\mathrm{M}_{2 \mathrm{WR}}-\mathrm{M}_{5 \mathrm{WR}}$ & .9996 & 1.0000 & .9873 & .9047 \\
\hline
\end{tabular}

Table 72. Regional differences of apoptotic osteocyte density, viable osteocyte density, percentage of apoptotic osteocytes, and percentage of viable osteocytes between right tibias unloaded for 2 weeks and right tibias unloaded for 5 weeks both used as controls. Standard deviations in parentheses.

2 Week Control/5 Week Control Region

\begin{tabular}{|c|c|c|c|c|}
\hline Quadrant & $\begin{array}{l}\text { Apoptotic } \\
\text { Osteocyte } \\
\text { Density }\end{array}$ & $\begin{array}{l}\text { \% Apoptotic } \\
\text { Osteocytes }\end{array}$ & $\begin{array}{l}\text { Viable } \\
\text { Osteocyte } \\
\text { Density } \\
\end{array}$ & $\begin{array}{l}\text { \% Viable } \\
\text { Osteocytes }\end{array}$ \\
\hline 2WR_Distal( $\left(D_{2 W R}\right)$ & $138.65(49.4)$ & $34.19(4.82)$ & $305.10(61.4)$ & $57.41(8.62)$ \\
\hline 2WR_Midshaft(MS $\left.{ }_{2 W R}\right)$ & $127.87(47.9)$ & $33.16(5.05)$ & $290.88(76.4)$ & $54.39(2.97)$ \\
\hline 2WR_Proximal $\left(P_{2 W R}\right)$ & $103.63(11.37)$ & $32.90(1.36)$ & $271.71(21.5)$ & $53.92(1.24)$ \\
\hline 5WR_Distal( D $\left._{5 \mathrm{WR}}\right)$ & $139.09(45.8)$ & $37.63(8.96)$ & $350.68(71.9)$ & $64.41(7.51)$ \\
\hline 5WR_Midshaft(MS (WR $\left._{5}\right)$ & $163.32(22.7)$ & $39.67(7.46)$ & $394.35(83.1)$ & $64.55(5.68)$ \\
\hline 5WR_Proximal $\left(\mathbf{P}_{5 \mathrm{WR}}\right)$ & $142.64(22.93)$ & $39.58(5.51)$ & $307.31(69.6)$ & $62.56(6.33)$ \\
\hline$D_{2 W R}-D_{5 W R}$ & 1.0000 & .9760 & .9389 & .6117 \\
\hline $\mathbf{M S}_{2 W R}-M_{5} S_{5 R}$ & .7029 & .7366 & .3385 & .2339 \\
\hline $\mathbf{P}_{2 W R}-\mathbf{P}_{5 W R}$ & .6161 & .7174 & .9782 & .3943 \\
\hline
\end{tabular}


Table 73. Mean regional data gathered from the cranial quadrant for apoptotic osteocyte density, viable osteocyte density, percentage of apoptotic osteocytes, and percentage of viable osteocytes compared between right tibias unloaded for 2 weeks and right tibias unloaded for 5 weeks both used as controls. Standard deviations in parentheses.

2 Week Control/5 Week Control Cranial Region

\begin{tabular}{|c|c|c|c|c|}
\hline Quadrant & \begin{tabular}{|l} 
Apoptotic \\
Osteocyte \\
Density
\end{tabular} & $\begin{array}{l}\text { \% Apoptotic } \\
\text { Osteocytes }\end{array}$ & $\begin{array}{l}\text { Viable } \\
\text { Osteocyte } \\
\text { Density }\end{array}$ & $\begin{array}{l}\text { \% Viable } \\
\text { Osteocytes }\end{array}$ \\
\hline 2WR_Distal( $\left(D_{2 W R}\right)$ & $131.09(54.8)$ & $34.08(3.96)$ & $311.52(82.5)$ & $57.40(11.25)$ \\
\hline 2WR_Midshaft(MS $\left.{ }_{2 W R}\right)$ & $133.45(46.1)$ & $36.55(6.04)$ & $291.28(113.2)$ & $58.95(7.50)$ \\
\hline 2WR_Proximal $\left(\mathbf{P}_{2 \mathrm{WR}}\right)$ & $119.69(7.01)$ & $37.96(2.02)$ & $314.25(20.9)$ & $60.82(0.92)$ \\
\hline 5WR_Distal $\left(D_{5 W R}\right)$ & $138.46(35.3)$ & $40.80(10.09)$ & $354.90(89.4)$ & $68.47(6.75)$ \\
\hline 5WR_Midshaft(MS 5WR $)$ & $164.57(27.5)$ & $40.87(7.98)$ & $408.90(123.1)$ & $67.21(4.17)$ \\
\hline 5WR_Proximal $\left(\mathbf{P}_{5 W R}\right)$ & $150.31(18.42)$ & $42.06(4.85)$ & $312.83(88.0)$ & $64.48(3.61)$ \\
\hline$D_{2 W R}-D_{5 W R}$ & .9995 & .7607 & .9867 & .1349 \\
\hline $\mathrm{MS}_{2 \mathrm{WR}}-\mathrm{MS}_{5 \mathrm{WR}}$ & .7505 & .9518 & .5296 & .3976 \\
\hline $\mathbf{P}_{2 W R}-P_{5 W R}$ & .7624 & .9613 & 1.0000 & .9500 \\
\hline
\end{tabular}

Table 74. Mean regional data gathered from the lateral quadrant for apoptotic osteocyte density, viable osteocyte density, percentage of apoptotic osteocytes, and percentage of viable osteocytes compared between right tibias unloaded for 2 weeks and right tibias unloaded for 5 weeks both used as controls. Standard deviations in parentheses.

2 Week Control/5 Week Control Lateral Region

\begin{tabular}{|c|c|c|c|c|}
\hline Quadrant & $\begin{array}{l}\text { Apoptotic } \\
\text { Osteocyte } \\
\text { Density }\end{array}$ & $\begin{array}{l}\text { \% Apoptotic } \\
\text { Osteocytes }\end{array}$ & $\begin{array}{l}\text { Viable } \\
\text { Osteocyte } \\
\text { Density }\end{array}$ & $\begin{array}{l}\text { \% Viable } \\
\text { Osteocytes }\end{array}$ \\
\hline 2WR_Distal( $\left.\mathrm{D}_{2 \mathrm{WR}}\right)$ & $143.13(36.0)$ & $35.72(5.44)$ & $293.43(67.2)$ & $54.09(9.46)$ \\
\hline 2WR_Midshaft(MS $\left.{ }_{2 W R}\right)$ & $115.74(41.0)$ & $28.43(7.06)$ & $238.32(27.8)$ & $43.87(1.80)$ \\
\hline 2WR_Proximal( $\left(\mathbf{P}_{2 \mathrm{WR}}\right)$ & $64.08(23.4)$ & $20.74(2.88)$ & $194.92(47.2)$ & $41.14(7.09)$ \\
\hline 5WR_Distal( $\left(D_{5 W R}\right)$ & $136.41(26.3)$ & $35.30(6.60)$ & $328.00(64.6)$ & $59.19(9.15)$ \\
\hline 5WR_Midshaft(MS SWR $)$ & $191.78(69.1)$ & $39.62(8.77)$ & $365.40(99.9)$ & $58.69(11.38)$ \\
\hline 5WR_Proximal( $\left(\mathbf{P}_{5 \mathrm{WR}}\right)$ & $135.35(48.8)$ & $35.54(8.14)$ & $265.19(37.4)$ & $54.35(11.81)$ \\
\hline$D_{2 W R}-D_{5 W R}$ & .9999 & 1.0000 & .9751 & .9758 \\
\hline $\mathbf{M S}_{2 W R}-M_{5 W R}$ & .2412 & .2886 & .1164 & .3144 \\
\hline $\mathbf{P}_{2 W R}-\mathbf{P}_{5 W R}$ & .3025 & .0830 & .6711 & .4351 \\
\hline
\end{tabular}


Table 75. Mean regional data gathered from the caudal quadrant for apoptotic osteocyte density, viable osteocyte density, percentage of apoptotic osteocytes, and percentage of viable osteocytes compared between right tibias unloaded for 2 weeks and right tibias unloaded for 5 weeks both used as controls. Standard deviations in parentheses.

2 Week Control/5 Week Control Caudal Region

\begin{tabular}{|c|c|c|c|c|}
\hline Quadrant & $\begin{array}{l}\text { Apoptotic } \\
\text { Osteocyte } \\
\text { Density }\end{array}$ & $\begin{array}{l}\text { \%Apoptotic } \\
\text { Osteocytes }\end{array}$ & $\begin{array}{l}\text { Viable } \\
\text { Osteocyte } \\
\text { Density }\end{array}$ & $\begin{array}{l}\text { \% Viable } \\
\text { Osteocytes }\end{array}$ \\
\hline 2WR_Distal( $\left(\mathrm{D}_{2 \mathrm{WR}}\right)$ & $133.58(57.0)$ & $31.55(5.84)$ & $309.09(48.5)$ & $56.91(6.88)$ \\
\hline 2WR_Midshaft(MS $\left.{ }_{2 W R}\right)$ & $115.72(46.9)$ & $29.34(5.27)$ & $270.63(79.6)$ & 49.77(3.04) \\
\hline 2WR_Proximal $\left(\mathbf{P}_{2 \mathrm{WR}}\right)$ & $87.54(4.45)$ & $29.74(1.01)$ & $252.90(52.5)$ & $49.47(5.94)$ \\
\hline 5WR_Distal( $\left(D_{5 W R}\right)$ & $136.99(60.2)$ & $34.62(10.86)$ & $359.66(81.8)$ & $61.89(9.12)$ \\
\hline 5WR_Midshaft(MS $\left.{ }_{5 \mathrm{WR}}\right)$ & $155.41(25.9)$ & $38.86(7.33)$ & $396.47(83.9)$ & $64.60(6.96)$ \\
\hline 5WR_Proximal $\left(\mathbf{P}_{5 \mathrm{WR}}\right)$ & $132.08(25.1)$ & $38.56(6.21)$ & $350.45(97.9)$ & $66.50(9.72)$ \\
\hline $\mathrm{D}_{2 \mathrm{WR}}-\mathrm{D}_{5 \mathrm{WR}}$ & 1.0000 & .9913 & .9478 & .9449 \\
\hline $\mathbf{M S}_{\mathbf{2 W R}}-\mathbf{M S}_{\mathbf{5 I}}$ & .7471 & .4870 & .2861 & .1285 \\
\hline WI & 6499 & .5668 & .5509 & .0594 \\
\hline
\end{tabular}

Table 76. Mean regional data gathered from the medial quadrant for apoptotic osteocyte density, viable osteocyte density, percentage of apoptotic osteocytes, and percentage of viable osteocytes compared between right tibias unloaded for 2 weeks and right tibias unloaded for 5 weeks both used as controls. Standard deviations in parentheses.

2 Week Control/5 Week Control Medial Region

\begin{tabular}{|c|c|c|c|c|}
\hline Quadrant & $\begin{array}{l}\text { Apoptotic } \\
\text { Osteocyte } \\
\text { Density }\end{array}$ & $\begin{array}{l}\text { \% Apoptotic } \\
\text { Osteocytes }\end{array}$ & $\begin{array}{l}\text { Viable } \\
\text { Osteocyte } \\
\text { Density } \\
\end{array}$ & $\begin{array}{l}\text { \% Viable } \\
\text { Osteocytes }\end{array}$ \\
\hline 2WR_Distal( $\left(D_{2 W R}\right)$ & $162.81(42.1)$ & $39.17(3.84)$ & $298.90(38.3)$ & $61.43(6.88)$ \\
\hline 2WR_Midshaft($\left(M_{2 W R}\right)$ & $172.28(58.3)$ & $37.96(6.36)$ & $421.17(65.7)$ & $63.17(4.14)$ \\
\hline 2WR_Proximal( $\left(\mathbf{P}_{2 \mathrm{WR}}\right)$ & $168.77(35.7)$ & $39.63(4.38)$ & $312.88(92.7)$ & $58.51(13.4)$ \\
\hline$\overline{5 W R \_D i s t a l}\left(\mathrm{D}_{5 \mathrm{WR}}\right)$ & $144.39(79.4)$ & $39.21(11.13)$ & $342.81(65.2)$ & $69.06(8.48)$ \\
\hline 5WR_Midshaft $\left(M^{2} S_{5 R}\right)$ & $155.11(10.82)$ & $37.32(6.66)$ & $397.45(95.8)$ & $65.21(5.78)$ \\
\hline 5WR_Proximal $\left(\mathbf{P}_{5 \mathrm{WR}}\right)$ & $165.20(61.2)$ & $38.51(9.86)$ & $268.59(73.3)$ & $59.62(9.94)$ \\
\hline$D_{2 W R}-D_{5 W R}$ & 9966 & 1.0000 & 9621 & .7958 \\
\hline $\mathrm{MS}_{2 \mathrm{WR}}-\mathrm{MS}_{5 \mathrm{WR}}$ & .9976 & 1.0000 & .9976 & .9993 \\
\hline $\mathbf{P}_{2 \mathrm{WR}}-\mathbf{P}_{5 \mathrm{WR}}$ & 1.0000 & 1.0000 & 9607 & 1.0000 \\
\hline
\end{tabular}




\section{DISCUSSION}

The goal of this study was to try to find a correlation between osteocyte apoptosis and the amount of cyclical loading applied, or lack thereof, in order to show that apoptotic osteocytes may be an important signaling factor in the bone remodeling process. For this study, mice were procured and used due to their easy availability, affordability, and size, making them relatively easy to handle. Three mice were cyclically loaded for two weeks and six mice were cyclically loaded for 5 weeks, where the right hindlimb of each mouse was used as a control and the left hindlimb was cyclically loaded. Hindlimbs were used as opposed to forelimbs due to their larger cross sectional area and ability to be cyclically loaded with ease in the loading fixture utilized in this study. After the tibias were resected, processed, and sectioned with a microtome, each section was stained using a TUNEL assay, to detect apoptotic osteocytes, and counterstained with methyl green to detect viable osteocytes. The density of apoptotic osteocytes was measured by region (proximal, midshaft, and distal) and quadrant (cranial, caudal, lateral, and medial) in loaded and unloaded murine cortical bone. The percent of apoptotic osteocytes, density of viable osteocytes and percent of viable osteocytes were also similarly quantified. Statistical analyses were performed on all loaded and unloaded samples independently of each other as well as compared against each other in order to find any statistically significant data. Samples were analyzed by comparing quadrants, averaged across all regions and then isolated to each individual region as well, and then by comparing regions, averaged across all quadrants as well as isolated to each individual quadrant. In this study, it was hypothesized that higher amounts of apoptotic osteocytes would be seen in bones that were cyclically loaded when compared against unloaded bones, with the highest amount seen in the 5 week loaded bones. It was also hypothesized 
that more pronounced regional variation would be seen in the 5 week loaded samples compared to the 2 week loaded samples as a result of the additional loading that they experienced.

Looking, individually, at each type of bone analyzed in this study, 2 week loaded, 2 week unloaded, 5 week loaded and 5 week unloaded, a number of trends and statistically significant information could be seen. As a general trend, 2 week loaded bones had densities and percentages of both viable and apoptotic osteocytes that were much lower in the lateral quadrant and slightly lower in the caudal quadrant, when both were compared to the other two quadrants. This trend was generally strongest in the proximal region for apoptotic osteocytes and strongest in the distal region for viable osteocytes. Similarly, for 2 week unloaded bones, viable and apoptotic osteocytes were much lower in the lateral quadrant and slightly lower in the caudal quadrant, when compared to the other two quadrants, with this trend being the strongest in the proximal region for apoptotic osteocytes and strongest in the midshaft for viable osteocytes. Generally, 5 week loaded bone showed lower viable osteocytes in the lateral quadrant, compared to the other quadrants, with this trend being strongest in the proximal region. Another general trend for 5 week loaded bone was that higher apoptotic and viable osteocytes were seen in the midshafts compared to the other regions, when averaged across all quadrants. No trends and only one statistically significant difference was seen within the 5 week unloaded bone data; when looking only within the medial quadrant, a higher density of viable osteocytes were seen in the midshaft compared to the proximal region. Overall, 5 week loaded samples showed the most variation within themselves with 24 significant $\mathrm{p}$-values found in the analysis. 
Comparing the results from this study to the data presented in a similar previous study, by Jessica Chan, yields some similarities (Chan 2011). No cyclical loading, however, was performed in the latter study and, thus, only data from individual control samples in this study can be compared to the data presented in her study. In both studies, there weren't a lot of statistically significant findings, when looking solely at differences within unloaded bone samples. However, when analyzing samples by quadrant, the current study showed some general trends, with some statistically significant p-values, of lower apoptotic and viable osteocyte values in the lateral and caudal quadrants when compared to the other quadrants. Jessica's research showed a similar trend for the apoptotic and viable osteocyte densities, although no statistically significant p-values were found to support this trend in her study. Only a few statistically significant differences were found in Jessica's study; midshafts were shown to have higher viable and apoptotic osteocytes when compared to the other regions. In the current study, although not seen in 2 week samples, this trend was similarly observed within the 5 week loaded and unloaded samples, with statistically significant p-values only seen in the 5 week loaded samples. Differences observed between the samples used in this study and the samples from Jessica's study may be due to the fact that a lower quantity of mice that were younger in age, and possibly skeletal maturity, were used in the study performed by her. Overall, given that the samples analyzed in Jessica's study only yielded some statistically significant p-values when looking at the midshafts, and nowhere else, the most prevalent trend between samples used in both studies is the general lack of statistically significant findings seen for unloaded bone samples. This should then 
provide some evidence that the control samples in this study and the samples used in Jessica's study are relatively similar (Chan 2011).

In order to shed more light on the role of apoptotic osteocytes in the remodeling process, statistical analyses comparing each type of sample, loaded and unloaded, to one another is necessary. The first comparison analyzed in this study was 2 week loaded samples against 2 week unloaded control samples. When comparing 2 week loaded bones samples against 2 week unloaded control samples, only one statistically significant difference was found; the percentage of apoptotic osteocytes in 2 week loaded samples was shown to be higher than the 2 week unloaded bones when analyzed within the medial quadrant of the proximal region. Overall, the 2 week loaded samples showed little statistically significant differences to the unloaded samples. However, 2 week loaded bones showed a trend of slightly more apoptotic osteocytes and less viable osteocytes than 2 week control samples, even though there weren't any statistically significant pvalues to support this trend. This could be because 2 weeks is only enough time to reach the start of the remodeling process. A study by Noble et al. showed that load induced DNA damage is followed by cellular apoptosis process within 2 weeks of initial damage stimulus (Noble, et al. 2003). In the study, at 14 days after loading, less cells with DNA fragmentation and less viable cells were observed as well as the first signs of Haversion remodeling (Noble, et al. 2003). This observation from Noble's study could explain the general trend of slightly more apoptotic osteocytes, less viable osteocytes and overall lack of statistically significant differences seen in this study's samples loaded for 2 weeks, when compared to the controls. 5 week unloaded and 2 week unloaded samples were also compared against one another. As expected, the 2 week unloaded and 5 week 
unloaded samples showed no statistically significant differences when compared against each other. Given that the samples cyclically loaded for the most amount of time were expected to show the most differences when compared against unloaded samples, 5 week loaded samples were compared against both 5 week unloaded and 2 week loaded samples.

As previously mentioned before, no significant differences were found between 2 week loaded samples and 2 week unloaded samples nor between 2 week unloaded samples and 5 week unloaded samples. It makes sense, then, that comparing 5 week loaded samples against both 5 week unloaded samples and 2 week loaded samples yielded many similarities. Except for two statistically insignificant p-values when compared with 2 week loaded samples, all locations within 5 week loaded samples showed significantly higher percentages of apoptotic osteocytes than those of both the 5 week unloaded samples and the 2 week loaded samples, when averaged across all regions, averaged across all quadrants and when isolated to each individual region or quadrant. Including p-values of .0565 or less, 5 week loaded samples showed statistically higher densities of apoptotic osteocytes than 5 week unloaded control samples for each quadrant, when averaged across all regions, and for each region, when averaged across all quadrants and when looking at the cranial and caudal quadrants individually. For 2 week loaded versus 5 week loaded samples, all 5 week loaded quadrants, except the cranial quadrant, showed higher densities of apoptotic osteocytes, when averaged across all regions. Also, densities of apoptotic osteocytes were higher in 5 week loaded midshafts, when averaged across all quadrants and when analyzed in the caudal or lateral quadrants individually. The percentage of viable osteocytes in 5 week loaded bones was 
significantly higher than in 2 week loaded bones for all quadrants, when averaged across all regions, and in all regions, when averaged across all quadrants.

Fitting with this study's hypothesis, 5 week loaded samples showed the biggest differences when compared with all other samples, especially in terms of the density and percentage of apoptotic osteocytes present. Statistically significant values, indicating that each quadrant and region in 5 week loaded samples had a higher percentage of apoptotic osteocytes than any other sample group, provides strong evidence in support of increased apoptosis and regional variations in samples that are cyclically loaded. 5 week loaded samples also showed an increase in the density of apoptotic osteocytes, but not to the same magnitude that the percent of apoptotic osteocytes data showed. There were also many statistically significant regions and quadrants showing increased viable osteocytes in 5 week loaded samples compared to 2 week loaded samples. This difference was not also observed between 5 week loaded samples and the controls because the difference appears to be due to the specific time points in which the two difference loading groups were loaded and subsequently sacrificed. As previously discussed, the 2 week loaded samples may have shown slightly more apoptotic osteocytes and less viable osteocytes than 2 week unloaded samples because, as described by Noble, samples exhibited less apoptotic and viable osteocytes as well as the first signs of remodeling at 14 days after the initial damage stimulus from loading. In the same study by Noble et al., at 7 days after loading, more osteocytes with DNA fragmentation and similar viable osteocytes, when compared to the control samples, were seen (Noble, et al. 2003). These two observations, from Noble's study, help shed light on why statistically significant differences in the amount of viable osteocytes were only observed between 5 week and 2 
week loaded samples. All of these previously discussed trends involving the 5 week loaded samples, showing increased values apoptotic and viable osteocyte values in these samples, are further strengthened by the fact that no significant trends were observed when comparing the 2 week unloaded samples against both the 2 week loaded and 5 week unloaded samples, thus agreeing with the rationalizations given in this discussion as well as the observations presented here from other studies; only 5 week loaded samples, in this study, showed multiple statistically significant differences to other samples.

The results from this study were focused on quantifying variations in the amount of apoptotic osteocytes present in loaded mice hindlimbs, unloaded mice hindlimbs and any differences there may be between the two, in an attempt to better explain the mechanisms and factors in which bone remodeling is initiated. Bones repair and replace themselves in response to the specific mechanical loads that they experience throughout each region (Noble, et al. 2003). How bones specifically use this information has been a question that has attempted to be answered by various theories, one of which involves naming apoptotic osteocytes as the signaling mechanism in which osteoblasts and osteoclasts are targeted, as necessary. The data from this study did in fact support the hypothesis that osteocyte apoptosis was increased and regional variations were enhanced due to cyclical loading applied to murine tibias. Other research has similarly made observations about bone remodeling and osteocyte apoptosis. One study, by Noble et al., demonstrated a U-shaped correlation with osteocyte apoptosis and bone loading, with disuse and fatigue loading microdamage showing increased apoptosis (Noble, et al. 2003). A study by Verborgt et al. showed that microdamage caused by fatigue loading showed increased levels of apoptotic osteocytes, especially concentrated around the 
regions with microdamage or resorption (Verborgt, et al. 2000). Another study, by Cardoso et al., showed similar results indicating how apoptotic osteocytes are temporally and spatially linked to fatigue induced microdamage and the intracortical bone remodeling that follows (Cardoso, et al. 2009). A study by Hedgecock et al. showed a strong correlation between apoptotic osteocytes and remodeling parameters (Hedgecock, et al. 2007). In the same study, the researchers stated that their approximation of viable osteocytes showed no linear correlation with any of the remodeling or modeling factors studied (Hedgecock, et al. 2007). Although there is still much information lacking, especially in terms of the specific cellular interactions and communication networks at play from the beginning initiation of the remodeling process to the end of it, it is the hope of this study that the data analyzed and discussed within joins the previously mentioned studies in providing evidence in support of the role that apoptotic osteocytes must play in the remodeling process.

\subsection{Limitations}

Despite being a continuation of a previous study (Chan 2011), there are many limitations to the current study. Firstly, efforts were put forth to maintain all mice under the same day to day conditions by giving them similar living, dietary and loading conditions. However, as the mice were allowed to move around day to day, when not being loaded, there may have been some differences in the amount of exercise that each mouse received. Secondly, even though care was taken to ensure consistency from sample to sample when taking cross-sectional slices from the distal, midshaft and proximal regions of each sample, the location within each region that sample was taken from may have been different from subject to subject, which may cause unwanted 
differences when analyzing the data. In regards to the TUNEL and methyl green staining, best efforts were put forth to use the same staining procedure with all samples for equivalency, however, some samples showed clearer color, indicating that the staining in some samples may have been better than others; TUNEL staining may also be subject to false staining which may have affected some of the counted data. In order to perform the TUNEL and methyl green staining, two adjacent samples were cut and the TUNEL stain was applied to one sample while the methyl green was applied to the other. Although this eliminated some of the problems encountered with co-staining, the two adjacent samples used may not have been entirely similar, which could have caused more unwanted differences or discrepancies in the data analysis. Also, by not co-staining the two methods together, the TUNEL stain may have incorrectly stained non-apoptotic osteocytes that contain DNA breaks, which was not accounted for in this study (Hedgecock, et al. 2007). When counting the amount of apoptotic and viable osteocytes present in each sample, there may have been some error in the actual values counted as this was done one by one by a single person, which leaves room for potential error.

\subsection{Applications and Future Work}

Experiments such as the current study provide more information surrounding apoptotic osteocytes and their role in the bone remodeling process. The results from this study give support to the idea that apoptotic osteocytes play an important role in bone remodeling and give data showing differences between unloaded and loaded bones in terms of apoptotic osteocytes. Future work should be performed to further look at the effects that apoptotic osteocytes have on neighboring cells and communication networks. This may include looking deeper into any signaling, an example being osteoclastogenic 
signaling, that may be occurring between other neighboring osteocytes, both apoptotic and non-apoptotic, as well as any spatial or temporal patterns between the cells present while various types of remodeling communication is occurring.

\subsection{Conclusion}

This study set out to demonstrate regional and quadrant differences, namely increases in the number of apoptotic and viable osteocytes, in cyclically loaded murine tibiae when compared with unloaded bones in attempt to provide evidence in support of apoptotic osteocytes playing a role in the remodeling process. The results of this study showed increased apoptotic osteocytes, both in percentage and density, for the 5 week loaded samples when compared against the unloaded controls as well as the 2 week loaded bones. An increased percentage of viable osteocytes was also observed in the 5 week loaded bones when compared with the 2 week loaded samples. Individually, 5 week loaded samples also showed the most enhanced regional variation. Overall, 5 week samples showed an increase in apoptotic osteocytes as well as the most regional and quadrantal variation when compared against all other samples, thus, supporting our initial hypothesis and providing evidence in support of apoptotic osteocytes playing a role in the remodeling process. Further research that delves into the specific mechanisms of how apoptotic osteocytes help initialize bone remodeling as well as other potential localized interactions or communication that apoptotic osteocytes provide will further our understanding of the human body and the bone remodeling process. 


\section{REFERENCES}

Aarden, E. M., et al. (1994). "Function of osteocytes in bone." Journal of Cellular Biochemistry, 55(3): 287-299.

Bakker, A. D., et al. (2001). "The production of nitric oxide and prostaglandin $\mathrm{E}(2)$ by primary bone cells is shear stress dependent." J Biomech 34(5): 671-7.

Bell, L. S., et al. (2008). "The mineralized osteocyte: A living fossil." Am. J. Phys. Anthropol. 137(4): 449-456.

Bentolila, V., et al. (1998). "Intracortical remodeling in adult rat long bones after fatigue loading." Bone 23(3): 275-81.

Bilezikian, J. P., et al. (2008). Principles of Bone Biology. San Diego, Elsevier Inc.

Bonewald, L. F. (2006). "Mechanosensation and Transduction in Osteocytes." Bonekey Osteovision 3(10): 7-15.

Bronckers, A. L., et al. (1996). "DNA fragmentation during bone formation in neonatal rodents assessed by transferase-mediated end labeling." J Bone Miner Res 11(9): 1281-91.

Burr, D. B., et al. (1985). "Bone remodeling in response to in vivo fatigue microdamage." J Biomech 18(3): 189-200.

Cardoso, L., et al. (2009). "Osteocyte apoptosis controls activation of intracortical resorption in response to bone fatigue." J Bone Miner Res 24(4): 597-605.

Gewies, A. (2003). "Introduction to Apoptosis." 2014 (October 10).

Chan, J. (2011). A Study of Osteoycte Apoptosis by Region and Quadrant in Murine Cortical Bone. Biomedical Engineering. San Luis Obispo, California Polytechnic State University. Masters: 455.

Hedgecock, N. L., et al. (2007). "Quantitative regional associations between remodeling, modeling, and osteocyte apoptosis and density in rabbit tibial midshafts." Bone 40(3): 627-37.

Henriksen, K., et al. (2009). "Local communication on and within bone controls bone remodeling." Bone, 44(6): 1026-1033.

Hill, P. A. (1998). "Bone remodelling." Br J Orthod 25(2): 101-7.

Hock, J. M., et al. (2001). "Osteoblast apoptosis and bone turnover." J Bone Miner Res 16(6): $975-84$. 
International Osteoporosis Foundation. (2011). "Basic Bone Biology." Retrieved July 23, 2011, from http://www.iofbonehealth.org/health-professionals/aboutosteoporosis/basic-bone-biology.html

Jilka, R. L., et al. (2007). "Quantifying osteoblast and osteocyte apoptosis: challenges and rewards." J Bone Miner Res 22(10): 1492-501.

Klein-Nulend, J., et al. (1995). "Pulsating fluid flow increases nitric oxide (NO) synthesis by osteocytes but not periosteal fibroblasts--correlation with prostaglandin upregulation." Biochem Biophys Res Commun 217(2): 640-8.

Lanyon, L. E. (1993). "Osteocytes, strain detection, bone modeling and remodeling." Calcif Tissue Int 53 Suppl 1: S102-6; discussion S106-7.

Li, Gang, et al. (2003). "Rapid new bone tissue remodeling during distraction osteogenesis is associated with apoptosis." Journal of Orthopaedic Research 21(1): 28-35.

Marieb, E. N. (2005). Anatomy \& Physiology. San Francisco, Pearson Education.

Martin, R. B., et al. (1998). Skeletal Tissue Mechanics. New York, Springer-Verlag.

Mosley J. R., et al. (1997). "Strain magnitude related changes in whole bone architecture in growing rats." Bone 20(3):191-198

Noble, B. (2008). "The osteocyte lineage." Arch Biochem Biophys 473(2):106-111.

Noble, B. (2003). "Bone microdamage and cell apoptosis." Eur Cell Mater 6: 46-55; discusssion 55.

Noble, B. S., et al. (2003). "Mechanical loading: biphasic osteocyte survival and targeting of osteoclasts for bone destruction in rat cortical bone." Am J Physiol Cell Physiol 284(4): C934-43.

Noble, B. S., et al. (1997). "Identification of apoptotic changes in osteocytes in normal and pathological human bone." Bone 20(3): 273-82.

Power, J., et al. (2002). "Osteocyte density in aging subjects is enhanced in bone adjacent to remodeling haversian systems." Bone 30(6): 859-865

Robling, A. G., et al. (2006). "Biomechanical and molecular regulation of bone remodeling." Annu Rev Biomed Eng 8: 455-98.

Somerville, J. M., et al. (2004). "Growth of C57B1/6 Mice and the Material and Mechanical Properties of Cortical Bone from the Tibia." Calcified Tissue International 74(5): 469-475. 
Skerry, T. M., et al. (1989). "Early strain-related changes in enzyme activity in osteocytes following bone loading in vivo." J Bone Miner Res 4(5): 783-8.

Verborgt, O., et al. (2000). "Loss of osteocyte integrity in association with microdamage and bone remodeling after fatigue in vivo." J Bone Miner Res 15(1): 60-7. 


\section{APPENDICES}

Appendix A

Mice Loading Protocol

Equipment needed:

Bose Enduratec 3220

Load cell

Wintest PCI control system

Enduratec signal box

Mouse fixture with weights

Surgical tape

Q-tips

\section{Procedure:}

1) Turn on the Enduratec signal box, Wintest PCI control system and the computer.

2) Open the program: WinTest

3) File $\rightarrow$ Open Project $\rightarrow$ 05-177 Cal poly pchang test.prj

4) Setup $\rightarrow$ Limits $\rightarrow$ Display check limits (ensure that fixture will not hit bottom of the plunger)

\begin{tabular}{|c|c|c|c|c|c|c|c|}
\hline \multicolumn{8}{|c|}{ imits for all Channels } \\
\hline Channel & Minimum & Maximum & Time & Action & & Group & \\
\hline Disp & 2.500 & 6.000 & 0.0002 & Abort & 7 & Group 1 & . \\
\hline Load & -200.00 & 200.00 & 0.0002 & Abort & $=$ & Group 1 & $=$ \\
\hline Ch 3 & 8.00 & 5.00 & 0.0002 & Abort & $=$ & All & \pm \\
\hline Ch 4 & -10.00 & 10.00 & 0.0002 & Undefined & 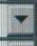 & All & \pm \\
\hline Null & -10.00 & 10.00 & 0.0002 & Undefined & \pm & Group 1 & \pm \\
\hline UserCalc & -10.00 & 10.00 & 0.0002 & Undefined & & All & \pm \\
\hline Axial cmd & -44.00 & 44.00 & 0.0002 & Undefined & \pm & Group 1 & \pm \\
\hline Axial err & -100.00 & 100.00 & 0.0002 & Undefined & $I$ & Group 1 & \pm \\
\hline OK & Cancel & \multicolumn{6}{|c|}{ ॠ Include Mover Count } \\
\hline
\end{tabular}


5) Setup $\rightarrow$ Channels $\rightarrow$ Autotare

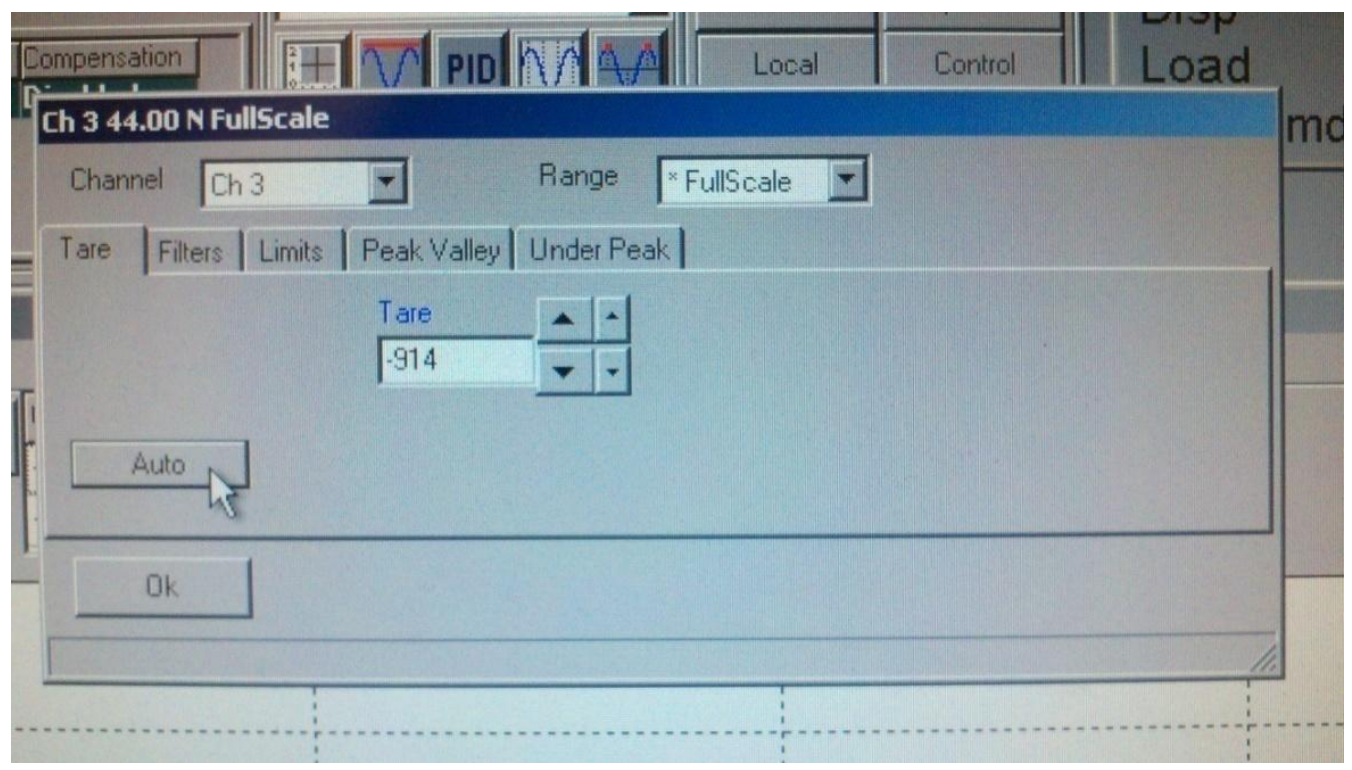

6) Feedback $\rightarrow$ Set axial feedback to displacement

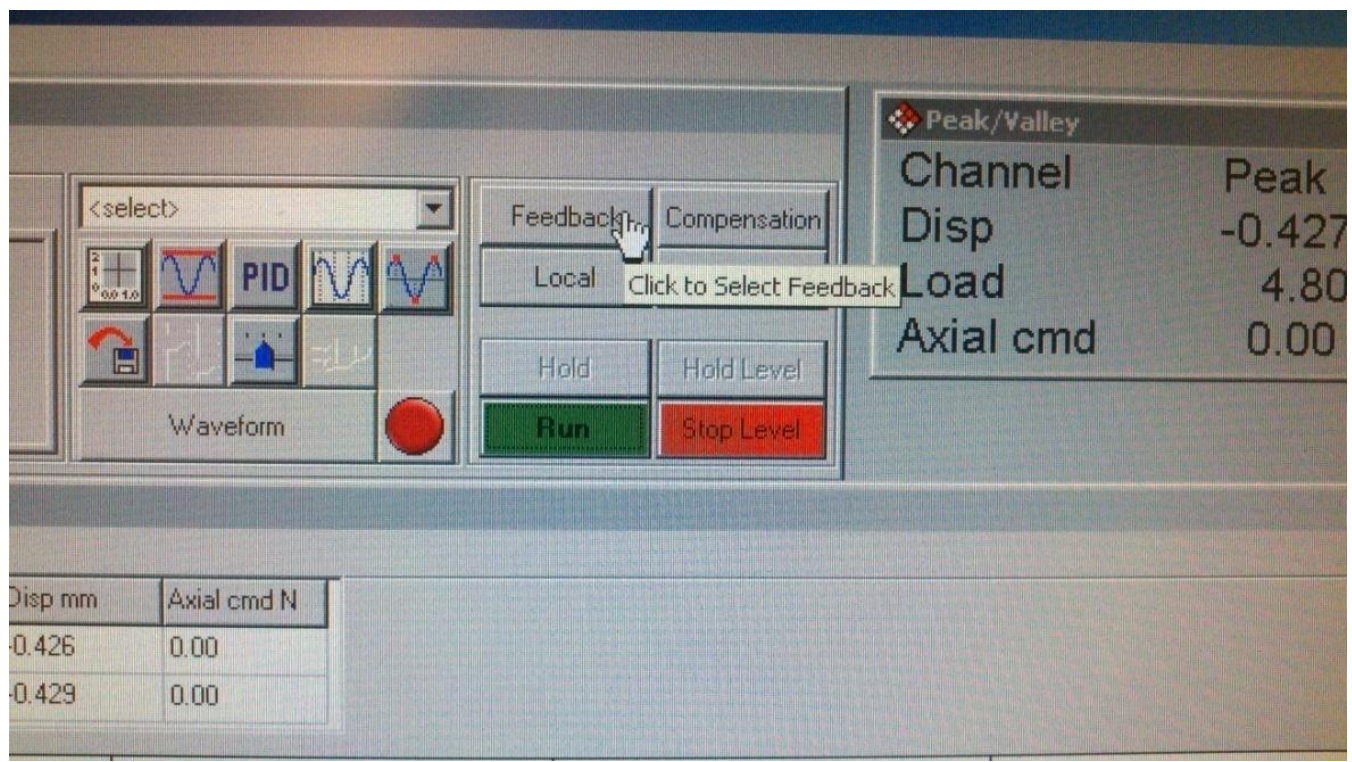




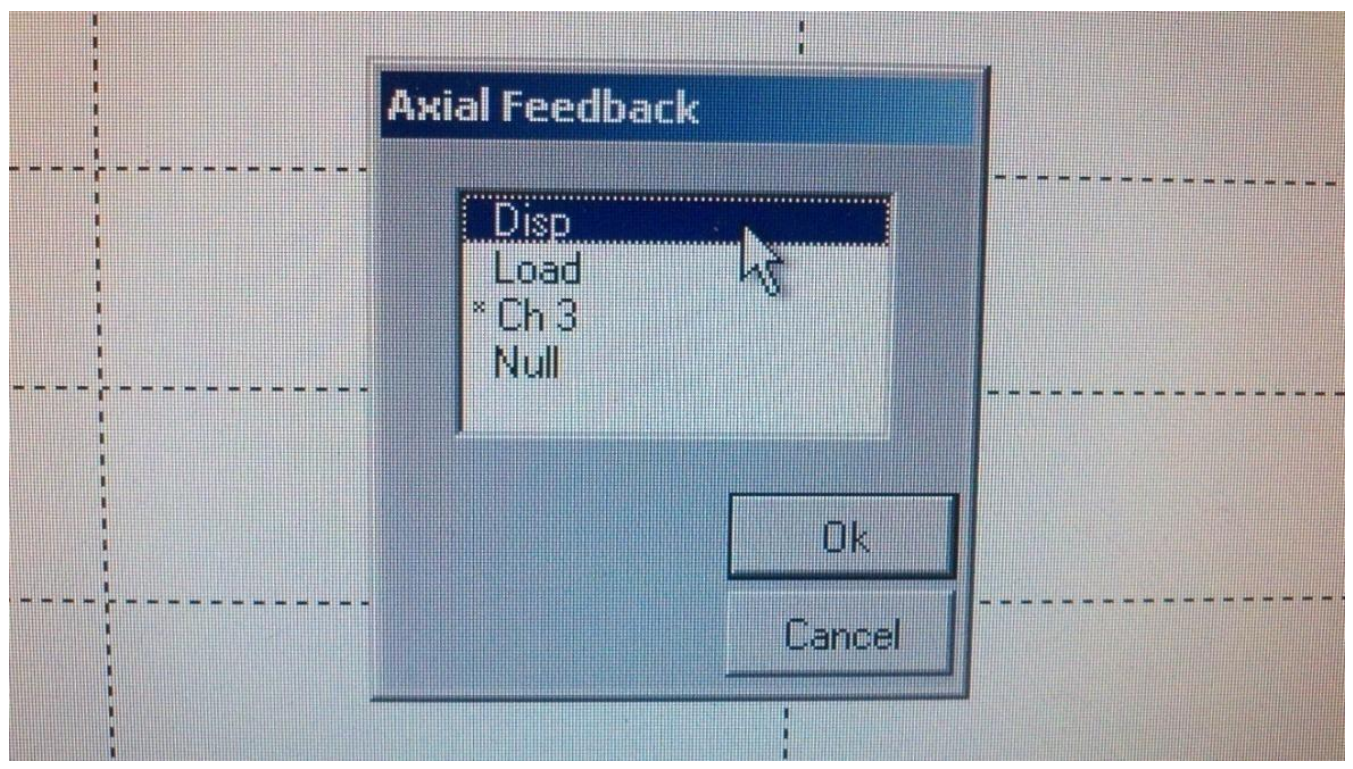

7) Local $\rightarrow$ High (means displacement can be adjusted live)

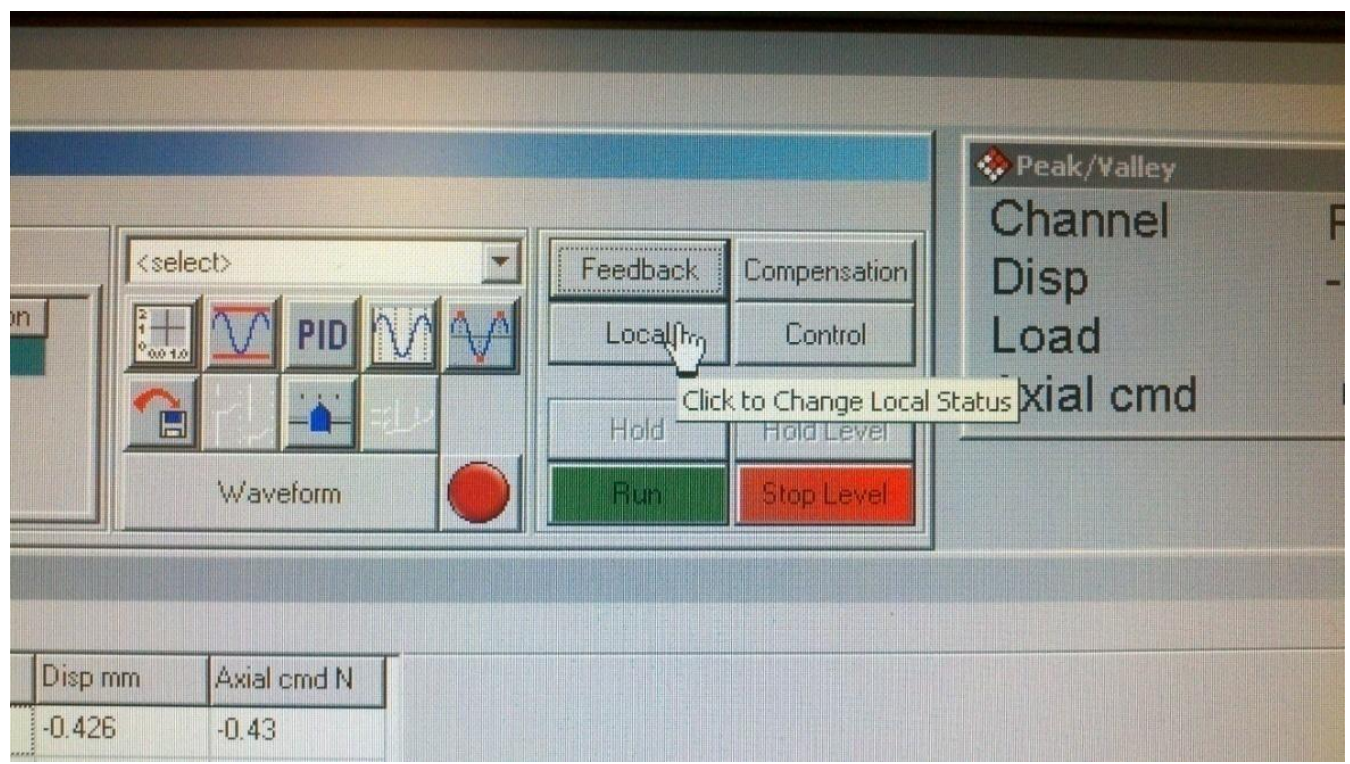




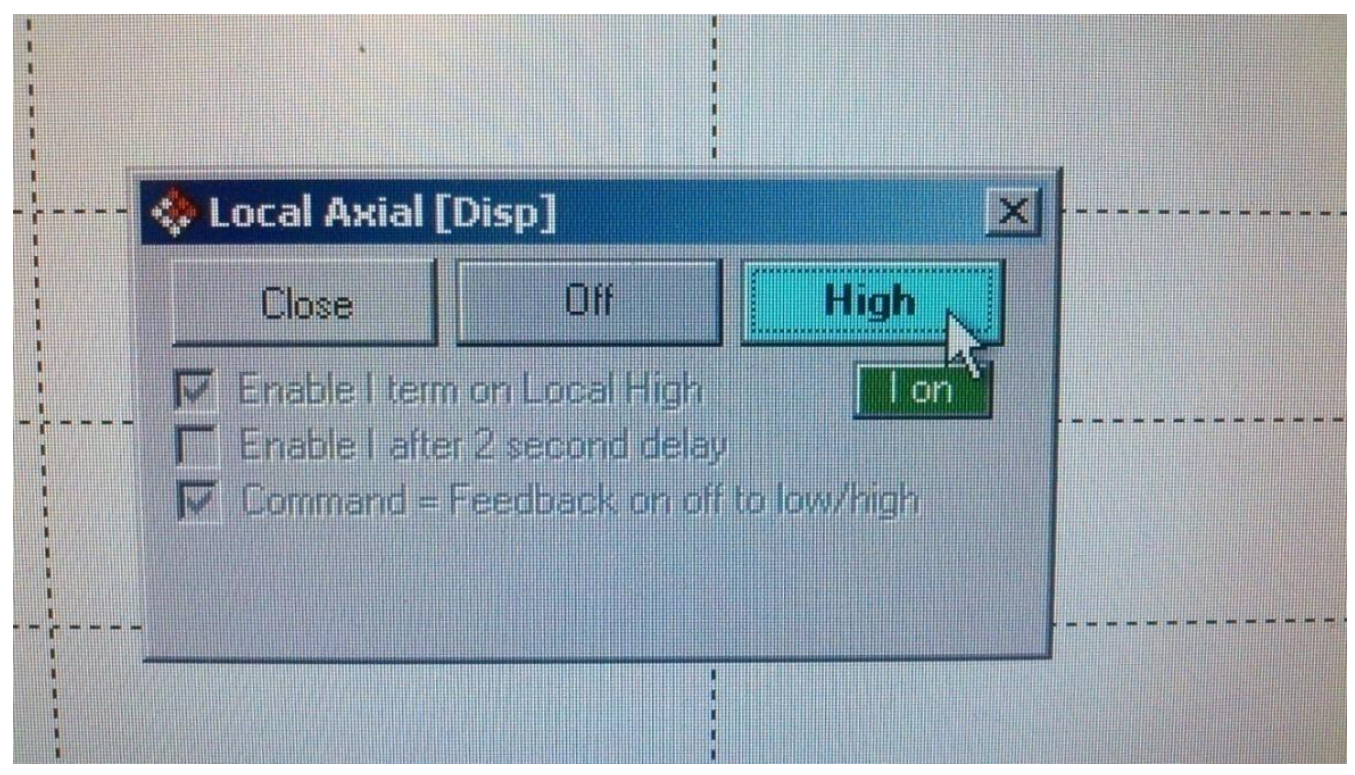

8) Click position button $\rightarrow$ raise so that the mouse can fit underneath the plunger

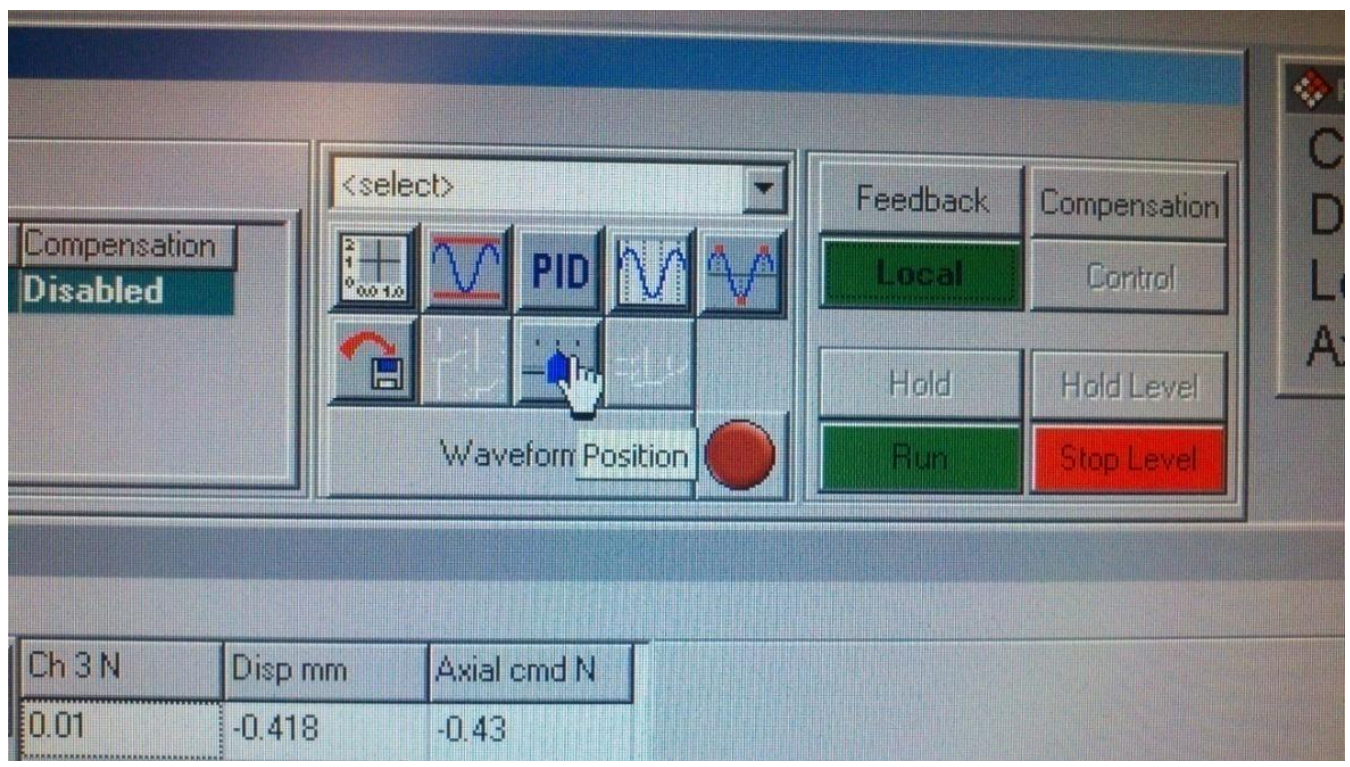




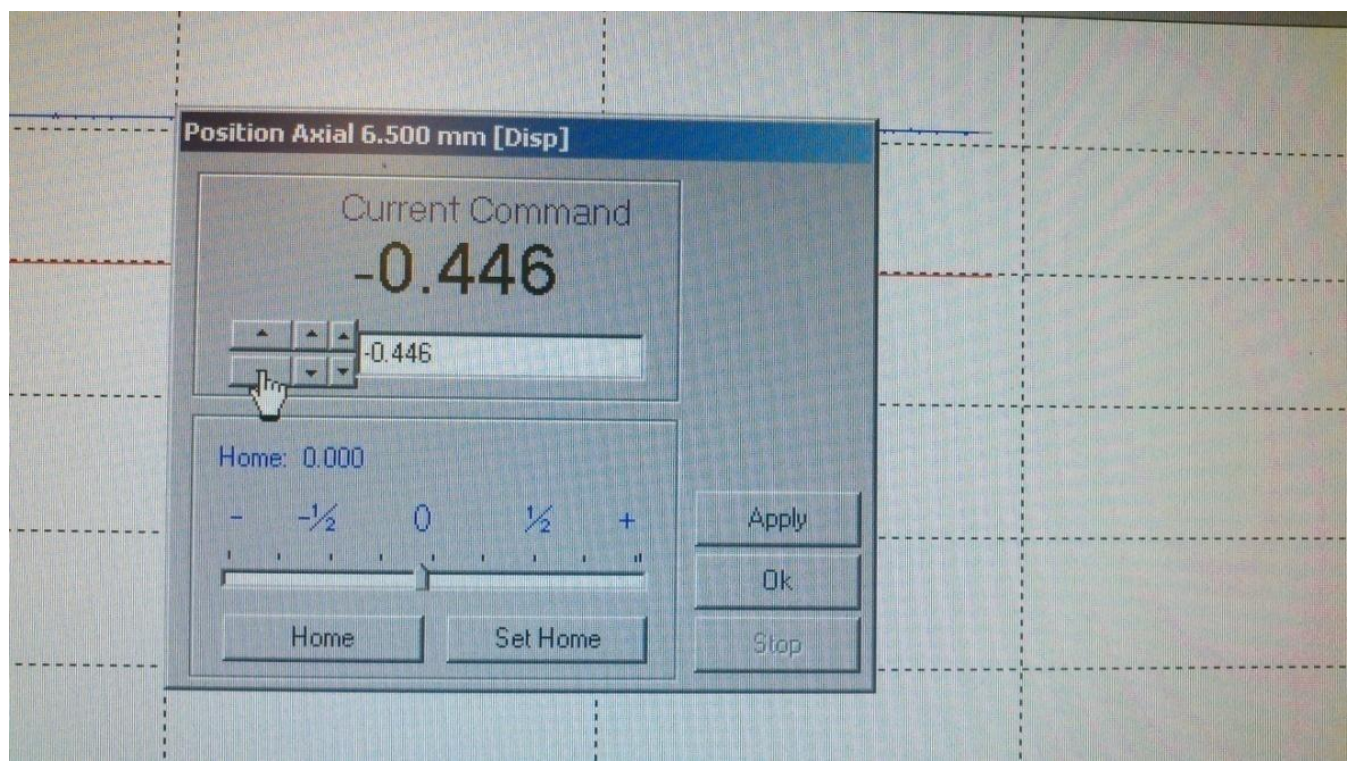

9) Ensure that nose cone is fasten securely with the chemistry stand and that it is not touching the fixture. Chemistry stand should be secured to the table with C-clamps. 10) Set up the isoflurane anesthesia machine so that it is connected to the anesthesia chamber but readily available to be connected to the nose cone tubing.

11) In the chamber, $4.5 \%$ isoflurane should be release at $3 \mathrm{~L} / \mathrm{min}$.

12) Place a piece of surgical tape on the forelimbs of the mouse.

13) Once anesthetized in the chamber, the chamber tubing should be switched with the nose cone tubing and the anesthesia machine should be set to $2 \%$ isoflurane at $1 \mathrm{~L} / \mathrm{min}$. 14) The mouse is then placed on top of the ramp fixture.

15) Ensure that the nose of the mouse is secured in the nose cone (use the pieces of the tape on the forelimbs to help secure the nose location).

16) Put left heel of the mouse into the groove on the ramp fixture. Use a piece of surgical tape to secure the foot down. 
17) Lower the plunger position slowly until a force of $-0.04 \mathrm{~N}$ is achieved. Use the q-tip to push the top of the femur so that the knee joint is fully constrained by the plunger cup indentation.

18) Click waveform $\rightarrow$ block signal tab $\rightarrow$ peak/valley $\rightarrow$ browse $\rightarrow$ name the file.
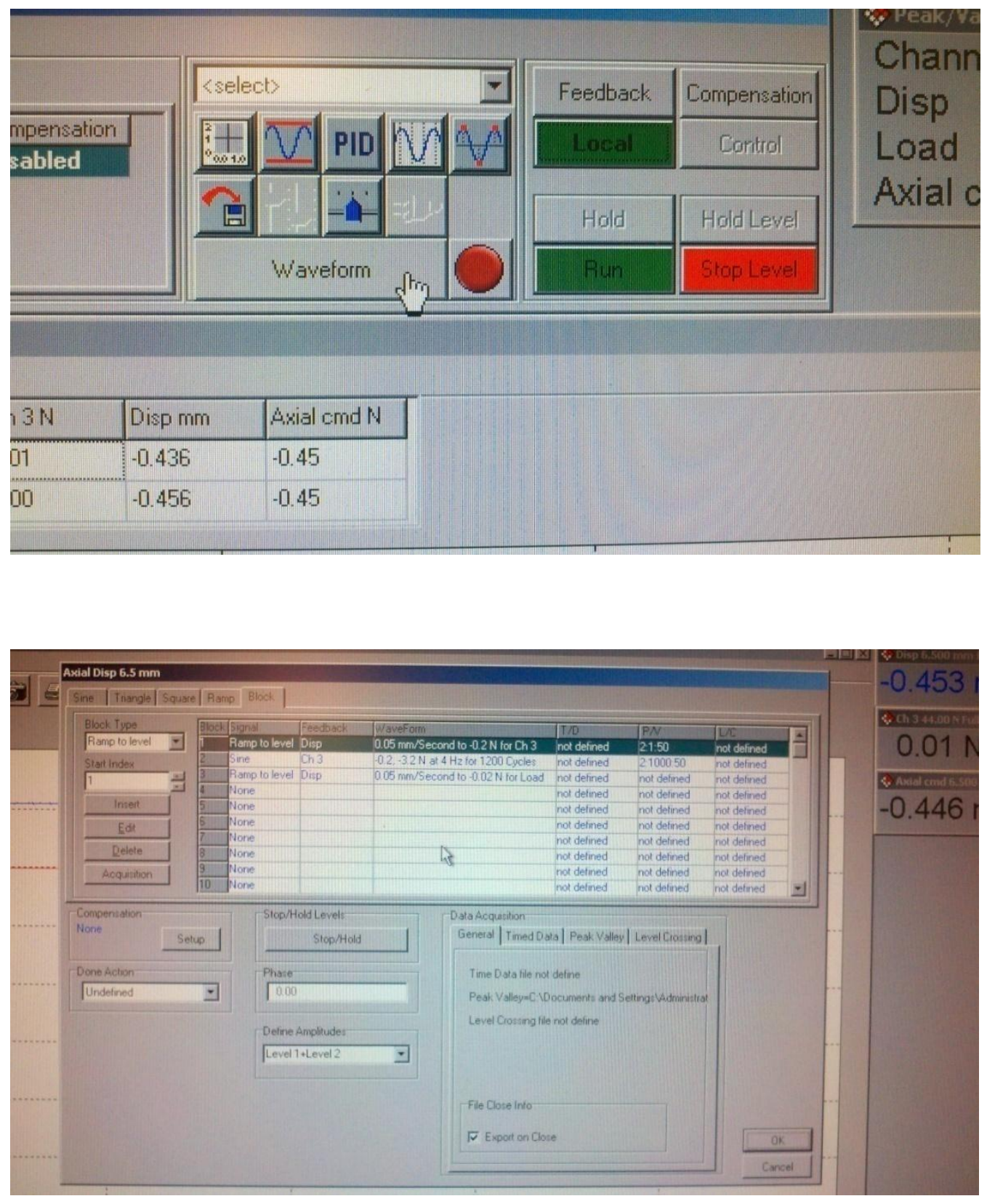
19) Click the scope for group 1 eraser icon

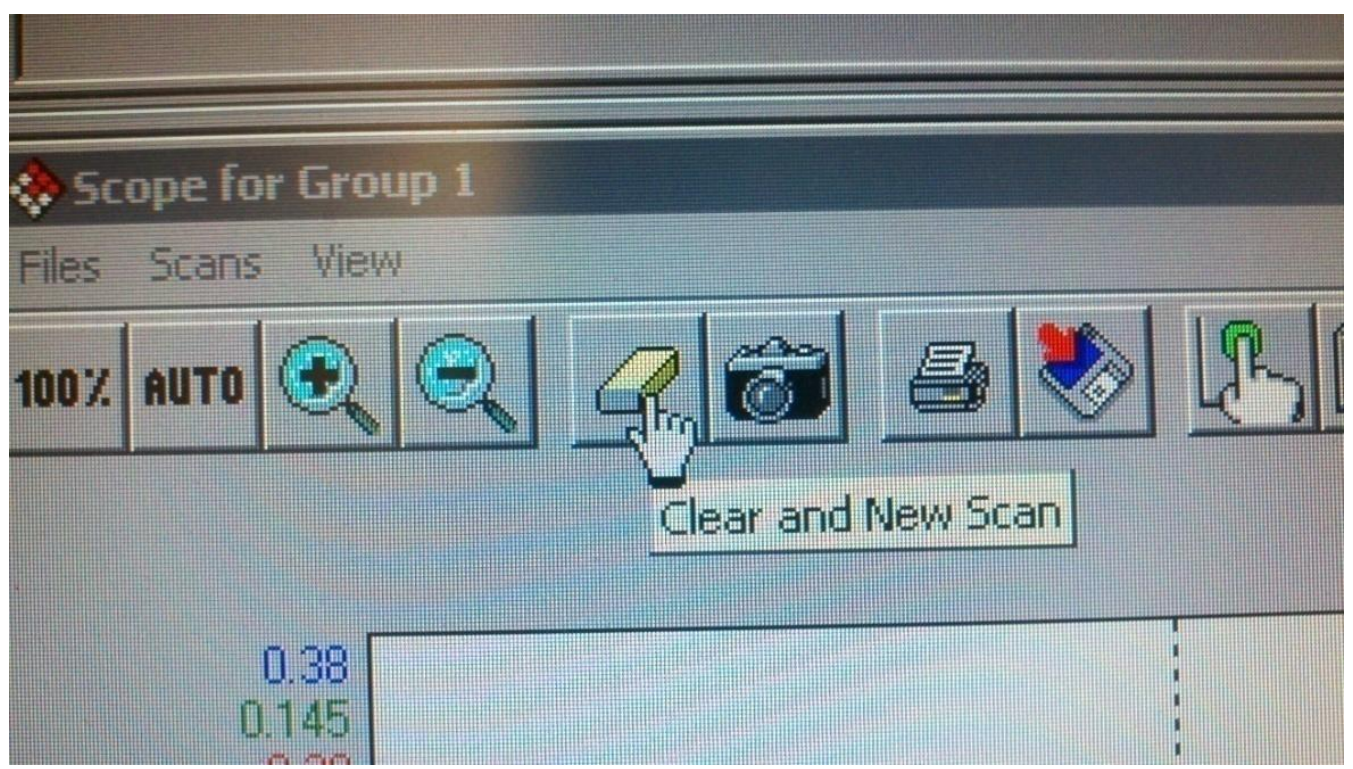

20) Hit the disk icon $\rightarrow$ save scope $\rightarrow$ export file (turns yellow)

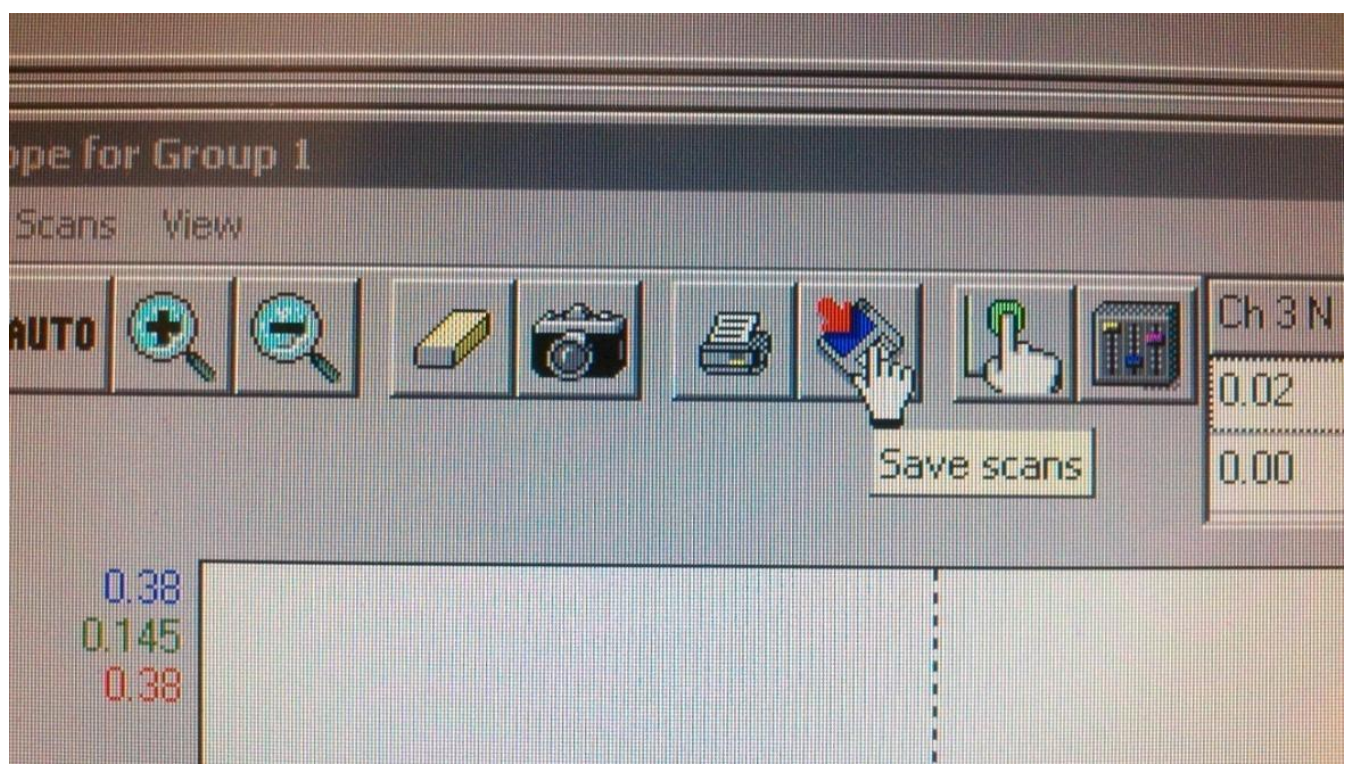


21) Click on run $\rightarrow$ zero start
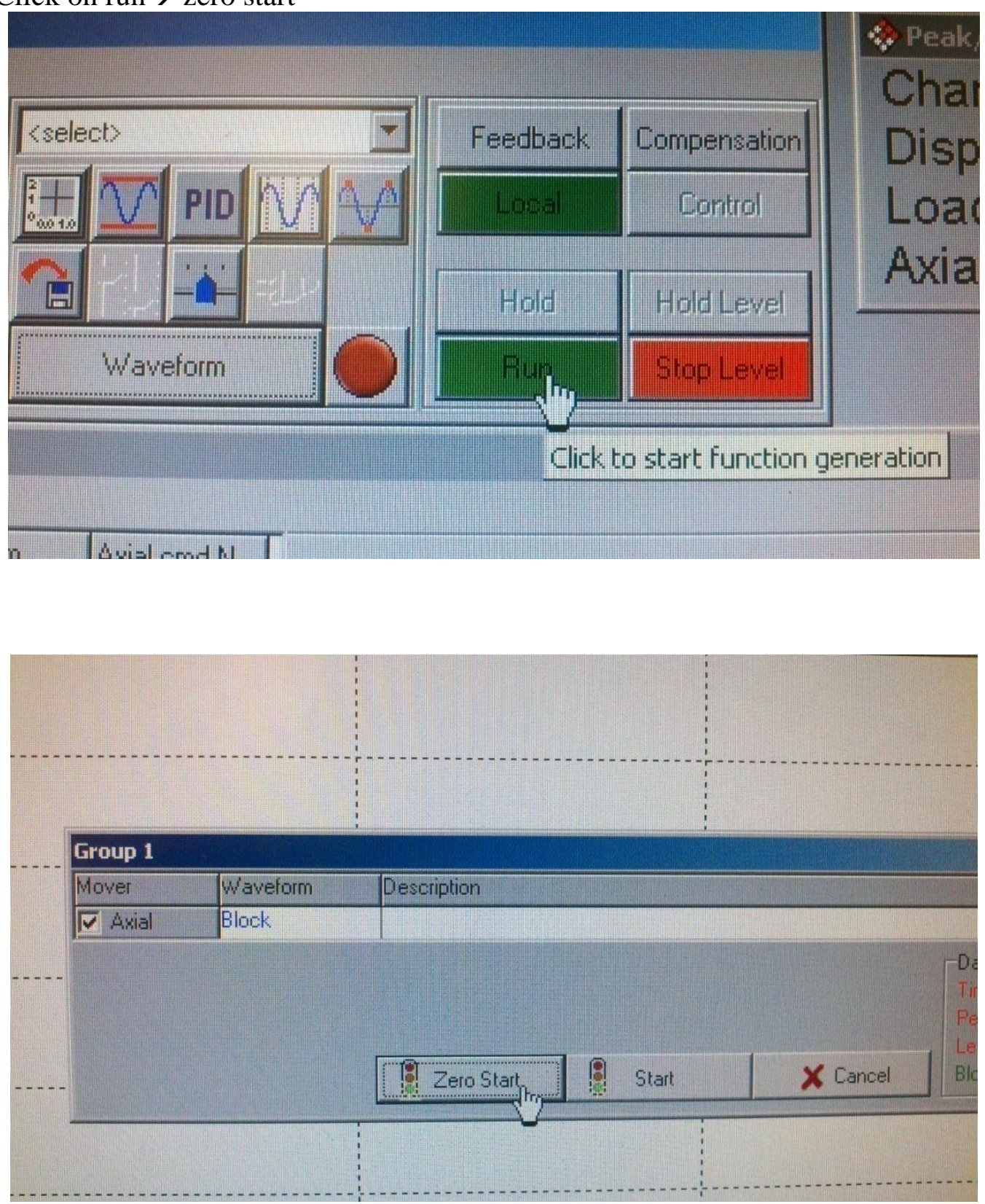

22) Once it finishes, click the disk icon again and name the file.

23) Click the position icon $\rightarrow$ raise the plunger until the mouse 


\section{Appendix B}

\section{Microtome Protocol}

1) Put paraffin embed sample block(s) in the refrigerator for at least 30 minutes.

2) Wash hands and water bath with soap (try not to get the front of the water bath wet).

3) Dry with paper towels.

4) Put gloves on.

5) Fill water bath with distilled water.

6) Write name in the logbook.

7) Use the lever to secure wax block in the holding mechanism.

8) Insert the blade into the designated slot and lightly tighten until secure.

9) Release the handle lock on the right side of the microtome.

10) Push the base, holding the blade, up to the tissue block and lock in place.

11) Set the microtome to $20 \mu \mathrm{m}$ and face the block a few times to take off the top layers of wax and reveal the bone.

12) Set the microtome to $7 \mu \mathrm{m}$ and cut sections as needed.

13) Use the tweezers to carefully carry and place the sections in the water bath

14) Use blunt dissection cuts to separate individual sections so they fit on a microscope slide.

15) Angle the microscope slide into the water below the sections and raise it slowly to the surface ensuring that the section gets carefully placed onto the microscope (be sure that the microscope slide is oriented properly so that it can still be written on and labeled). 


\section{Appendix C}

TUNEL and Methyl Green Staining Procedures

\section{TUNEL Staining Procedure}

1. Deparaffinize the tissue sections

Immerse the slides in xylene for 5 minutes

2. Immerse in $100 \%$ ethanol for 8 minutes (wash)

3. Rehydrate through graded ethanol washes

$95 \%$ ethanol for 3 minutes

$85 \%$ ethanol for 3 minutes

$70 \%$ ethanol for 3 minutes

$50 \%$ ethanol for 3 minutes

4. Air dry for 20 minutes

5. Immerse in PBS for 5 minutes (wash)

6. Immerse in HistoChoice for 15 minutes (fix)

7. Immerse in PBS for 10 minutes (wash)

8. Remove liquid from tissue and place slides on a flat surface

Prepare a $20 \mu \mathrm{g} / \mathrm{ml}$ proteinase k solution:

1 part $10 \mathrm{mg} / \mathrm{ml}$ proteinase $\mathrm{k}$ stock solution (see Appendix for procedure)

to

499 parts PBS

Add $100 \mu \mathrm{L}$ of the proteinase k solution to each slide to cover the tissue section

Incubate slides for $\underline{10}$ to 30 minutes (set out to dry)

Use shorter incubation times because of the thinner sections. 
9. Immerse in PBS for 5 minutes (wash)

10. Immerse in HistoChoice for 5 minutes (refix)

11. Immerse in PBS for 5 minutes (wash)

For positive control: treat sample with DNase I $\rightarrow$ causes DNA fragmentation

12. Tap the slides to remove excess liquid (use Kimwipes)

Cover the cells with $100 \mu \mathrm{L}$ of equilibration buffer

Equilibrate for 5 to $\underline{10}$ minutes

13. Thaw biotinylated nucleotide mixture on ice

Prepare rTdT reaction mixture, keep on ice

$100 \mu \mathrm{L}$ of the reaction mixture per slide will be enough to cover the section

For positive control:

Combine: $\quad 98 \mu \mathrm{L}$ of equilibration buffer

$1 \mu \mathrm{L}$ of biotinylated nucleotide mixture

$1 \mu \mathrm{L}$ of rTdT

14. Blot around equilibrated areas with tissue paper

Add $100 \mu \mathrm{L}$ of the rTdT reaction mixture to the sections on each slide

Do not allow the sections to dry out

15. Cover the sections with plastic coverslips to evenly distribute the reagent

Incubate at 37 degrees $\mathbf{C}$ for 60 minutes inside of a humidified chamber (wet paper towel over dish)

This step allows the end-labeling reaction to occur 
16. Dilute: 1 part 20x SSC solution

to

10 parts deionized water

Remove coverslips

Immerse in the $2 x$ SSC solution for 15 minutes

This step terminates the end-labeling reaction

17. Immerse in fresh PBS for 15 minutes (wash)

This step removes unincorporated biotinylated nucleotides

18. Dilute: 1 part $3 \%$ hydrogen peroxide

to

10 parts PBS

Immerse in the $0.3 \%$ hydrogen peroxide solution for $\mathbf{3}$ to $\underline{\mathbf{5}}$ minutes

Do not use the 20x hydrogen peroxide

This step blocks endogenous peroxidases

19. Immerse in PBS for $\mathbf{1 5}$ minutes (wash)

20. Dilute streptavidin HRP solution 1:500 in PBS

Add $100 \mu \mathrm{L}$ to each slide

Incubate for $\mathbf{3 0}$ minutes (set out to air dry)

21. Immerse in PBS for 15 minutes (wash) 
22. Combine DAB components right before use

Add $50 \mu \mathrm{L}$ of DAB substrate 20x buffer to $950 \mu \mathrm{L}$ of deionized water

Add $50 \mu \mathrm{L}$ of DAB chromagen and $50 \mu \mathrm{L}$ of hydrogen peroxide $20 x$

Add $100 \mu \mathrm{L}$ of this DAB mixture to each slide and develop until there is a light

brown background, approximately 20 minutes

Keep DAB components and mixture away from light and use mixture within 30 minutes

23. Rinse several times in deionized water

24. Mount slides with permount

\section{Methyl Green Staining Procedure}

1. Do steps 1 through 4 of TUNEL procedure

To do simultaneously with the TUNEL procedure, offset the Methyl Green slides by 8 minutes behind.

2. Immerse in deionized water for 5 minutes

3. Immerse in $2 \%$ Methyl Green for 45 seconds

4. Rinse in distilled water

5. Rinse in deionized water

6. Mount slides with permount 


\section{Proteinase k Reconstitution Procedure}

Proteinase $k$ comes in a powdered form and needs to be reconstituted with a proteinase $k$ buffer solution.

Proteinase k Buffer:

$100 \mathrm{mM}$ Tris- $\mathrm{HCl}(\mathrm{pH} 8.0)$

50mM EDTA

1. Micropipette $0.100 \mathrm{~mL}$ of $1 \mathrm{M}$ Tris- $\mathrm{HCl}(\mathrm{pH} 8.0)$ into a $1 \mathrm{~mL}$ aliquot.

2. Micropipette $0.100 \mathrm{~mL}$ of $0.5 \mathrm{M}$ EDTA (pH 8.0) into the aliquot.

3. Bring the volume to $1 \mathrm{~mL}$ with deionized water.

4. Mix $10 \mathrm{mg}$ of the proteinase $\mathrm{k}$ powder with $1 \mathrm{~mL}$ of the buffer.

This reconstituted proteinase $k$ will be a $10 \mathrm{mg} / \mathrm{mL}$ solution. 